\title{
Mise en Scène and the Decisive Moment of Visual Legal Rhetoric
}

\author{
Michael D. Murray*
}

\section{INTRODUCTION}

This article explores the attorney author's understanding and implementation of principles that define how visual rhetorical works fulfill the task of effective visual communication and advocacy. These principles - referred to as mise en scène - will guide the attorney in the identification or creation of works that will exhibit the "decisive moment" of effective visual rhetoric in legal contexts. In equal measure, knowledge and understanding of these principles will enable lawyers to design and use effective visuals, and to challenge or respond to the visual rhetorical works proffered by their opponents.
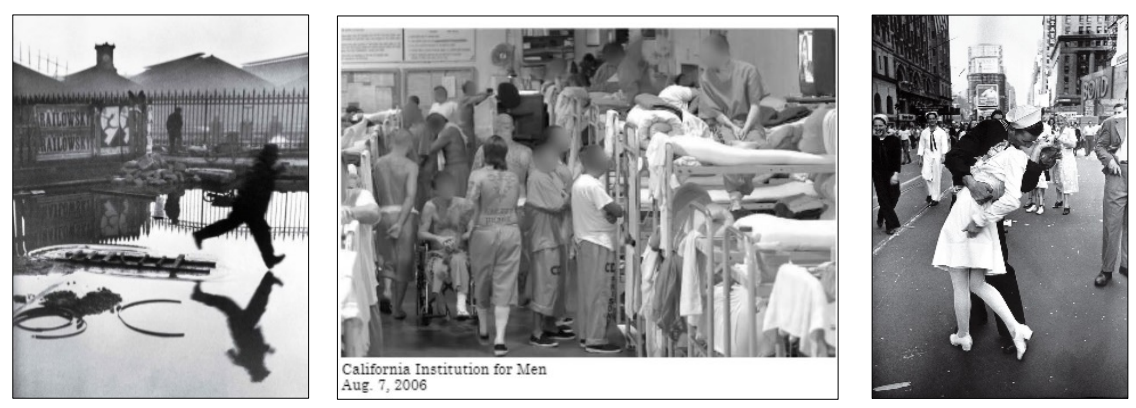

The article displays and analyzes a series of works of visual rhetoric

\footnotetext{
* Professor Michael D. Murray (J.D., Columbia Law School, Harlan Fiske Stone Scholar) currently teaches at the University of Kentucky College of Law. Previously, he taught at the University of Massachusetts School of Law, the University of Michigan Law School, Valparaiso University School of Law, the University of Illinois College of Law, and Saint Louis University School of Law. This article benefits from the comments of Michael Asimow (Stanford), Camilla Baasch Andersen (University of Western Australia), Scott Bauries (Kentucky), Chris Bradley (Kentucky), Josh Douglas (Kentucky), Jane Grise (Kentucky), Jeremiah Ho (Massachusetts), Dustin Marlan (Massachusetts), Jeremy Mullem (Duke), Cathren Page (Barry), Ruth Anne Robbins (Rutgers), Ticien Sassoubre (Stanford), Kathryn Stanchi (Temple), and Melissa Weresh (Drake). Professor Murray gratefully acknowledges the support of Dean David A. Brennen and the University of Kentucky College of Law faculty research program. Professor Murray especially thanks Joy Merklen, as well as Emily Matta, Ryan Kelly, Garrison Matthews, Riley Nickel, Blake Saffels, and Mary Kate Workman of the Kansas Law Review for their excellent and helpful editorial work on this article.
} 
similar to the three images above, ${ }^{1}$ and critiques the power and potential effectiveness of the images for the communication of the message or argument of the author. The goal of this article is both to motivate attorneys to employ visual works in legal communication and advocacy, and to educate attorneys in the selection or creation of images that show the decisive moment of the client's narrative or the point of argument that the image is to communicate.

Mise en scène literally translates from French as "setting the stage" in the sense of staging or placing a scene in a production. ${ }^{2}$ In visual rhetoric and artistic expression, mise en scène refers to the elements of authorship of a visual, theatrical, photographic, or audiovisual work (including film, television, or video) that pertain to framing, composition, set, costume, lighting, makeup, and visual design, and considers both what is included in the scene, and what is excluded beyond the frame or the lens. ${ }^{3}$ This article will guide attorneys in setting the stage for effective visual legal rhetoric.

Mise en scène is directly tied to visual legal rhetoric - the use of visual works by attorneys for communication and persuasion ${ }^{4}$ - because an "attorney planning to use a visual work is an author," and as I have

1. Images from left to right: Henri Cartier-Bresson, The Puddle, or Behind the Gare SaintLazare (1932) (Henri Cartier-Bresson/Magnum Photos), discussed infra pp. 246, 260-61; Brown v. Plata, 563 U.S. 493, 548-49 app. B (2011), discussed infra pp. 262-64; Alfred Eisenstaedt, Sailor Kissing White-Clad Woman in Times Square, V-J Day, Aug. 14, 1945, No. 2 (1945) (Alfred Eisenstaedt/Pix Inc./Time \& Life Pictures/Getty Images) [hereinafter Eisenstaedt, Sailor Kissing White-Clad Woman, No. 2], discussed infra pp. 282-85.

2. DAVID BORDWELL \& KRISTIN THOMPSON, FILM ART: AN INTRODUCTION 112 (8th ed. 2008); Timothy CORRIGAN \& PATRicia White, The Film EXPERIENCE: An InTRODUCtion 64 (3d ed. 2012).

3. See Michael Asimow \& Shannon Mader, Law And Popular Culture: A Course Book 11 , 14 (2007); CorRigan \& White, supra note 2, at 64; Jill MARShall \& ANGela Werndly, The LANGUAGE OF Television 84 (2002); Gabe Moura, Mise-en-Scène, ElemENTS CinEMA (July 1, 2014), http://www.elementsofcinema.com/directing/mise-en-scene-in-films/ [https://perma.cc/3TML-TAGD]; Kimberlianne Podlas, The Tales Television Tells: Understanding the Nomos Through Television, 13 TeX. WESLEYAN L. REV. 31, 41 (2006).

4. Michael D. Murray, Visual Rhetoric: Topics of Invention and Arrangement and Tropes of Style, 21 Legal Writing 185, 185-87 (2016) [hereinafter Murray, Visual Rhetoric: Topics and Tropes].

5. Michael D. Murray, The Sharpest Tool in the Toolbox: Visual Legal Rhetoric, 68 J. LEGAL EDUC. 64, 67 (2018) [hereinafter Murray, Sharpest Tool]; see also Burrow-Giles Lithographic Co. v. Sarony, 111 U.S. 53, 57-58 (1884) (discussing the definition of authorship of visual media); Michael D. Murray, Post-Myriad Genetics Copyright of Synthetic Biology and Living Media, 10 OKLA. J.L. \& TECH. 72, 7-8 (2014) (same) [hereinafter Murray, Post-Myriad Genetics Copyright]. 
explained elsewhere:

[W]ith every visual work, the author will decide the content of the image: what image to use [or to create]; how much and what parts of the scene to include in the visual work; how long a segment to display of a preexisting video work; what exhibits should be assembled and created for the communication [or argument]; what perspective on the subject matter will be observed; which details will remain in the frame, and which [will be] excluded. ${ }^{6}$

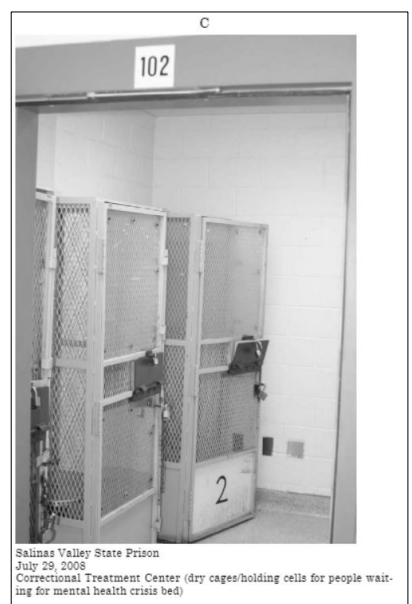

Image (above) of "Dry cage" used by Associate Justice Kennedy in the United States Supreme Court's opinion in Brown v. Plata, ${ }^{7}$ discussed infra pp. 262-64.

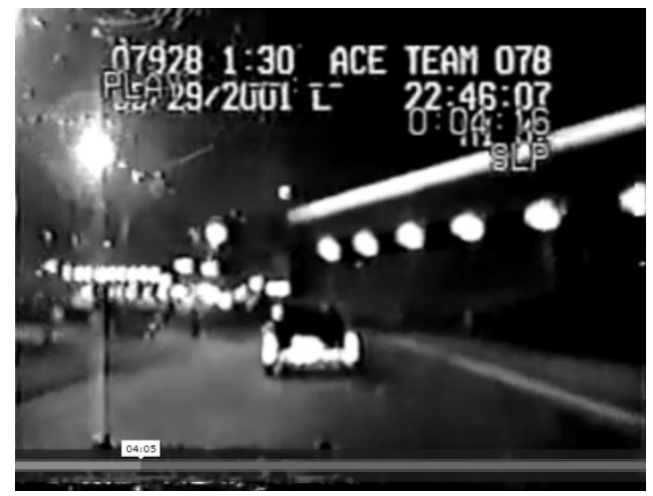

Screen capture (above) from the dashcam car chase video referenced by Justice Scalia in the United States Supreme Court's decision in Scott $v$. Harris ${ }^{8}$ discussed infra pp. 287-88.

Visual legal rhetoric is anticipated to become a standard part of legal practice in litigation, transactional practice, and all areas of law, ${ }^{9}$ because

6. Murray, Sharpest Tool, supra note 5, at 67.

7. 563 U.S. 493,549 app. C (2011).

8. 550 U.S. 372,391 (2007)

9. See generally NeAl Feigenson \& Christina Spiesel, LaW on Display: The Digital Transformation of Legal Persuasion And Judgment 1-4 (2009) (discussing the shift from words to visuals in courtrooms because of technological advancements); Lenora Ledwon, Understanding Visual Metaphors: What Graphic Novels Can Teach Lawyers About Visual Storytelling, 63 DRAKE L. REV. 193, 237 (2015) (describing the use of visual metaphors in a Legal Storytelling class setting); Elizabeth G. Porter, Taking Images Seriously, 114 CoLUM. L. REV. 1687, 1782 (2014); Richard K. Sherwin et al., Law in the Digital Age: How Visual Communication Technologies are Transforming the Practice, Theory, and Teaching of Law, 12 B.U. J. SCI. \& TECH. L. 227, 231 (2006); Christina O. Spiesel et al., Law in the Age of Images: The Challenge of Visual Imagery, in CONTEMPORARY ISSUES OF THE SEMIOTICS OF LAW 231, 231-32 (Anne Wagner et al. eds., 2005) [hereinafter Spiesel et al., Law in the Age of Images]; Richard K. Sherwin, A Manifesto for Visual Legal Realism, 40 LOY. L.A. L. REV. 719, 724-36 (2007). 
of the communicative and rhetorical power of visual media. ${ }^{10}$ My own research and scholarship on visual legal rhetoric has discussed the uses of, ${ }^{11}$ and the ethical and professional considerations regarding, visual legal rhetoric. ${ }^{12}$ This article continues the discussion by focusing on identifying and implementing the principles of visual content that make some visuals better than others. The principles define the truly extraordinary examples of visual rhetoric that convey a "decisive moment" in communicating information about the substance of a case or a client's narrative in support of a legal proposition or point of argument. The principles work both offensively and defensively when attorneys are designing effective visuals for advancing their cases and client matters and raising objections to or attempting to counter the rhetorical effect of an opponent's submission. ${ }^{13}$

10. See, e.g., Fred Galves, Where the Not-So-Wild Things Are: Computers in the Courtroom, the Federal Rules of Evidence, and the Need for Institutional Reform and More Judicial Acceptance, 13 HARV. J.L. \& TECH. 161, 190 (2000); Michael J. Higdon, Oral Argument and Impression Management: Harnessing the Power of Nonverbal Persuasion for a Judicial Audience, 57 U. KAN. L. REV. 631, 631-33 (2009); Lucille A. Jewel, Through a Glass Darkly: Using Brain Science and Visual Rhetoric to Gain A Professional Perspective on Visual Advocacy, 19 S. CAL. INTERDISC. L.J. 237, 264-66 (2010); David S. Santee, More Than Words: Rethinking the Role of Modern Demonstrative Evidence, 52 SANTA CLARA L. REV. 105, 108 (2012) (discussing concerns over the potentially prejudicial effects of computer animations in jury trials); Kathryn M. Stanchi, The Power of Priming in Legal Advocacy: Using the Science of First Impressions to Persuade the Reader, 89 OR. L. REV. 305 (2010) [hereinafter Stanchi, Power of Priming] (discussing the power of first impressions in writing); Kathryn M. Stanchi, Playing with Fire: The Science of Confronting Adverse Material in Legal Advocacy, 60 RUTGERS L. REV. 381 (2008) (discussing the practical and ethical implications of addressing unfavorable, adverse material in legal advocacy); Kathryn M. Stanchi, The Science of Persuasion: An Initial Exploration, 2006 MICH. ST. L. REV. 411 (2006) (discussing the theories of persuasion and how to best frame a legal argument).

11. See generally Murray, Sharpest Tool, supra note 5; Murray, Visual Rhetoric: Topics and Tropes, supra note 4; Michael D. Murray, Leaping Language and Cultural Barriers with Visual Legal Rhetoric, 49 U.S.F. L. REV. F. 61 (2015) [hereinafter Murray, Leaping Language].

12. See generally Michael D. Murray, The Ethics of Visual Legal Rhetoric, 13 LEGAL COMM. \& RHETORIC: JALWD 107 (2016).

13. Observers have noted that uses of adversarial visual rhetoric often are one-sided, with one party in litigation exploiting the power and effectiveness of visual media, and the other side responding with nothing. See, e.g., Jewel, supra note 10, at 280, 295 ("The ability to recognize and attack logical fallacies in text-based arguments has always been a part of effective advocacy; now, attorneys must learn how to apply that skill to visual arguments.... Most of the cases involving improprieties in visual advocacy have also contained grievous imbalances in the deployment of visual arguments."). 

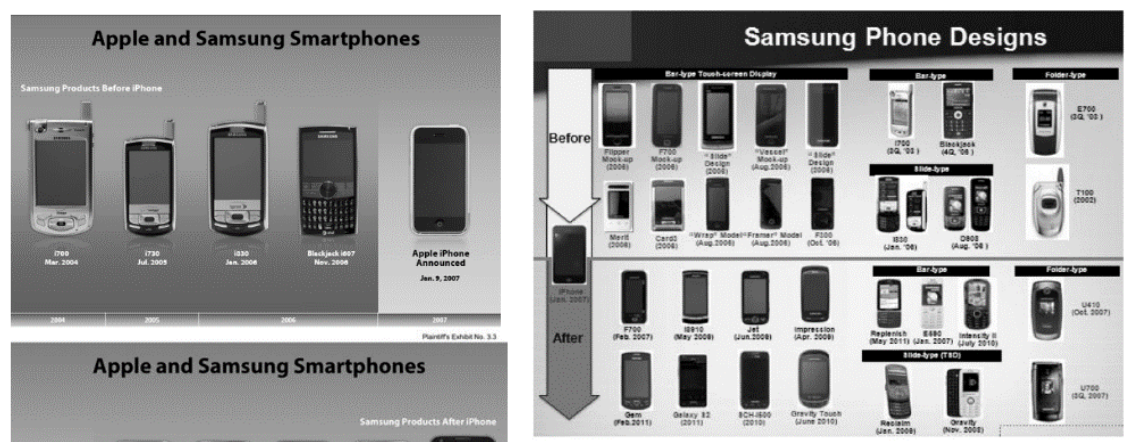

Exhibits used as legal argument regarding allegedly infringing cell phone design in Apple v. Samsung. ${ }^{14}$

The "decisive moment" in regard to a visual work refers to an author's ability to capture a precise moment in time and record it in an image that reveals the larger truth of a situation. ${ }^{15}$ When visual rhetoric is combined with narrativity (i.e., applied legal storytelling), ${ }^{16}$ the need arises for the author of visual legal rhetoric to consider the ways that great examples of

14. Jon Brodkin, Apple's Case that Samsung Copied the iPhone and iPad-in Pictures, ARS TECHNICA (Aug. 8, 2012, 8:30 AM), https://arstechnica.com/tech-policy/2012/08/apples-case-thatsamsung-copied-the-iphone-and-ipad-in-pictures/ [https://perma.cc/5V2W-2RSC] (referencing Trial Exhibits, Apple (left) and Samsung (right), used in Apple, Inc. v. Samsung Elecs. Co., No. 12-CV00630-LHK, 2012 WL 2936432 (N.D. Cal. Apr. 15, 2011)). The rhetorical use of these images is critiqued in Murray, The Ethics of Visual Legal Rhetoric, supra note 12, at 133-36. Apple attempted to show that Samsung's phone designs looked nothing like the iPhone before the iPhone came out, but Samsung's phones started to look like the iPhone when the iPhone came out. Samsung countered by showing that several of its designs "before the iPhone resembled the iPhone," while many of its phone designs before and after the iPhone looked nothing like the iPhone. Id.

15. Henri Cartier-Bresson, The Decisive Moment 3-5, 14 (2015) (the French edition title is IMAGES À LA SAUVETTE - which may be translated as "Images in Haste," or "Furtive Images"); see also Press Kit for Henri Cartier-Bresson, Images à la Sauvette (Jan. 11, 2017), https:/ /www.henricartierbresson.org/wp-content/uploads/2016/12/Press-Kit-Images-a\%cc\%80-la-SauvetteFHCB-GB.pdf [https://perma.cc/44GJ-NX8E]. Cartier-Bresson's retrospective and commentary on his own photography influenced generations of photographers. The term "the decisive moment" defined the concept of the apex in which all elements in the photographic frame accumulate to form the perfect image - not necessarily the climax of the action, but the formal, visual apex of the narrative of the photograph. See ClÉMENT ChÉROuX, A Bible For Photographers: The DeCisive MOMENT 15 (2014) (companion booklet of history and commentary on Cartier-Bresson's text). A quote from Cardinal de Retz introduces the preface of THE DECISIVE MOMENT: "Il n'y a rien dans ce monde qui n'ait un moment décisif" ("There is nothing in this world that does not have a decisive moment"). CARTIER-BRESSON, supra note 15, at 1-2,14. In Cartier-Bresson's own words, "Photographier: c'est dans un même instant et en une fraction de seconde reconnaître un fait et l'organisation rigoureuse de formes perçues visuellement qui expriment et signifient ce fait" ("[P]hotography is the simultaneous recognition, in a fraction of a second, of the significance of an event as well as of a precise organization of forms which give that event its proper expression"). Id.

16. See discussion infra Part I and notes 27-29. 
visual media tell stories, and strive to create and employ images that communicate a story vividly. An attorney should adopt an artist's eye to evaluate the imagery that will be used to communicate or rebut communication.

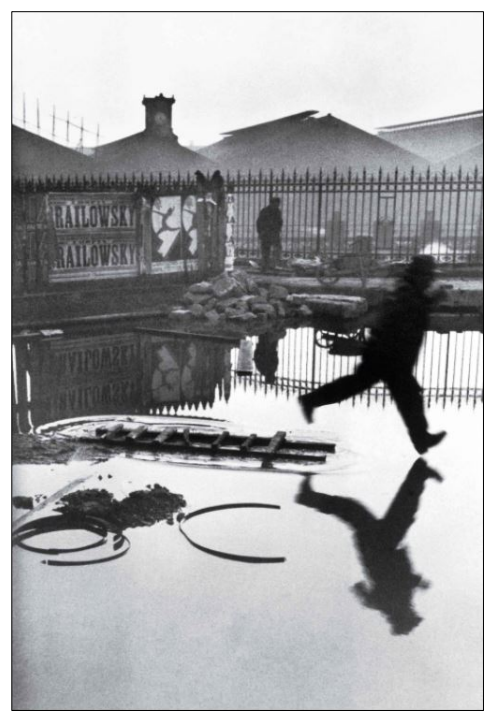

In this classic "decisive moment" photograph by Henri Cartier-Bresson, ${ }^{17}$ - sometimes referred to as "the greatest Decisive Moment photograph of all time"-Cartier-Bresson captures in time the movement of a man leaping over a puddle in a construction area behind the Gare Saint-Lazare in Paris. As described in Time magazine's 100 Photos: The Collection, "The resulting image is a masterpiece of form and light. As a man leaps across the water, evoking the dancers in a poster on the wall behind him, the ripples in the puddle around the ladder mimic the curved metal pieces nearby." 18

The art of applying mise en scène principles to capture the "decisive moment" of a visual work has been celebrated in the photography of Henri Cartier-Bresson, ${ }^{19}$ but the decisive moment concept is present not only in representational photographic media, but also in line drawings, cartoons, and artworks. ${ }^{20}$ The decisive moment communicates the narrative and meaning of a scene visually to audiences at a level that is not dependent on language. ${ }^{21}$ A major benefit of visual imagery is its ability to communicate across language and cultural barriers. ${ }^{22}$ The renowned photographer, Luca Bracali, has stated that "[p] hotography is the most international language of all." ${ }^{, 3}$ Each form of visual media can be entirely

17. Cartier-Bresson, supra note 1 (discussed infra pp. 260-61).

18. Behind the Gare Saint-Lazare: Henri Cartier-Bresson, 1932, Time 100Pнотоs, http://100ph otos.time.com/photos/henri-cartier-bresson-behind-gare-saint-lazare [https://perma.cc/E63T-TM5Y] (last visited Oct. 15, 2019).

19. See sources cited supra note 15.

20. See, e.g., David Machin, Introduction to Multimodal ANAlysis $57-58$ (2007); Henry John Pratt, Medium Specificity and the Ethics of Narrative in Comics, 1 STORYWORLDS: J. NARRATIVE STUD. 97, 97-110 (2009).

21. See CARTIER-Bresson, supra note 15, at 14; ChÉROUX, supra note 15, at 15.

22. See generally Murray, Leaping Language, supra note 11.

23. Bud Ward, This Photographer is Documenting Radical Change in the Arctic, Yale Climate CONNECTIONS (Sept. 9, 2017), https://www.yaleclimateconnections.org/2017/09/photographer-lucabracali-documents-change-in-the-arctic/ [https://perma.cc/QC59-DA3X]. 
apt at communicating narrative, meaning, and messages to wide audiences if images are carefully chosen and created with regard to mise en scène principles.

Margaret Bourke-White's photograph of Mahatma Gandhi with a charkha-shaped spinning wheel ${ }^{24}$ is hailed as a marvelous narrative image. Without using words, it tells the story of an important man who is comfortable doing a routine task; his lack of clothes reveals that the man has no pretensions about

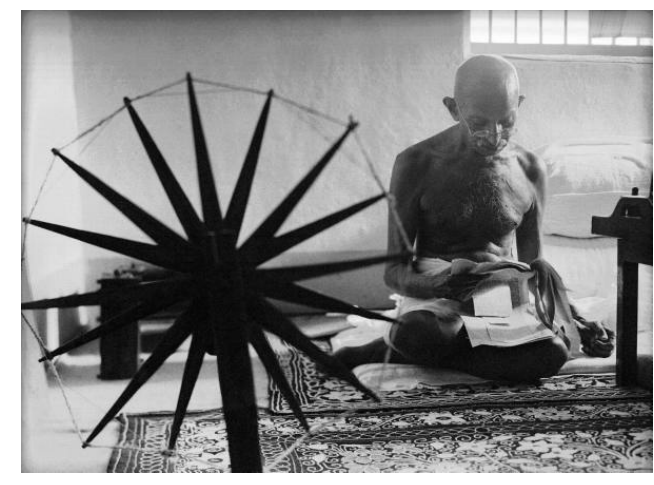
needing to project power or importance. The spinning wheel charkha image became synonymous with Gandhi's movement, and was incorporated as the central element of India's flag after independence.

This article seeks to guide attorney authors in setting the stage for effective visual legal rhetoric. The goal of an attorney's effort should be to choose or create images that show the decisive moment of the client's narrative or the point of argument that the image is to communicate. This article displays and analyzes a series of works of visual rhetoric and critiques the power and potential effectiveness of the image for the communication of the message or argument of the author. Part I discusses the role and communicative power of visual devices in the context of legal rhetoric. Part II discusses mise en scène principles that contribute to the design and implementation of effective visual devices, including those that convey the decisive moment of a scene or narrative. Part III is my conclusion.

\section{THE CONTEXT: VISUAL LEGAL RHETORIC AND NARRATIVITY}

The context for this discussion is rhetoric, the art and science of effective communication, and within this subject area, the specific subtopics of visual legal rhetoric and narrativity. ${ }^{25}$ Visual legal rhetoric is the

24. Margaret Bourke-White, Gandhi and the Spinning Wheel (1946) (Margaret Bourke-White; The Life Picture Collection/Getty Images).

25. See, e.g., Elizabeth Fajans \& Mary R. Falk, Untold Stories: Restoring Narrative to Pleading Practice, 15 Legal Writing 3 (2009); Brian J. Foley, Applied Legal Storytelling, Politics, and Factual Realism, 14 Legal Writing 17 (2008); Steven J. Johansen, Was Colonel Sanders A Terrorist? An Essay on the Ethical Limits of Applied Legal Storytelling, 7 J. Ass'N LEGAL WRITING 
use of graphics, photographs, and other depictions for communication, for construction of knowledge and understanding, and ultimately for persuasion of the truth and rightness of a legal communication. ${ }^{26}$ Narrativity, which is sometimes described as narrative reasoning or "applied legal storytelling," advocacy to focus on the tools that best communicate clients' storiestheir situation, conditions, and circumstances - along with the "story" of the development, growth, and meaning of the law itself that provides the context for the clients' legal situation. ${ }^{28}$ Communicating the story of the development of the law and the story of a particular legal situation (e.g., a client's case) to various audiences is an essential part of legal education and law practice. In adversarial practice, attorneys must be skilled in communicating their own client's narrative, and in counter-narrative to rebut their opponents' communication of narrative.

Visual legal rhetoric is a certain category (more particularly, a topic of invention or arrangement, or a trope of style) within the larger field of rhetoric, ${ }^{29}$ which is the study of effective communication and persuasion. ${ }^{30}$

DiRECTORS 63 (2010); Cathren Page, Not So Very Bad Beginnings: What Fiction Can Teach Lawyers About Beginning A Persuasive Legal Narrative Before A Court, 86 Miss. L.J. 315, 318-20 (2017) [hereinafter Page, Not So Very Bad Beginnings]; J. Christopher Rideout, Applied Legal Storytelling: A Bibliography, 12 LEgAL COMM. \& RHETORIC: JALWD 247 (2015); Ruth Anne Robbins, Harry Potter, Ruby Slippers, and Merlin: Telling the Client's Story Using the Characters and Paradigm of the Archetypal Hero's Journey, 29 SEATtLe U. L. ReV. 767 (2006); Ruth Anne Robbins, An Introduction to Applied Storytelling and to this Symposium, 14 LEGAL WRITING 3 (2008). See also sources cited infra notes 26-28.

26. See Murray, Visual Rhetoric: Topics and Tropes, supra note 4, at 197-98; Murray, Leaping Language, supra note 11, at 68 .

27. Derek H. Kiernan-Johnson, A Shift to Narrativity, 9 LEGAL COMM. \& RHETORIC: JALWD 81, 93-95 (2012) (addressing the narrativity aspect of "applied legal storytelling"); see also Daniel A. Farber \& Suzanna Sherry, Telling Stories Out of School: An Essay on Legal Narratives, 45 STAN. L. REV. 807, 820-24 (1993) (discussing the role of stories in "practical reasoning"); Page, Not So Very Bad Beginnings, supra note 25, at 318-20 (discussing the necessity of a "hook" in persuasive legal narratives); Kim Lane Scheppele, Foreward: Telling Stories, 87 MICH. L. REV. 2073, 2085-88 (1989) (discussing "legal storytelling" and how one fact pattern can tell several stories depending on how the facts are framed).

28. Christy H. DeSanctis, Narrative Reasoning and Analogy: The Untold Story, 9 LeGAL COMM. \& RHETORIC: JALWD 149, 150-54 (2012); Stephen Paskey, The Law is Made of Stories: Erasing the False Dichotomy Between Stories and Legal Rules, 11 LEGAL COMM. \& RHETORIC: JALWD 51, $52-$ 53 (2014) ("Every governing legal rule ... has the underlying structure of a stock story, a story template stated in general terms.... [T] he elements of the rule correspond to the elements of a story and have a logical relationship that qualifies as a 'plot."').

29. See generally Murray, Visual Rhetoric: Topics and Tropes, supra note 4.

30. See, e.g., ARISTOtLe, On Rhetoric: A TheORy of Civic Discourse 35-36 (George A. Kennedy trans., 2d ed. 2007); ARISTOTLE, RHETORIC 4 (W. Rhys Roberts trans., 2000) ("Rhetoric may be defined as the faculty of observing in any given case the available means of persuasion."); JOHN J. MAKAY, SPEAKING WITH AN AUDIENCE: COMMUNICATING IDEAS AND ATTITUDES 11 (1977) ("Rhetoric may be thought of as the process of human communication in which a speaker sorts, selects, and sends symbols for the specific purpose of evoking a precise response from the [audience]."); 
The linear model of communication ${ }^{31}$ describes the process of a speaker creating a message in a certain context to a particular audience:

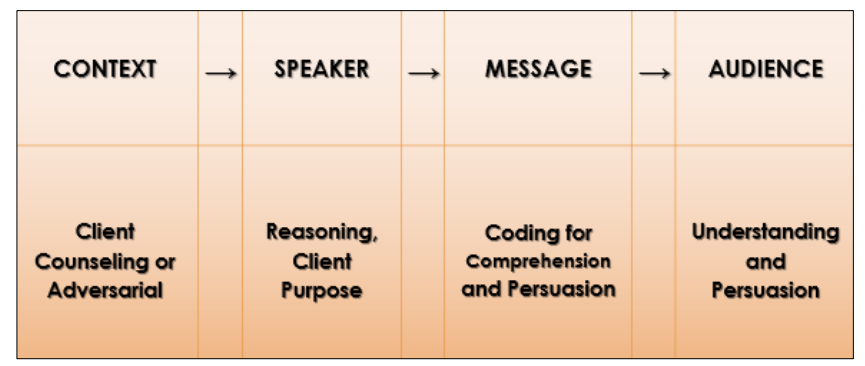

Visual legal rhetoric, like all discussions of rhetoric, involves the consideration of a rhetorical situation, ${ }^{32}$ which I visually depict as a circular flow chart: ${ }^{33}$

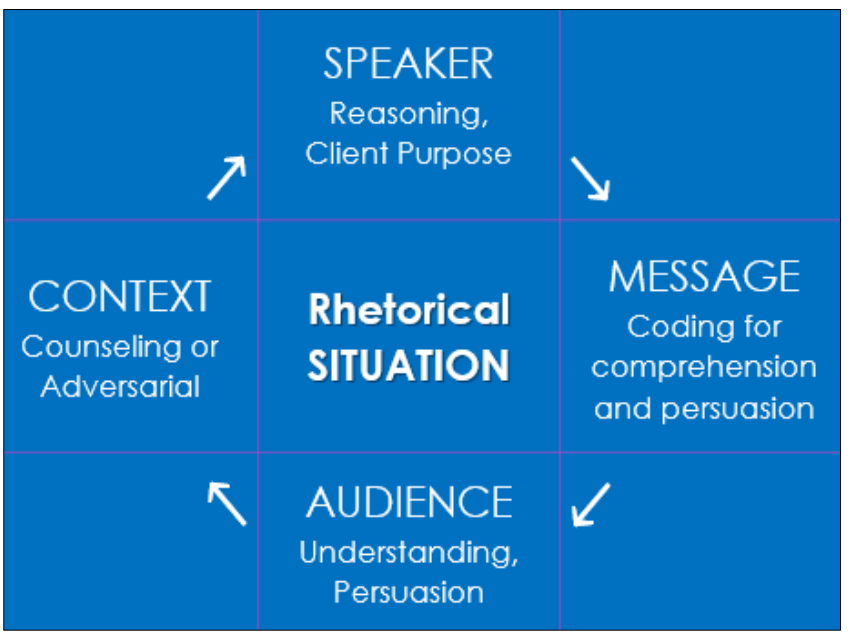

KRISTEN KONRAD ROBBINS-TISCIONE, RHETORIC FOR LEGAL WRITERS: THE THEORY AND PRACTICE OF ANALYSIS AND PERSUASION 9 (2009) ("[R]hetoric here refers to the art of persuasion through eloquent, inventive, and strategically organized discourse, both oral and written."); Gerald B. Wetlaufer, Rhetoric and Its Denial in Legal Discourse, 76 VA. L. REV. 1545, 1546 (1990) ("By 'rhetoric,' I mean the discipline... in which the objects of formal study are the conventions of discourse and argument.”).

31. Michael D. Murray, The Great Recession and the Rhetorical Canons of Law and Economics, 58 LOY. L. REV. 615, 632 (2012) [hereinafter Murray, Great Recession]; JAKOB WISSE, ETHOS AND PATHOS FROM ARISTOTLE TO CICERO 6-8 (1989).

32. See James L. Kinneavy, A Theory of Discourse: The Aims of Discourse 19 (1971); WISSE, supra note 31, at 7-8; Lloyd F. Bitzer, The Rhetorical Situation, 1 PHIL. \& RHETORIC 1, 6-8 (1968); Linda L. Berger, A Reflective Rhetorical Model: The Legal Writing Teacher as Reader and Writer, 6 LEGAL WRITING 57, 67 (2000); Murray, Great Recession, supra note 31, at 633-34; Teresa Godwin Phelps, The New Legal Rhetoric, 40 Sw. L.J. 1089, 1091 (1986) (describing "methods for defining legal discourse for students" in law schools).

33. Michael D. Murray, After the Great Recession: Law and Economics'Topics of Invention and Arrangement \& Tropes of Style, 58 LOY. L. REV. 897, 905-06 (2012); see also sources cited supra note 32 (describing the flow of input within a rhetorical situation). 
The charts illustrate the attorney author's position in making decisions about the content of communication. Based on the rhetorical situationcommunication of information, counseling a client, advocating a position on the law, or outright litigation - an attorney should consider the coding of the contents of a communication for the most effective comprehension and persuasion of the audience in the situation. The remainder of this section will discuss the factors that should motivate attorney authors to select and design visual devices as part of their communication repertoire.

\section{A. Speed and Power of Visual Works}

Visual works are powerful rhetorical devices because of their amazing speed $^{34}$ of communication with audiences compared to verbal media, ${ }^{35}$ and because visual works have an unusual advantage over verbal works in attaining the belief and adherence of the audience to the message of the communication. ${ }^{36}$ The speed of visual works is attributed to the survival instinct ingrained by human (and animal) development that prioritizes visual perception to detect threats, and ties the input to the fastest portions of our brain, the precognitive portions referred to as the "protoreptilian formation" or R-complex (which is often referred to as the "reptilian

34. Studies have found that the brain processes visual images roughly 60,000 times faster than it processes text. Daniel Newman, Why Visual Content Will Explode in 2015, ForBES (Dec. 23, 2014, 9:17AM), https://www.forbes.com/sites/danielnewman/2014/12/23/why-visual-content-will-explode-in-20 15/\#1f3e31971cb5 [https://perma.cc/ZHJ5-S5VE]. See also Michael S. GaZZAniga, Nature'S Mind: The Biological Roots of Thinking, Emotions, Sexuality, Language, and INTELLIGENCE 95-102 (1992); ALLEN NEWELL, UNIFIED THEORIES OF COGNITION 24 (1990); Mirjam Keetels \& Jean Vroomen, Perception of Synchrony Between the Senses, in THE NeURAL BASES OF MULTISENSORY PROCESSES (Micah M. Murray \& Mark T. Wallace eds., 2012) (noting that sounds "travel through air much slower than visual information"); Mirjam Keetels \& Jean Vroomen, The Role of Spatial Disparity and Hemifields in Audio-Visual Temporal Order Judgments, in $167 \mathrm{~J}$. EXPerimental Brain Res. 635-40 (2005); Douglas R. Vogel et al., Persuasion and the Role of Visual Presentation Support: The UM/3M Study (Mgmt. Info. Sys. Res. Ctr., Working Paper No. MISRC-WP-86-11, 1986), http://misrc.umn.edu/workingpapers/fullpapers/1986/8611.pdf [https://perma .cc/5SED-UDXX].

35. Ann Marie Seward Barry, Visual intelligence: Perception, image, and MANIPULATION IN VISUAL COMMUNICATION 15 (1997) [hereinafter BARRY, VISUAL INTELLIGENCE]; DONIS A. DONDIS, A PRIMER OF VISUAl Literacy 18 (1973); Nevzat Özel, Developing Visual Literacy Skills Through Library Instructions, in INFORMATION VISUALIZATION TECHNIQUES IN THE SOCIAL SCIENCES AND HuMANITIES 37 (Veslava Osinska \& Grzegorz Osinski eds., 2018); see also sources cited supra note 34.

36. See Timothy Gangwer, Visual Impact, Visual Teaching: Using Images to Strengthen Learning 24 (2009); Özel, supra note 35, at 37; Sabrina Bresciani, Do You See What I See? The Effect of Culture on the Reception of Visual Communication, in THEORETICAL TURBULENCE IN INTERCULTURAL COMMUNICATION STUDIES 82 (Saila Poutiainen ed. 2014) (focusing on visuals in intercultural communication); COLIN WARE, INFORMATION VISUALIZATION: PERCEPTION FOR DESIGN 2-6 (2d. ed. 2012). 
brain"). ${ }^{37}$ The protoreptilian function triggers a fight or flight, preservation perception-reaction to visual input, ${ }^{38}$ and then immediately thereafter the visual is processed by the paleomammalian brain (also referred to as the "limbic system"), which assists primarily "with controlling emotional responses." 39

The lessons of brain science for the attorney employing visual media is that the viewer's first impression of a piece of visual rhetoric is likely to be an emotional perception: viewers will instantly perceive and process whether they feel threatened by the subject of the visual, and nearly instantly record how they feel about the subject or scene depicted. ${ }^{40}$ And the emotional take is stubborn. ${ }^{41}$ Cognitive functions lag behind sensory perception, and when they catch up, studies of brain science show that viewers most often make a cognitive decision justifying and sustaining the emotional take on the visual device. ${ }^{42}$ It is difficult, but not impossible, for the cognitive brain to overturn the emotional decision. ${ }^{43}$ Furthermore, repeated perception-reactions to certain stimuli of the reptilian brain and the amplification of reactions by the paleomammalian brain form neural pathways or "canals" in the brain (a better term would be neural "superhighways") make the perception and reaction to visual stimuli all the more rapid and all the more difficult to overturn with logical cognitive

37. Barry, Visual Intelligence, supra note 35, at 16-19; Ann Marie Barry, Perception Theory, in HANDBook of Visual COMmunication: Theory, Methods, AND MEdia 56 (Kenneth L. Smith et al. eds., 2004); Robert K. Naumann et al., The Reptilian Brain, 25(8) Current BiologY R317, R317-21 (2015).

38. Kenneth D. Chestek, Fear and Loathing in Persuasive Writing: An Empirical Study of the Effects of the Negativity Bias, 14 LEGAL COMM. \& RHETORIC: JALWD 1, 3-5 (2017); see also PAUL D. Maclean, The Triune Brain in Evolution: Role in Paleocerebral Functions 15-17 (1990); David Ball \& Don C. Keenan, Reptile: The 2009 Manual of the Plaintiff'S REVOLUTION 13 (2009) (discussing lessons in advocacy to be drawn from the Triune Brain theory and the speed of the reptilian brain).

39. See Chestek, supra note 38, at 4; MACLEAN, supra note 38, at 16-17.

40. See, e.g., sources cited supra note 37.

41. See, e.g., Lynn Johnson, Effective Stress Management, 16 UTAн B. J. 28, $29-31$ (2003) (discussing the triune brain theory of reptile, mammalian/limbic system, and neocortex, and the elaborate steps necessary for the cognitive brain to overturn emotional reactions held by the "lower" order brain functions). It is also true that "emotions are a crucial part of the decision-making process .... A brain that can't feel can't make up its mind." JONAH LEHRER, HOW WE DECIDE 15 (2009).

42. Chestek, supra note 38, at 4-5; BALL \& KeENAN, supra note 38, at 26 ("Logic cannot budge a Reptile out of survival stance.”); see also JOSEPH LEDOuX, THE EMOTIONAL BRAIN: THE MYSTERIOUS UNDERPINNINGS OF EMOTIONAL LIFE 98-101 (1996).

43. Daniel Kahneman, the Nobel Prize-winning cognitive psychologist and brain scientist, has described the process as System 2 (cognitive brain functions) overcoming the workings of System 1 (automatic, non-cognitive brain functions) that lead to rapid decisions and cognition, as well as to biases, heuristics, predictions, assessments, and judgments that are stubbornly adhered to and not easily overcome by logic and cognitive assessment. DANIEL KAHNEMAN, THINKING, FAST AND SLOW 21-25, 28, 232-33 (2011). 
thought. ${ }^{44}$ All of which makes it critical for attorneys to be aware of the contents and design of their own and their opponents' visuals, and to consider the possible emotional reactions of different members of the audience who will view the video or images. ${ }^{45}$

The unusual communicative and persuasive advantage of visual rhetoric is that visual works of a representational nature that purport to depict scenes or subjects in the real world, such as photographs, film, and video, "generally are perceived by audiences as 'showing the truth,' as opposed to making an appeal to persuade or manipulate the audience." As Professor Rebecca Tushnet explains:

The power of images comes not just from the emotions they evoke but also from the linked feature that they are hard to see as arguments: they persuade without overt appeals to rhetoric. Though every image has a purpose, 'the most general claims of the discourse are a kind of disclaimer, an assertion of neutrality; in short, the overall function of photographic discourse is to render itself transparent. ${ }^{47}$

The reason for this advantage of visual communication over verbal, textual communication is described as a form of neural "programming" 48 of our brains that contemporary cognitive studies and brain science refer

44. See Lucy Jewel, Neurorhetoric, Race, and the Law: Toxic Neural Pathways and Healing Alternatives, 76 MD. L. REV. 663, 663-64, 670-71 (2017).

45. The particular characterization of the interaction of the conscious aspects of cognition and unconscious aspects of brain activity is an issue of active research and debate in the scientific community. See, e.g., Joseph E. LeDoux, Evolution of Human Emotion: A View Through Fear, 195 PROGRESS BRAIN RES. 431, 439 (2012); Louis J. Sirico, Jr., The Trial Lawyer and the Reptilian Brain: A Critique, 65 CLEV. ST. L. REV. 411, 417 (2017) (discussing how appealing to notions of danger to the community invokes jurors' "Reptilian survival mode"); Gerald Wiest, Neural and Mental Hierarchies, 3 FRONTIERS PSYCHOL. 516 (2012). The particular claims and warrants I am asserting here, however, represent widely-accepted lessons of cognitive neuroscience and brain studies that are applicable to communication and advocacy studies. See sources cited supra notes 37-42.

46. Murray, The Ethics of Visual Legal Rhetoric, supra note 12, at 123.

47. Rebecca Tushnet, Worth a Thousand Words: The Images of Copyright, 125 HARV. L. REV. 683, 692 (2012) (quoting Allan Sekula, On the Invention of Photographic Meaning, in PHOTOGRAPHY AGAINST THE GRAIN 37 (1984)).

48. "Programming" is my term; the more appropriate term as discussed in the literature cited below is "bias" or "heuristic." 
to as naïve realism ${ }^{49}$ or cognitive illiberalism. ${ }^{50}$ These terms describe the concept that representational images are viewed as transparent, unmediated receptacles of reality, not as coded messages. ${ }^{51}$ This programming disguises the fact that every image has an author, and every author creates the image. ${ }^{52}$ The verbs used with representational mediacompose, frame, capture, depict, render-might disguise some of the creative role of the author, but creation is what occurs. ${ }^{53}$ Every visual work reflects the perspective and point of view of an author. ${ }^{54}$ The

49. See generally Dale W. Griffin \& Lee Ross, Subjective Construal, Social Inference, and Human Misunderstanding, 24 ADVANCES EXPERIMENTAL SOC. PSYCHOL. 319 (1991); Varda Liberman et al., Naïve Realism and Capturing the "Wisdom of Dyads," 48 J. EXPERIMENTAL SOC. PSYCHOL. 507 (2012); W.J.T. MitCHELl, PiCTURE ThEORY: ESSAYS ON VERBAL AND VisuAL REPRESENTATION 282-87, 303, 306-09 (1994); Lee Ross \& Andrew Ward, Naive Realism: Implications for Social Conflict and Misunderstanding, in VALUES AND KNOWLEDGE 103 (T. Brown et al. eds., 1996); Lee Ross \& Donna Shestowsky, Contemporary Psychology's Challenges to Legal Theory and Practice, 97 Nw. U. L. REV. 1081, 1090 (2003). See also Adam Benforado \& Jon Hanson, Nä̈ve Cynicism: Maintaining False Perceptions in Policy Debates, 57 EMORY L.J. 499, 513-14 (2008); Natalie Frank, Psychology and the Construction of Reality: Challenges to Naive Realism, OWLCATION (Sept. 3, 2018), https://owlcation.com/humanities/Psychology-and-the-Construction-ofReality-Challenges-to-Native-Realism [https://perma.cc/H55D-2B4U]; Bryan D. Lammon, What We Talk About When We Talk About Ideology: Judicial Politics Scholarship and Naive Legal Realism, 83 ST. JOHN'S L. REV. 231, 241 (2009).

50. Dan M. Kahan et al., "They Saw a Protest": Cognitive Illiberalism and the Speech-Conduct Distinction, 64 Stan. L. REV. 851, 861-62, 885-89 (2012); Dan M. Kahan et al., Whose Eyes Are You Going to Believe? Scott v. Harris and the Perils of Cognitive Illiberalism, 122 HARV. L. REV. 837, 843-44, 852-54 (2009) [hereinafter Kahan et al., Whose Eyes Are You Going to Believe?]; see also Brooke A. ACKerly, Just Responsibility: A Human Rights THEORY OF Global Justice 104127 (2018).

51. See FEIGENSON \& SPIESEL, supra note 9, at 9 ("People tend (again, initially and unreflectively) to conflate representations with direct perceptions of reality, to 'look through' the mediation at what is depicted. To see the picture is to see the real thing, unmediated. What a picture depicts just seems to have presence, a kind of being in the world. As a consequence, the meaning of the picture is understood to be identical to its content.") (internal citation omitted); Jennifer L. Mnookin, The Image of Truth: Photographic Evidence and the Power of Analogy, 10 YALE J.L. \& HUMAN. 1, 2 (1998) ("Seeing a photograph almost functions as a substitute for seeing the real thing."); Sekula, supra note 47, at 3, 5 ("Put simply, the photograph is seen as a re-presentation of nature itself, as an unmediated copy of the real world. The medium itself is considered transparent. The propositions carried through the medium are unbiased and therefore true."); Spiesel et al., Law in the Age of Images, supra note 9, at 237 ("[V]isual stories use a different code for making meaning than do written texts or oral advocacy. ... They are . . . rich in emotional appeal, which is deeply tied to the communicative power of imagery. This power stems in part from the impression that visual images are unmediated. They seem to be caused by the reality they depict."); Tushnet, supra note 47, at 691 ("[P]hotographs 'stop us from thinking' because they are so immediately persuasive") (quoting Michael Meyer, Recovering Reality: Errol Morris Takes on Abu Ghraib, CoLUM. JouRnALISM REV. (Mar. 5, 2008), https://archives.cjr.org/behind_the_news/recovering_reality.php [https://perma.cc/A6 PA-C4ZJ]).

52. See sources cited supra note 51 .

53. There must be creation for copyright to apply, and since 1884, it is undisputed that photographs are copyrightable. See Burrow-Giles Lithographic Co. v. Sarony, 111 U.S. 53, 58 (1884); Murray, Post-Myriad Genetics Copyright, supra note 5, at 43.

54. See generally André Bazin \& Hugh Gray, The Ontology of the Photographic Image, 13 FILM 
elements that are to be included in a visual work, and the elements that will be excluded, are all under the direction and control of the author. ${ }^{55}$ In short, the very meaning of every photo is under the control of an author. ${ }^{56}$ But naïve realism - the bias or heuristic that controls the cognitive side of our visual perception so that we believe that what we are seeing in the world is actually there, that it is actually "true" - carries over to believing that what we are seeing in highly representational media such as photographs and video also is true. ${ }^{57}$

One can understand why the heuristic of naïve realism developed in human perception: if we doubted everything that our eyes see, we would proceed extremely cautiously every moment of our lives. ${ }^{58}$ We would move through each moment of our lives as slowly as a private investigator moves when lured into a house of mirrors. Our confidence that what we see in the world before our eyes is really there, really occurring, allows us to move at the speed of modern life- but this heuristic carries over to our viewing of photographs and realistic visual media. ${ }^{59}$ Without some additional warning or signal that trickery is occurring, we tend to believe the truth of a depiction simply because we can see it for ourselves. Audiences from lay people to United States Supreme Court justices are ready to say that a photograph or video "quite clearly" speaks for itself; it obviously is the truth. ${ }^{60}$

Q. 4, 7-9 (1960) (discussing how photography creates a more objective vision than painting but noting that "the personality of the photographer [still] enters into the proceedings ... in his selection of the object to be photographed and by way of the purpose he has in mind"); James J. Gibson, Pictures, Perspective, and Perception, 89 DAEDALus 216 (1960).

55. See sources cited supra note 54.

56. See sources cited supra note 54; see also Murray, Post-Myriad Genetics Copyright, supra note 5 , at 43 .

57. See Sherwin, A Manifesto for Visual Legal Realism, supra note 9, at 725-26 ("Viewers tend to react to screen images in the same way that they react to reality. Naïve realism apparently is the natural default setting for visual common sense. Subject to our unthinking gaze, which is mostly how we watch, the screen seems to present a window onto reality. We tend to look through the medium rather than at it. Moreover, once we comprehend what we see, that's usually all we need to believe it. In other words, the familiar commonplace that 'seeing is believing' is not just idle folk knowledgenot that there is anything 'idle' about folk knowledge. Indeed, such knowledge is a major source not only of mental content but also of the cognitive tools most people use most of the time.") (footnotes and internal citations omitted); see also Benforado \& Hanson, supra note 49, at 513-14; Ross \& Shestowsky, supra note 49, at 1090; Lammon, supra note 49, at 241-42.

58. See generally sources cited supra note 49.

59. See generally sources cited supra notes 49 and 57.

60. See Scott v. Harris, 550 U.S. 372, 378-79, 381-82 (2007). In Scott, the Supreme Court reversed the Court of Appeals' decision denying summary judgment because the videotape of the car chase filmed from the pursuing police car "quite clearly" contradicted the version of the facts put forth by the respondent Harris and accepted by the Court of Appeals. Id. at 378, 386. Justice Scalia, writing for the majority, stated that the Court of Appeals "should have viewed the facts in the light depicted by the videotape." Id. at 381 . 


\section{B. The Audience's Role in Visual Communication}

Visual communication transcends the limits and gaps in verbal language when one's primary goal is to communicate information so that it is received and understood. ${ }^{61}$ In rhetorical terms, the goal should be to construct knowledge and understanding in the audience, not to destroy knowledge and confuse comprehension. But visual media is a complex tool because human perception is relative to each viewer, ${ }^{62}$ and therefore messages communicated by visual media require a certain amount of interpretation regarding the actual meaning of the message. ${ }^{63}$ The conclusion to be drawn is that visual rhetorical devices do not carry or communicate a single message to all users. ${ }^{64}$ They are not static, independent bearers of unambiguous truth.

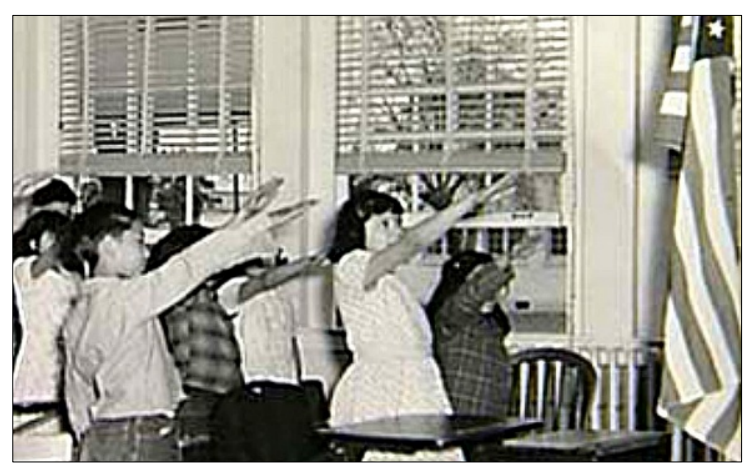

The Supreme Court in West Virginia Board of Education v. Barnette evaluated flag salutes, ${ }^{65}$ such as the salute depicted at left here, and stated, "Symbolism is a primitive but effective way of communicating ideas .... [but a] person gets from a symbol the meaning he puts into it, and what is one man's comfort and inspiration is another's jest and scorn."

61. See generally Murray, Leaping Language, supra note 11, at 68-69.

62. See, e.g., Tracy D. Gunter, Can We Trust Consumers with Their Brains? Popular Cognitive Neuroscience, Brain Images, Self-Help and the Consumer, 11 IND. Health L. REV. 483, 484, 496-97 (2014) (asserting that the notion that brain science can trace neural activity of an individual in response to rhetoric and generalize the applicability of such lessons to a larger population is highly questionable); Kevin W. Saunders, A Disconnect Between Law and Neuroscience: Modern Brain Science, Media Influences, and Juvenile Justice, 2005 UTAH L. REV. 695, 696-732 (2005) (summarizing the difficulties of evaluating the cognitive effects of violent media because of the different developmental and experiential differences in individual adolescents).

63. See Roland Barthes, Rhetoric of the Image, in IMAGE, Music, TeXT 157-63 (Stephen Heath trans., 1977); George L. Dillon, Art and the Semiotics of Images: Three Questions About Visual Meaning (July 1999), http://faculty.washington.edu/dillon/rhethtml/signifiers/sigsave.html [https://perma.cc/4H4G-R6GF]; Claudia E. Haupt, Active Symbols, 55 B.C. L. ReV. 821, 850-58 (2014); PAUl Messaris, Visual PERSUASION: THE Role OF IMAGES IN ADVERTISING xiii-xvi (1997); Qadir Qeidary, Dilemma of Trade Dress, Informational Values and Enigmatic Distinctiveness; Semiotics Illuminating the Status of Distinctiveness, B.C. InTELl. PROP. \& TECH. F. 1, 4-5, 39 (Mar. 8, 2017), http://bciptf.org/wpcontent/uploads/2017/03/Dilemma-of-Trade-dress-Combined-Edits.pdf [https://perma.cc/KT5J-GD28].

64. See BARRY, VisuAl INTELligence, supra note 35, at 16-17; see also sources cited supra notes 62 and 63.

65. 319 U.S. 624 (1943).

66. Id. at 632-33. The image, of unknown origin, shows children saluting the U.S. flag. 
The same can be said, of course, of all communicative media. Letters are symbolic instruments that are combined and interpreted as forming words, which are further combined and interpreted as forming a language that attempts to communicate clearly and objectively, but every language is susceptible to the propagation of ambiguities that plague both legal and nonlegal communication. ${ }^{67}$ With visual communication, the ambiguities might be more subtle, while the communication of the message (clearly or ambiguously) happens even more rapidly than with words. $^{68}$ Nevertheless, the law often must regulate and accommodate visual media as if it has an "objective appearance" when used for factual proof $f^{69}$ or rhetorical argument in legal communication. ${ }^{70}$

The famous photographer, Richard Avedon, once stated, "There is no such thing as inaccuracy in a photograph. All photographs are accurate. None of them is the truth." 71 This pithy comment reminds us that photographs, depictions, and other visual material in legal discourse are not neutral, "transparent" vessels of truth. ${ }^{72}$ They are a coded message in a certain medium. ${ }^{73}$ The medium itself does not lie - the camera and the darkroom equipment or software that produces the final displayed image tell no untruths on their own. It is the author of the work who creates the

67. See Barton Beebe, The Semiotic Analysis of Trademark Law, 51 UCLA L. REV. 621, 626-33 (2004); Peter Goodrich, Europe in America: Grammatology, Legal Studies, and the Politics of Transmission, 101 Colum. L. ReV. 2033, 2043-54 (2001); Roderick A. MacDonald, Legal Bilingualism, 42 MCGILL L.J. 119, 130-31 (1997).

68. See sources cited supra notes 34-35.

69. This article does not focus on the admissibility of visual devices under evidence law. I have discussed the evidence rules and professional conduct rules that govern visual evidence in my work, Murray, The Ethics of Visual Legal Rhetoric, supra note 12, at 113-22, and concluded that evidence law is only a partial gatekeeper of visual rhetorical devices in litigation contexts, because visual rhetorical works are not always offered as proof of facts, but often as argumentative devices, visual metaphors, or figures of speech (topics of invention and arrangement, or tropes of style). Id. See also Murray, Visual Rhetoric: Topics and Tropes, supra note 4, at 201-09. Visual works offered as demonstrative evidence to illustrate the testimony of a witness, or as a "silent witness" of facts, or as substantive proof of a fact (real evidence), must be authenticated through supporting testimony (affidavits or declarations). Murray, The Ethics of Visual Legal Rhetoric, supra note 12, at 113-22. If the work contains verbal testimony, printed or recorded, it must further overcome hearsay objections. Id. at 118. Naturally, the role of evidence is not negligible, and attorneys seeking to confront or rebut an opponent's use of a visual legal rhetorical device will seek to challenge it on relevance and prejudice grounds under Federal Rules of Evidence 401 and 403, in addition to any possible authentication or testimonial challenges. Id.

70. See Murray, Visual Rhetoric: Topics and Tropes, supra note 4, at 201-09.

71. Susana Martinez-Conde \& Stephen L. Macknik, 5 Illusions Reveal How Portraits Can Lie, SCI. AM. (July 1, 2014), http://www.scientificamerican.com/article/5-illusions-reveal-how-portraitscan-lie/ [https://perma.cc/7FRS-CVQ6] (quoting Richard Avedon).

72. See generally BARRY, VISUAL INTELLIGENCE, supra note 35, at 15-16; see also sources cited supra notes 62 and 63.

73. See sources cited supra notes 4 and 54 . 
scene depicted in the photograph using the tools of her trade ${ }^{74}$ who might slant or undermine the truth. An advocate might not be the one to create the image, but she might choose a deceptive or misleading visual to bootstrap an argument. ${ }^{75}$

\section{Narrative and Applied Legal Storytelling}

When visual rhetoric is employed in the context of visual narrativity, two enormous powers are unleashed: the cognitive and persuasive power of visual communication, ${ }^{76}$ and the cognitive and persuasive power of narrative. ${ }^{77}$ Narrative is powerful because it is nearly essential to our understanding and processing of the world. ${ }^{78}$ Humans cannot help but express their experiences, and those of others, and lessons to be learned from experience, in the form of stories. ${ }^{79}$ We are hard-wired to listen to and process stories. ${ }^{80}$ We are cognitively dependent on story-forms of communication. ${ }^{81}$ Given the chance, we will construct our own story to

74. See generally Murray, Post-Myriad Genetics Copyright, supra note 5, at 35-47.

75. The potential for abuse of visual rhetorical devices and the ethical considerations that should regulate such conduct are the subject of my work, Murray, The Ethics of Visual Legal Rhetoric, supra note 12, at 107-11. See also Murray, Visual Rhetoric: Topics and Tropes, supra note 4, at 187 ("Visual topics and tropes are subject to abuse and must be used ethically and with careful regard to their propriety as a tool to create meaning and inspire imagination and not as a tool of deception or obfuscation ....".).

76. See sources cited supra notes 33-36.

77. See sources cited supra notes 25,27 , and 28.

78. Linda L. Berger, The Lady, or the Tiger? A Field Guide to Metaphor and Narrative, 50 WASHBURN L.J. 275, 275-76 (2011); Sean D. O'Brien \& Kathleen Wayland, Implicit Bias and Capital Decision-Making: Using Narrative to Counter Prejudicial Psychiatric Labels, 43 HOFSTRA L. REV. 751, 765-66 (2015); Anne Moses Stratton, Courtroom Narrative and Findings of Fact: Reconstructing the Past One (Cinder) Block at a Time, 22 QLR 923, 934 (2004); Jonathan K. Van Patten, Storytelling for Lawyers, 57 S.D. L. REV. 239, 240-42 (2012).

79. Leo Widrich, The Science of Storytelling: What Listening to a Story Does to Our Brains, BUFFER (Feb. 1, 2016), https://blog.bufferapp.com/science-of-storytelling-why-telling-a-story-is-themost-powerful-way-to-activate-our-brains [https://perma.cc/PHS8-C9GE]; see also Federico Corni, Stories in Physics Education, in FrontIERs OF FundAMENTAL PHYSICS AND PHYSICS EDUCATION RESEARCH 385-86, 388-89 (Burra G. Sidharth et al. eds., 2014); RUTH WAJNRYB, STORIES: NARRATIVE ACTIVITIES IN THE LANGUAGE CLASSROOM 8-11 (2003).

80. Jeremy Adam Smith, The Science of the Story, BERKELEY News (Aug. 25, 2016), https://news.berkeley.edu/berkeley_blog/the-science-of-the-story/ (explaining how hearing "a story alters our neurochemical process, and stories are a powerful force in shaping human behavior"). LISA CRON, WIRED FOR STORY: THE WRITER'S GUIDE TO USING BRAIN SCIENCE TO HOOK READERS FROM THE VERY FIRST SENTENCE 166-99 (2012); ANDREW O'KEEFFE, HARDWIRED HuMANS: SUCCESSFUL LEADERSHIP USING HUMAN INSTINCTS 175-76 (2011).

81. See Lewis Donohew et al., "The Nature of News" Revisited: The Roles of Affect, Schemas, and Cognition, in COMmunication, Social Cognition, AND AfFECT 212-13 (Lewis Donohew \& E. Tory Higgins eds., 1988); Yanna B. Popova, Narrativity and Enaction: The Social Nature of Literary Narrative Understanding, 5 FRONTIERS IN PSYCHOL. 1, 7-11 (2014); William P. Eveland, Jr. \& Mihye Seo, News and Politics, in Communication And Social Cognition: Theories AND METHODS 304-05 (David R. Roskos-Ewoldsen \& Jennifer L. Monahan eds., 2007). 
make sense of events and occurrences - it is that important to have a narrative framework for the processing of information. ${ }^{82}$ Humans receive the information better, process the information better, make sense of the information better, and make decisions about the information better when the information is delivered in the form of a story. ${ }^{83}$ It is unsettling to receive information about other people, events, transactions, or occurrences without the framework of a story. ${ }^{84}$

The analogical and rhetorical use of precedent cases as a source of narrative forms and "stories" in the law is well recognized in American legal method. Precedential cases contain a story, and multiple precedents can contain the same storyline or directly related and analogous storylines. ${ }^{85}$ In American legal method, an attorney often relates her client's situation to one or more of the precedent storylines if the outcome of the stories in the precedents is favorable to the client; by the same token, an attorney will attempt to tell a new story of the client to distinguish one or more precedent cases whose stories do not support a favorable disposition of the client's case. ${ }^{86}$

Add to the storytelling the speed and cognitive power of visuals, and there is a great potential to communicate both facts and fiction to an audience. "The audience's hard wiring toward processing facts through stories, coupled with the power of visual images to communicate effectively at the speed of the limbic system and reptilian brain, reveals the mischief that might potentially be wrought from disingenuous or misleading framing of the case through visual narrativity." 87 Visual images should be used responsibly and ethically not just to communicate a successful narrative but to build knowledge and understanding of the actual reality of the world. ${ }^{88}$ Images should not be created or selected for use with a view of constructing an alternative, false reality. ${ }^{89}$

82. See sources cited supra note 79 .

83. See sources cited supra notes 79-81.

84. See, e.g., Timothy Anderson, "To Tell My Story": Configuring Interpersonal Relations Within Narrative Process, in THE HANDBOOK OF NARRATIVE AND PSYCHOTHERAPY: PRACTICE, THEORY, AND RESEARCH 316-17 (Lynne E. Angus \& John McLeod eds., 2004); RoBERT LANGS, GROUND RULES IN PSYCHOTHERAPY AND COUNSELLING 55-56 (1998).

85. DeSanctis, supra note 28, at 150-51; Paskey, supra note 28, at 52-53.

86. See, e.g., LiNDA H. EDWARDS, LEGAL Writing: Process, ANALYSIS, AND ORGANIZATION 51-68, 117-28 (6th ed. 2014); Michael D. MurRay \& Christy H. DeSANCTIS, AdVANCED LeGal Writing AND ORAL ADVOCACY: TRIALS, APPEALS, AND MOOT COURT 61-127 (2d ed. 2014); Michael D. MurRay \& Christy H. DeSANCTIS, Legal Writing AND ANALYSis 93-176 (2d ed. 2015); Richard K. NEUMANN, JR. ET AL., LEgAL REASONING AND LEgAL WRiTiNG, 93-104 (8th ed. 2017).

87. Murray, The Ethics of Visual Legal Rhetoric, supra note 12, at 128.

88. Id.

89. Id. 


\section{MISE EN SCÈNE PRINCIPLES}

Mise en scène is a collective term to refer to the aspects of a visual work that affect the visual perception and communication of the scene. ${ }^{90}$ The term refers to more than just composition or framing, although these are part of the concept. ${ }^{91}$ Mise en scène goes beyond contents and arrangement to examine the author's setting and handling of all visual aspects of the scene to enhance the perception of its meaning and message. $^{92}$

Mise en scène is often defined as having fifteen components: the dominant, lighting key, shot type, camera angle, color values, lens-filterfilm stock, subsidiary contrasts, density, composition, form, framing, depth of field, character placement, staging positions, and character proxemics. $^{93}$ Several of these terms refer most directly to the direction and creation of motion pictures, which is less likely to be a central activity of attorneys in creating illustrations and exhibits for their work. I will discuss the elements that most closely track the design and analysis of visual devices used in the law and in legal contexts:

- the dominant;

- lighting;

- color vs. black and white;

- point of view and perspective;

- composition and framing (including the arrangement of subjects, the Gestalt theory, and the figure-ground relationship).

In addition, I will discuss the rhetorical and ethical effects of staged images compared to captured (un-staged) images. With each element I will discuss various rules or guidelines that prevail in the analysis of the element, and what might happen when the rules are bypassed or broken, as they often are. I will illustrate the concepts with examples from Cartier-

90. See Mick Hurbis-Cherrier, Voice \& Vision: A Creative Approach to Narrative Film AND DV PRODUCTION 35-39, 56-57 (2007); JANE STADLER \& KELly MCWILliam, SCREEN Media: ANALysing Film and Television 1-3, 26-32 (2009); Jon WhitMore, Directing POSTMODERN THEATER: SHAPING SigNifiCATION IN PERFORMANCE 12-16 (1994).

91. See sources cited supra note 90.

92. Heather Graves, The Fifteen Points of Mise-en-Scene, WALKABOUTLA.orG, http://walkabou tla.org/robfilm2/15_Points_of_Mise-en-Scene.html [https://perma.cc/RW3H-JSCC] (last visited Feb. 15, 2019); Michael Hall, The 15 Basic Elements to Know to Better Your Film's Mise-en-Scene, MENTORLESS (Nov. 1, 2016), https://www.mentorless.com/2016/11/01/basics-elements-understandmies-en-scene/ [https://perma.cc/C63T-C3HM]. See generally JoHn GiBBS, MisE-EN-SCÈnE: FILM STYLE AND INTERPRETATION (2002) (explaining the nuances of mise-en-scène); ADRIAN MARTIN, Mise en ScĖne and Film Style: From Classical Hollywood to New Media ART (John Gibbs \& Douglas Pye eds., 2014).

93. See sources cited supra notes 90 and 92 . 
Bresson and other well-known photographers and photographs.

\section{A. The Dominant}

The "dominant" refers to the dominant image or dominant narrative in a scene, meaning the author's intended focus of primary attention for the viewer. $^{94}$

In all media, the dominant can be indicated by:

- the size of the dominant relative to other elements and content of the scene;

- the prominence of placement of the dominant (e.g., foreground or center vs. medium ground, background, or sides);

- the lighting of the dominant - whether it is the most brightly or properly lit subject in the scene;

- clarity and sharpness of focus of the dominant vs. blurriness, fuzziness, or "softness" of focus compared to other elements and content of the scene;

- (in video or motion pictures) whether the dominant is the only thing moving in the scene;

- whether other elements of the composition (e.g., lines-horizontal, vertical, and diagonal; shapes - rectangles and triangles) in the scene frame, or point to, or lead to the dominant; and

- whether other figures in the scene "give focus" to the dominant in a theatrical sense by staring at or pointing to the dominant. ${ }^{95}$

In color media, the dominant may be indicated by brighter, more vivid colors, especially contrasting colors that are more vivid than their contrastcolor partner in the scene. For example, a vivid yellow can be paired with a more muted blue which indicates that the yellow image is the dominant, or a bright and vibrant blue can be paired with muted yellow hues which indicates that the blue object is the dominant. ${ }^{96}$

In black and white/grayscale media, in addition to the general rules of size, placement, focus, and directional indicators, the dominant often is revealed by lighting and the resulting contrast of vivid shadows vs. vibrant brightness in the scene. ${ }^{97}$ In this classic "decisive moment" photograph

94. Graves, supra note 92; Hall, supra note 92; See TimOTHY CORRIGAN \& PATRICIA White, THE FILM EXPERIENCE: AN INTRODUCTION 63-64, 86-89 (2012) (describing film concepts used to create a dominant subject).

95. See Graves, supra note 92; Hall, supra note 92; see also sources cited supra note 94.

96. See Graves, supra note 92; Hall, supra note 92.

97. See Graves, supra note 92; Hall, supra note 92. 
by Henri Cartier-Bresson, ${ }^{98}$ the dominant image is conveyed through a dark silhouette on a bright, almost white surface, which might be thought to be sky, except for the additional visual clues that tell us it is reflected light from the surface of water. Nevertheless, the visual metaphor of leaping into space is eye-catching and entertaining, and the ability to achieve that communication through a black and white photograph explains the fame of this work.

Naturally, the rules of "the dominant" may be broken if the intent of the author is to obscure the message or narrative of the scene by

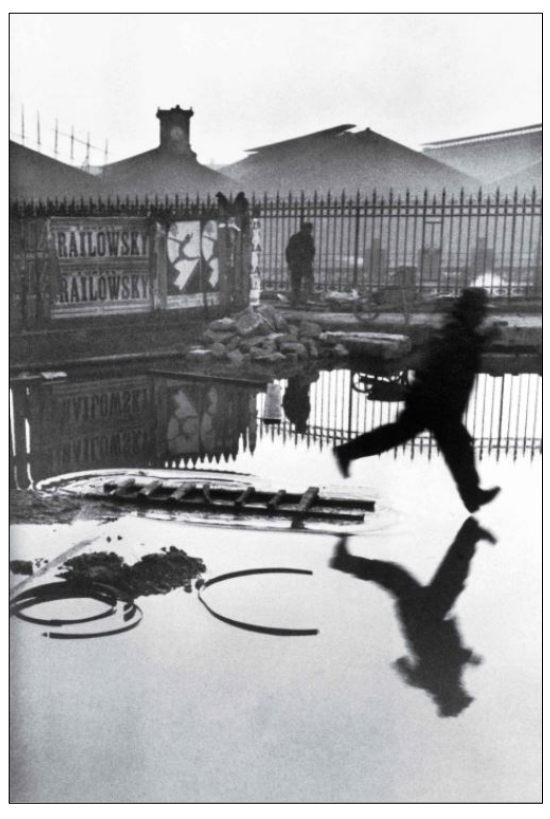
obscuring the dominant, and thus to set up a treasure hunt and reward for viewers who will "solve" the visual puzzle and discover the dominant, and with it the true narrative of the scene. An early master of photography, Alfred Stieglitz ${ }^{99}$ (also well known for being the husband of artist Georgia $\mathrm{O}^{\prime} \mathrm{Keef}^{100}$ ), pushed the boundaries of composition in photography in a manner that obscures the "dominant" imagery, but nonetheless communicates a narrative.

98. Cartier-Bresson, supra note 1.

99. Lisa Hostetler, Alfred Stieglitz, INT'L CTR. PHOTOGRAPHY, https://www.icp.org/browse/ archive/constituents/alfred-stieglitz?all/all/all/all/0 [https://perma.cc/3PWF-R4DC] (last visited Oct. 21, 2019); Lori Oden, Alfred Stieglitz, 1864-1946, INT'L PHOTOGRAPHY HALL FAME \& MUSEUM, http://iphf.org /inductees/alfred-stieglitz/ [https://perma.cc/W2YJ-EDL9] (last visited Oct. 21, 2019); John Szarkowski, Alfred Stieglitz, American Photographer, ENCYC. BRITANNICA (Aug. 30, 2019), https://www.britannica.com /biography/Alfred-Stieglitz [https://perma.cc/473P-H8DG].

100. Oden, supra note 99; Szarkowski, supra note 99. 
The Steerage, Stieglitz's 1907 work, tells the story of passengers in the low budget area of an ocean liner. ${ }^{101}$ The shape of the ship and the odd angles of the funnel, the gangplank, and the deck, make the viewer disoriented and uncomfortable, but not nearly as uncomfortable as the remarkable number of people crammed into the cluttered image under the chains of the railing and the low-hanging deck.

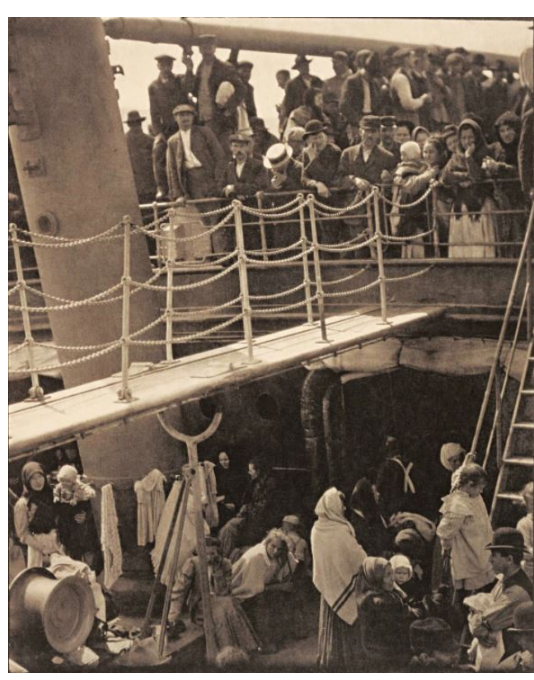

Observers held that Stieglitz had broken new ground, not just by the gritty realism and un-beautiful subject of the photograph, but by the fact that the groupings of the images in the photograph anticipated Cubist forms. ${ }^{102}$ The picture is held to be one of the first examples of photographic "modernism." 103 Compositionally, this crowded work, obscured by shadows, with no horizon and little or no sky, is questionable - but that appears to be the whole point of the image: this steerage passage is uncomfortable, overly-crowded, and poorly designed.

A comparable set of images used by Associate Justice of the Supreme Court Anthony Kennedy in Brown v. Plata,${ }^{104}$ communicates a similar narrative in a similar way. Brown v. Plata was a case about California prison-overcrowding and its effect on the mentally ill population in the prisons, and whether remedial measures undertaken to address the problem were ameliorating violations of Eighth Amendment cruel and unusual punishment standards. ${ }^{105}$ The Court majority voted to affirm the unusual (Justice Scalia, dissenting, called it "radical"106) injunctive relief ordered by a three-judge district court below that California must release

101. Alfred Stieglitz, The Steerage (1907) (Alfred Stieglitz Collection).

102. "Though [the artist Marius] de Zayas merely reported to Stieglitz that Picasso "understood and admired' the famous photograph, Stieglitz remembered a much stronger and more significant endorsement: 'Picasso was reported to have said, "This photographer is working in the same spirit as I am.'” Michael NoRTh, CAMERA WORKS: PHOTOGRAPHY AND THE TWENTIETH CENTURY WORD 42 (2005). Stieglitz wrote of his impressions when he took the photograph: "I stood spellbound for a while. I saw shapes related to one another-a picture of shapes, and underlying it, a new vision that held me." The Steerage, TIME 100Рнотоs, http://100photos.time.com/photos/alfred-stieglitz-steerage [https://perma.cc/BHQ8-PVK3] (last visited Sept. 8, 2019).

103. ENCYClOPEDIA OF NINETEENTH-CENTURY PhOtOGRAPHY 704, 1127, 1341-43 (John Hannavy ed., 2007); The Steerage, TIME 100Рнотоs, supra note 102.

104. 563 U.S. 493 (2011).

105. Id. at $493-503$.

106. Id. at 550 (Scalia, J., dissenting). 
tens of thousands of prisoners to relieve the overcrowding. ${ }^{107}$

Justice Kennedy punctuated the majority opinion with three images of the prisons' conditions:

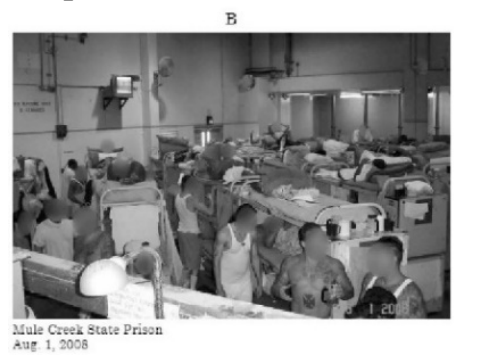

The first two black and white images resemble The Steerage in that the composition of the photographs is crowded, messy, cluttered, and disorienting. ${ }^{108}$ There is no single dominant subject - the subject is the chaos of these over-crowded, uncomfortable, and disorienting scenes. In the context of the case, Justice Kennedy

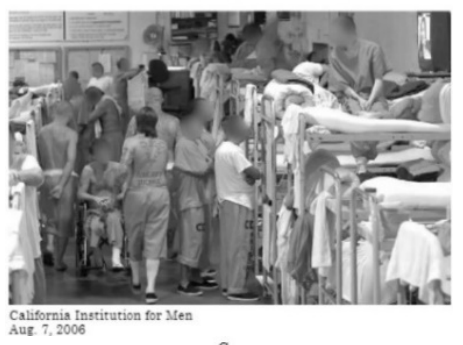
used these photographs to illustrate his findings that conditions in the prisons were unacceptable. ${ }^{109}$

In contrast to the busy, cluttered image of the prison spaces above, in the third picture $^{110}$ proffered by Justice Kennedy, he zeroed in on one specific feature of the prisons that spoke loudly albeit visually.

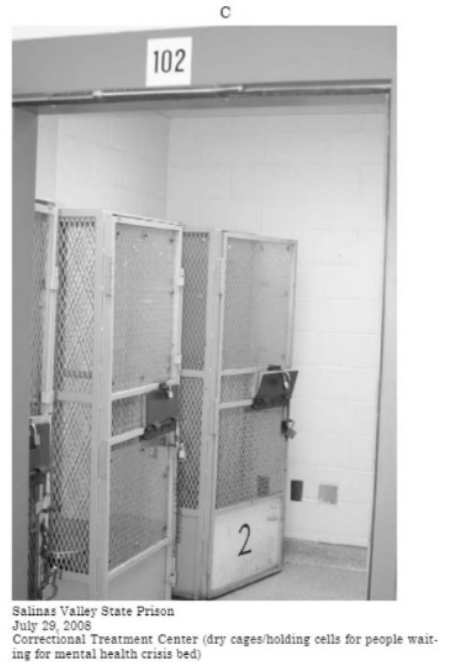

Here (left), the caption provides the necessary, and chilling, explanation of the dominant subjects: "Correctional Treatment Center (dry cages/holding cells for people waiting for mental health crisis bed)."111 Justice Kennedy's opinion notes that the cages were for prisoners with suicidal tendencies. ${ }^{112}$ These extremely cramped cages - that are even called "cages"-look inhumane even for animals. The mesh wire and enormous locks are straight out of set dressing for a laboratory torture scene. The fact that this is the "treatment" center makes the viewer wonder what sort of treatment prisoners receive.

\footnotetext{
107. Id. at 501-03.

108. Id. at $547-48$ app. B.

109. Id. at 502,504 .

110. Id. at 549 app. C.

111. Id.

112. Id. at 503-04.
} 
Critics of the use of these photographs in Brown v. Plata point out that the scenes do not speak for themselves, and that they reveal some of the problems of realistic depictions: the authors of the images strained to capture a particular scene, and composed the scene through point-of-view and cropping to best communicate an emotional message regarding the chaos and danger created by over-crowding. ${ }^{113}$ Justice Kennedy, who selected these images, is allowing the viewer to see one particularly composed and crafted scene from each of three different prisons on three different days. As discussed below, point of view and composition make huge differences in the message communicated by a scene. Nevertheless, the clutter and chaos also improve the verisimilitude of the images, as it is hardly conceivable that one would be able to realistically stage a scene with prisoners, beds, mattresses, chairs, and hardly room to stand or sit let alone enjoy personal space. ${ }^{114}$

In litigation, the most common examples of visual imagery involve the subject matter of the suit and the dominant subject of the image is clear:

This is the artifact photograph of Oscar Wilde taken by photographer Napoleon Sarony ${ }^{115}$ that is the subject of the suit, Burrow-Giles Lithographic

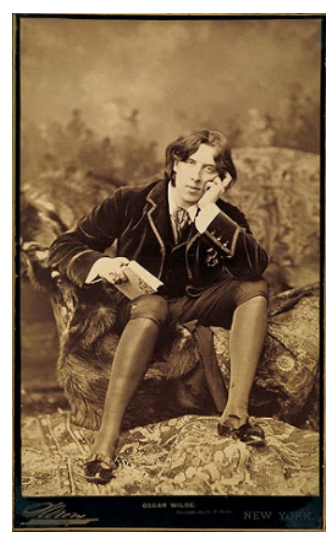
Co. v. Sarony. ${ }^{116}$ This charming sepia tone photograph launched the copyrightability of photographs. The dominant image is, of course, Mr. Oscar Wilde himself, and the lawsuit was about the unauthorized

113. See, e.g., Dahlia Lithwick, Show, Don't Tell: Do Photographs of California's Overcrowded Prisons Belong in a Supreme Court Decision About Those Prisons?, SLATE (May 23, 2011, 6:45 PM), $\mathrm{http} / / /$ www.slate.com/articles/news_and_politics/jurisprudence/2011/05/show_dont_tell.html [https:/ /perma.cc/N336-TKV9]; see also Nancy S. Marder, The Court and the Visual: Images and Artifacts in U.S. Supreme Court Opinions, 88 CHI.-KENT L. REV. 331, 331-33 (2013) (arguing in favor of cautiously including images in Supreme Court opinions).

114. The unexpectedly cluttered, unpretty, and chaotic composition of the images of the prison interiors self-verifies the truthfulness of the images and the conditions they purport to depict. In narrative reasoning and applied legal storytelling, the presence of realistic facts (in this instance, recognizable real-life images) in close proximity to unexpected and incongruous images aids the perception of truthfulness to the unexpected and incongruous images; no one would include such images unless they really were there, and therefore, the images really and truthfully depict the reality of the situation. See Cathren Page, Stranger than Fiction: How Lawyers Can Accurately and Realistically Tell a True Story by Using Fiction Writers' Techniques That Make Fiction Seem More Realistic Than Reality, 78 LA. L. REV. 907, 927-28, 934-36 (2018); Cathren Koehlert-Page, Tell Us a Story But Don't Make It a Good One: Embracing the Tension Regarding Emotional Stories and the Federal Rule of Evidence 403, 84 Miss. L.J. 351, 363-65 (2015).

115. Napoleon Sarony, Oscar Wilde, No. 18 (1882).

116. 111 U.S. 53, 54-55 (1884). 
reproduction of this photograph. ${ }^{117}$

Similarly, the visuals used in the amicus curie brief submitted by the Ethics and Public Policy Center in Van Orden v. Perry ${ }^{118}$ leave no mystery as to the dominant subject:

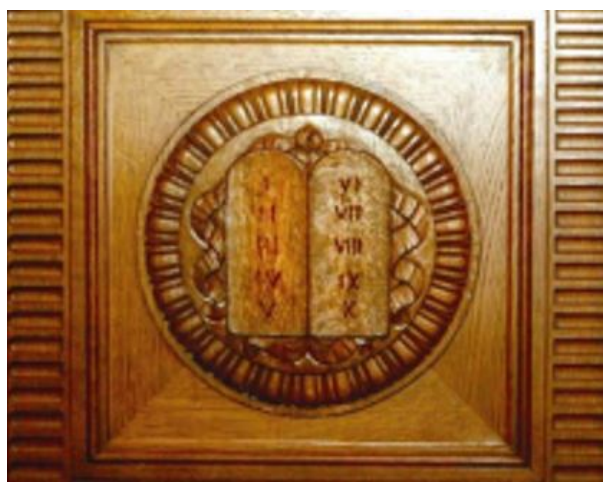

This is an image of the Ten Commandments on the United States Supreme Court courtroom door. ${ }^{119}$ The Ethics and Public Policy Center was arguing in favor of the placement of a Ten Commandments monument in front of the Texas Capitol, and endeavored to remind the justices that an image of the Ten Commandments was featured on the very doors of the high court's chamber. ${ }^{120}$

The Ethics and Public Policy Center added a photograph of a plaque featuring the Ten Commandments installed on the floor of the United States Archives: ${ }^{121}$

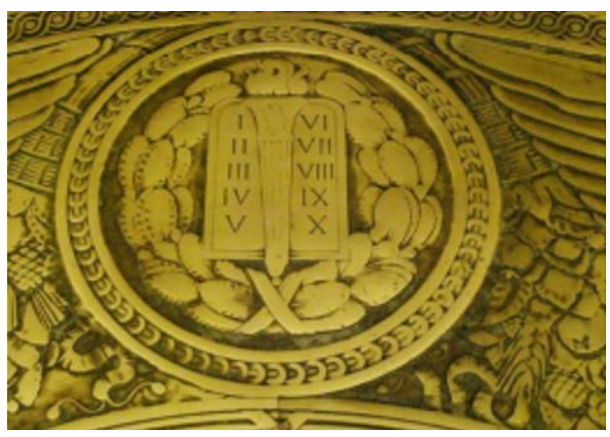

117. Id.

118. 545 U.S. 677, 681-82 (2005) (discussing the constitutionality of a display of the Ten Commandments on the grounds of the Texas Capitol); Brief for the Ethics \& Pub. Policy Ctr. as Amicus Curiae in Support of Respondents at 4-7, Van Orden v. Perry, 545 U.S. 677 (2005) (No. 03 1500) [hereinafter Amicus Brief for the Ethics \& Pub. Policy Ctr.].

119. Amicus Brief for the Ethics \& Pub. Policy Ctr., supra note 118, at 7.

120. Id.

121. Id. at 4. 

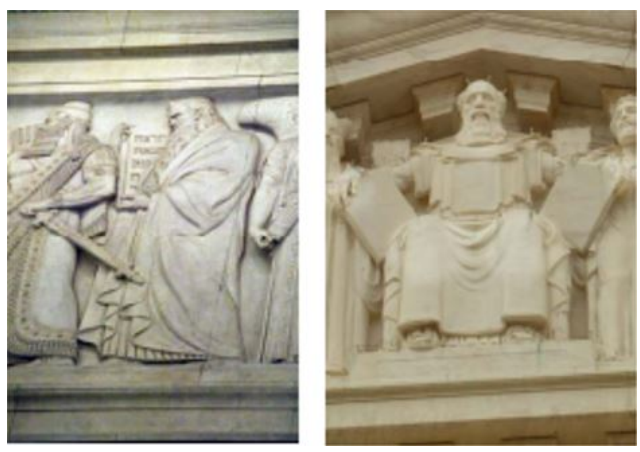

Lastly, The Ethics and Public Policy Center noted that sculptural images of Moses and the Ten Commandments adorn the walls of the United States Supreme Court building. ${ }^{122}$

Litigators will often work with artifact photographs from the record developed in a case, and in these photographs the dominant may not be as clear as desired. Consider this photograph used in conjunction with the reopened murder prosecution of Texas v. Feit, ${ }^{123}$ relating to the slain schoolteacher, Irene Garza, murdered in 1960:

The dominant is not obvious in this photograph. ${ }^{124}$ Is the ground? The marks on the ground? The rocks and scrub? The officer's foot? Where the officer's foot is pointing? The large post? The canal? This photograph does not "speak for itself."

As it turns out the photograph was used to show

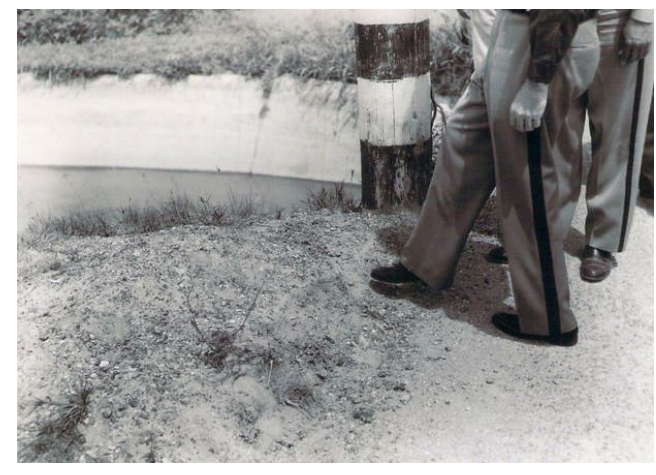
the area of the bank of an irrigation canal where the officers believed the body of Irene Garza was thrown into the water. ${ }^{125}$ Her body had been

122. Id. I previously analyzed The Ethics and Public Policy Center's use of these Ten Commandment images in its amicus curie brief and concluded that the use was effective because the brief was "not attempting to make a rhetorical point outside of the content and substance of the [Establishment Clause] issues in the case. The visuals bolster[ed] the verbal argument that the image of the Ten Commandments is used pervasively on and in government and court buildings as part of our history, culture, and heritage." See Murray, The Ethics of Visual Legal Rhetoric, supra note 12, at $140-44$.

123. No. CR-0464-16-A (Tex. Dist. Ct. Hidalgo Cty., 92nd Dist., Nov. 30, 2017), https://pa.co.hidalgo.tx.us/CaseDetail.aspx?CaseID=3295220 [https://perma.cc/27DF-C9U8] (to access the case, select "Criminal Case Records," type docket number into "Case Number" field, and select the case number attached to "Feit, John Bernard"); see Richard Schlesinger, Inside the Trial of Former Priest Charged with 1960 Murder of Texas Schoolteacher, FORTY EIGHT HOURS (Jan. 27, 2018), https:/www.cbsnews.com/news/inside-the-trial-of-former-priest-charged-with-1960-murderof-texas-schoolteacher/ [https://perma.cc/H8T5-TD4K].

124. Police File Photograph of Officer Pointing Foot at a Patch of Ground (1960) (Texas v. Feit, No. CR-0464-16-A (Tex. Dist. Ct. Hidalgo Cty., 92nd Dist., Nov. 30, 2017)); see Evidence Photos in the Irene Garza Murder Case, CBS NEwS, https://www.cbsnews.com/pictures/evidence-photos-in-the -irene-garza-murder-case/12/ [https://perma.cc/MH6R-593T] (last visited Sept. 8, 2019) [hereinafter Evidence Photos].

125. Evidence Photos, supra note 124. 
found in the canal five days after she had gone missing. ${ }^{126}$ The officer is attempting to point with his foot to marks from Garza's petticoat found on the banks of the canal near a partial heel print from a man's shoe, which was consistent with a theory that the body was rolled on the ground on the edge of the canal and then into the water. ${ }^{127}$ Further explanation and most likely supporting testimony would be needed to allow this visual to communicate the intended message in the case.

Photographs are effective in communicating a narrative with all of its emotional impact and appeal, or revulsion. ${ }^{128}$ Consider the following Vietnam War-era photograph:

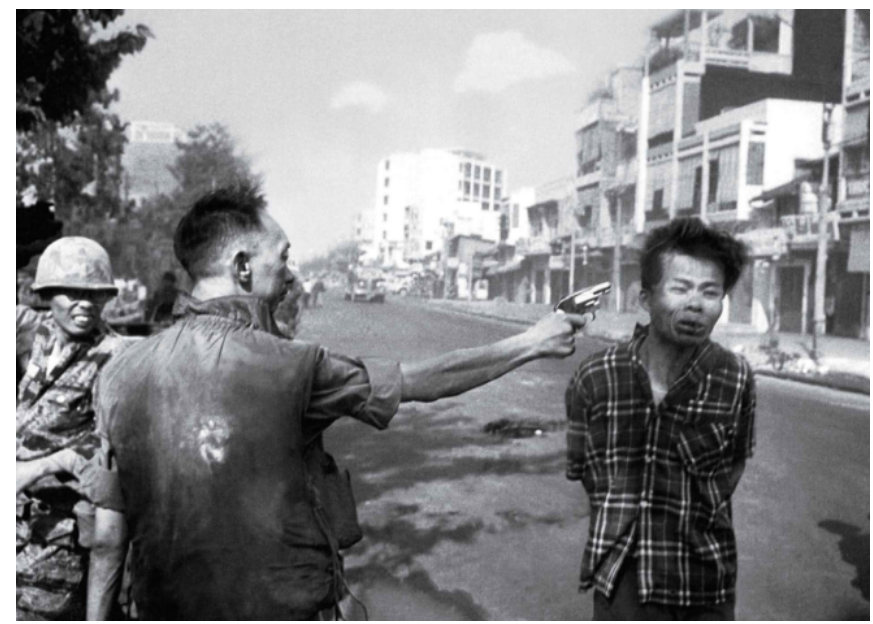

126. Schlesinger, supra note 123.

127. Id.

128. The deliberate use of images to inculcate anger or revulsion is referred to as "priming." See Stanchi, Power of Priming, supra note 10, at 306; LINDA L. BERGER \& KATHRYN M. STANCHI, LEGAL PERSUASION: A RHETORICAL APPROACH TO THE SCIENCE 107-22 (2018). When scientists are trying to prime for anger and aggression, sadness, or disgust, they often use visual imagery. See generally Craig A. Anderson, Effects of Violent Movies and Trait Hostility on Hostile Feelings and Aggressive Thoughts, 23 AGgRESSIVE BEHAV. 161 (1997) (testing scenes from The Karate Kid III against scenes from Gorillas in the Mist for priming effects on aggression); Brad J. Bushman, Moderating Role of Trait Aggressiveness in the Effects of Violent Media on Aggression, 69 J. PERSONALITY \& SOC. PSYCHOL. 950 (1995) (reporting that violent media was more likely to increase aggression in individuals with a high trait of aggression); Christopher J. Ferguson \& John Kilburn, The Public Health Risks of Media Violence: A Meta-Analytic Review, 154 J. PEDIATRICS 759 (2009) (describing the effect of violent media on aggressive behavior but finding "little support for the hypothesis that media violence is associated with higher aggression"); Randy J. McCarthy et al., Does Playing Video Games with Violent Content Temporarily Increase Aggressive Inclinations? A Pre-Registered Experimental Study, 67 J. EXPERIMENTAL SOC. PSYCHOL. 13 (2016) (describing video games' effect on aggressive behavior but finding no support for "hypothesis that playing a [violent video game] would increase aggressive inclinations"); Simone Schnall et al., Disgust as Embodied Moral Judgment, 34 Personality \& Soc. Psychol. Bull. 1096, 1104 (2008) (in which scenes from the films Trainspotting, The Champ, and Planet Earth were used to prime for and assess reactions of disgust and sadness). 
This Pulitzer Prize-winning photograph ${ }^{129}$ by Associated Press photographer Eddie Adams is credited with turning the tide of American public opinion on whether the Vietnam War could or should be won. ${ }^{130}$ Taken during the Tet Offensive in February 1968, the Adams photograph manages to capture in exquisite visual prose the moment of a summary street execution of a captured and hand-cuffed enemy combatant on February 1, 1968. ${ }^{131}$

As shown by other photographs taken by Adams on February 1, 1968, before and after the execution, ${ }^{132}$ the narrative included American troops who captured the Viet Cong combatant and escorted him down a public thoroughfare in Saigon, later joined by South Vietnamese soldiers, and then the abrupt execution occurred, after which General Loan calmly put his pistol into his holster, and left the executed man on the ground, alone, to bleed into the street.

It was the plain brutality and injustice of this scene, chronicled so well by Eddie Adams, that caused Americans to seriously rethink American involvement in the war.

These photographs ${ }^{133}$ were never a part of any litigation, but the images-especially the famous Pulitzer Prize-winning image of the execution itself - clearly speak a message about war, and its cruelty, injustice, and lack of civilized
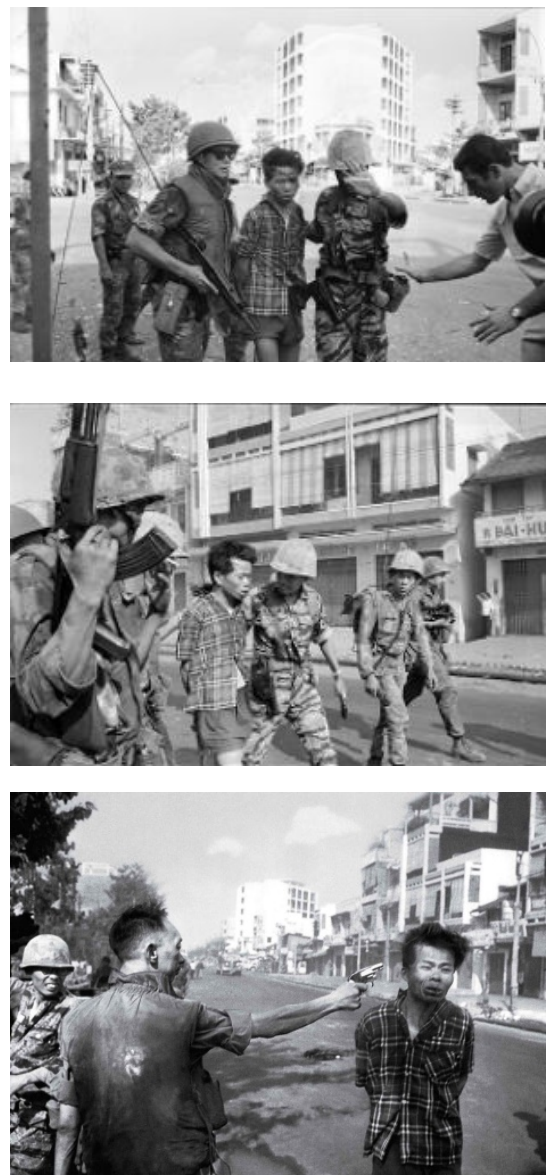

129. Eddie Adams, Saigon Execution (1968) (AP Photo/Eddie Adams).

130. Saigon Execution: Eddie Adams, 1968, TIME 100Pнотоs, http://100photos.time.com/pho tos/eddie-adams-saigon-execution [https://perma.cc/GP83-G3VH] (last visited Sept. 8, 2019) (AP Photo/Eddie Adams).

131. Id. The photograph shows the execution of Nguyễn Văn Lém, a Viet Cong soldier, by Brigadier General Nguyễn Ngọc Loan, South Vietnam's chief of National Police, during the Tet Offensive. $I d$.

132. Id. (select "See the sequence of events that led to the execution") (AP Photo/Eddie Adams).

133. Id. 

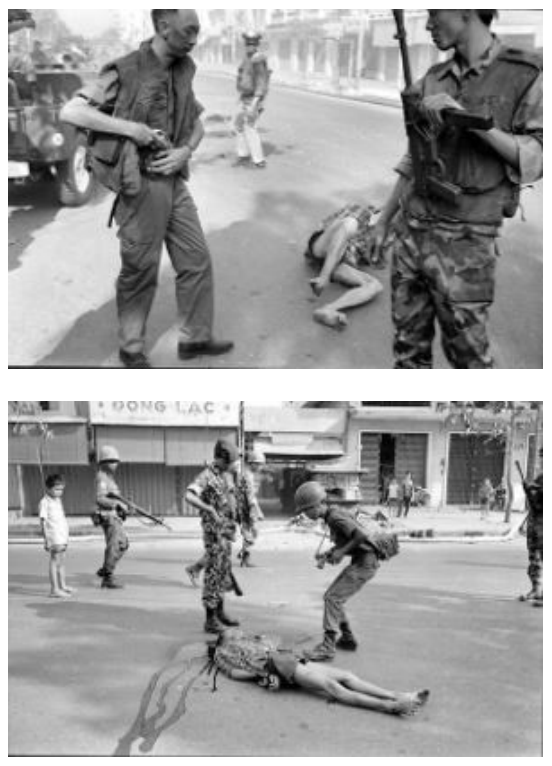

figures and the gun up slightly in the frame to the intersection of the vertical lines and the top horizontal line, and thereby removed part of the sky, but the image otherwise shows magnificent framing and composition. In fact it is this tiny imperfection in framing that adds to the verisimilitude of the image, although the idea that this image might have been staged or reenacted seems almost inconceivable, particularly when combined with the other gritty and dreadfully realistic images of the scene. ${ }^{135}$ Other South Vietnamese soldiers in the photographs "give focus" to the execution and the plight of the prisoner on the ground, but they are hardly necessary because of Adams's skill in capturing the decisive moment of the narrative. boundaries, and they do it without captions or explanation.

The dominant in the Viet Cong execution photographs was featured well, in the ambient light of the outdoors. The arm of the general, ending in the light-colored gun, provides a natural path for the eye to travel to the head of the Viet Cong prisoner.

Adams, as an extremely skilled photographer, even lined up the subjects of the execution in near perfect "thirds" (see composition and framing, "Rule of Thirds," below ${ }^{134}$ ) of the vertical axes of the frame.

Adams might have moved the

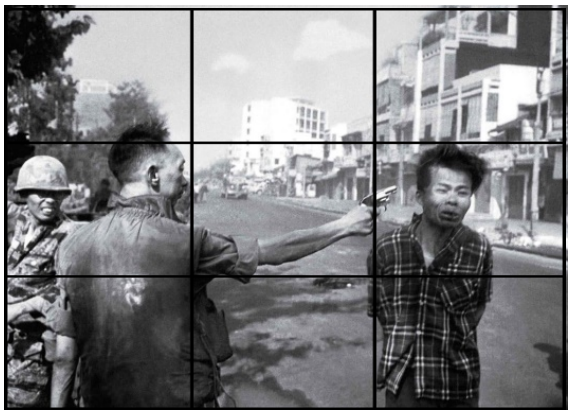

134. See infra Section II.E.1.

135. See generally sources cited supra note 114 (unexpectely chaotic composition can self-verfiy the truthfulness of images and the situation they depict as no one would include such images unless they really were there). 


\section{B. Lighting}

Lighting in a visual device affects the mood or emotion of the scene. ${ }^{136}$ It can provide drama and plot to the narrative. ${ }^{137}$ It can send messages by highlighting or obscuring positive or negative imagery in the scene, and create associations of different subjects based on their similar lighting or shadowing. ${ }^{138}$

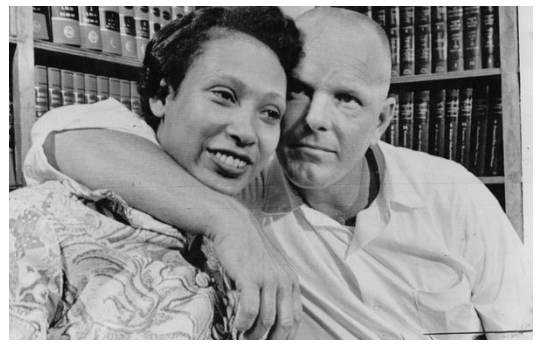

Loving v. Virginia $(1967)^{140}$
In visual media, particularly film, there are several terms for lighting effects:

High-Key Lighting - a bright, welllit scene where the direct light (key light) is matched by a strong indirect light (fill light) to soften or eliminate shadows in the scene. ${ }^{139}$

136. See Blain Brown, Motion Picture AND Video Lighting FOR CinEMATOGRAPHERS, GAFFERS AND LightiNG TECHNICIANS 57-90 (3d ed. 2019); Yashar Deldjoo et al., Recommending Movies Based on Mise-en-Scène Design, in ProceEdings of THE 2016 CHI CONFERENCE EXTENDED ABSTRACTS ON HUMAN FACTORS IN COMPUTING SYSTEMS 1544 (2016); Gail Lathrop and David O. Sutton, Elements of Mise-en-Scene 4-5 (2014), http://www.proseproductionsink.com/1102_licata_elements_of_mise-en-scene modified.pdf [https://perma.cc/AF9Z-GYE2]; GERALD Millerson, THE TECHNIQUE OF LiGHTING FOR TELEVISION AND FILM 15-17, 60-83, 86-94 (3d ed. 1991); Janey A. Place \& Lowell S. Peterson, Some Visual Motifs of Film Noir, 10 FILM COMMENT 30, 30-31 (1974).

137. Corrigan \& White, supra note 2, at 82; Daniel Barratt, "Twist Blindness": The Role of Primacy, Priming, Schemas, and Reconstructive Memory in a First-Time Viewing of The Sixth Sense, in PuzZle Films: COMPleX StORYTElling IN CONTEMPORARY CineMA 64-65 (Warren Buckland ed., 2009); see generally Lathrop \& Sutton, supra note 136, at 4-5; MILLERSON, supra note 136, at 15-17, 86-94; Place \& Peterson, supra note 136, at 30-31.

138. See sources cited supra notes $92,136$.

139. On high-key lighting generally, see FiL HunTER ET AL., LiGHT-SCIENCE \& MAGIC: AN INTRODUCTION TO PHOTOGRAPHIC LIGHTING 212 (3d ed. 2007); BROWN, supra note 136, at 57-71; Zeeshan Rasheed et al., On the Use of Computable Features for Film Classification, 15 IEEE TransaCtions ON CIRS. AND SyS. For VidEO TECH. 52, 58-60 (2005); GRAEME TURNER, FILM AS SOCIAL PRACTICE 65-68 (3d ed. 2002).

140. Photograph of Mildred and Richard Loving (1967) (United Press International). This photograph was taken after the ruling in Loving $v$. Virginia, 388 U.S. 1 (1967), that ended antimiscegenation laws prohibiting interracial marriage in Virginia and other states. See Amisha Padnani \& Celina Fang, Same-Sex Marriage: Landmark Decisions and Precedents, N.Y. TIMES (June 26, 2015), https://www.nytimes.com/interactive/2015/06/26/us/samesex-marriage-landmarks.html [https: //perma.cc/8SPL-TKSB]. 


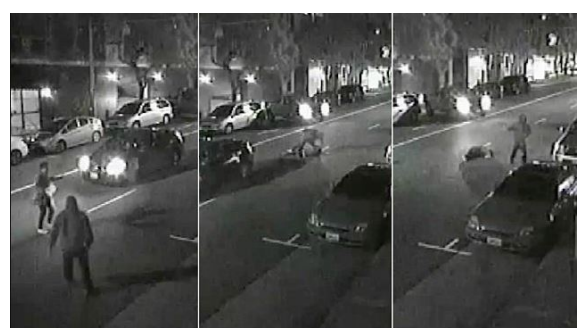

Low-Key Lighting - subdued or darkened lighting with low-level key lighting and fill lighting, and a strong backlight to outline the dominant subjects of the scene. ${ }^{141}$ It is unlikely that an attorney would select or seek to create an image or video with low-key lighting, but sometimes artifact photographs or video in low-key light will exist in the record of the case, such as the surveillance video excerpted

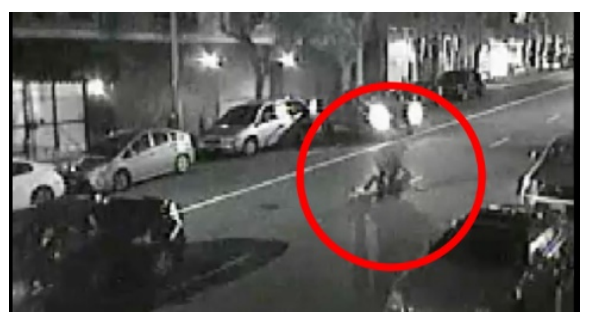
here. With this evidence, highlighting may aid the perception of the dominant subject of the scene, ${ }^{142}$ as shown in the bottom image at left.

These images (above) are excerpted from the surveillance video of the murder of Paul Tam, a British tourist in San Francisco. ${ }^{143}$ The final frame shows the dominant subject circled. ${ }^{144}$

141. On low-key lighting generally, see HUNTER ET AL., supra note 139, at 211-12; BROWN, supra note 136, at 62-70; Place \& Peterson, supra note 136, at 31-35; Rasheed et al., supra note 139, at 5860.

142. Evidence law generally permits the highlighting of portions of visual evidence through enlargement, light adjustment, and other clarifications to aid the viewer, particularly when the viewers have access to the unaltered original. See, e.g., People v. Anderson, 74 N.E.3d 639, 641-42 (N.Y. 2017) (determining that PowerPoint slides with captions and images with superimposed circles around objects of interest were permissible); People v. Williams, 147 A.D.3d 983, 984-85 (N.Y. App. Div. 2017) (determining that the "prosecutor's highlighting" of visual aids and "use of visual aids during summation was not in error"); State v. Stapley, 249 P.3d 572, 575-79 (Utah Ct. App. 2011) (applying the 403 balancing test to gruesome, close-up color photographs of gaping lacerations).

143. Collage of three frames of surveillance video footage of Paul Tam, a forty-four-year-old British tourist who was stabbed in the head during a mugging in San Francisco on Feb. 18, 2016. Kalhan Rosenblatt, The Horrifying Moment a British Tourist Was Fatally Stabbed in the Head Trying to Flee a Bag Snatcher on a Busy San Francisco Street, DAILY MAIL (Mar. 25, 2016, 9:32 PM), http:// www.dailymail.co.uk/news/article-3510093/The-horrifying-moment-British-tourist-48-fatally-stabbe d-head-mugging-San-Francisco.html [https://perma.cc/3SL7-E9JJ] (footage from San Francisco police).

144. A single frame of surveillance video footage of Paul Tam, with the image of the stabbing circled. Tanveer Mann, Horrific Footage Shows British Tourist Stabbed to Death in the Head During Mugging, METRO (Mar. 26, 2016, 11:52 AM), https://metro.co.uk/2016/03/26/horrific-footage-show s-british-tourist-stabbed-to-death-in-the-head-during-mugging-5776871/ [https://perma.cc/YUW5-8J $\mathrm{XX}$ ] (footage from San Francisco police). 


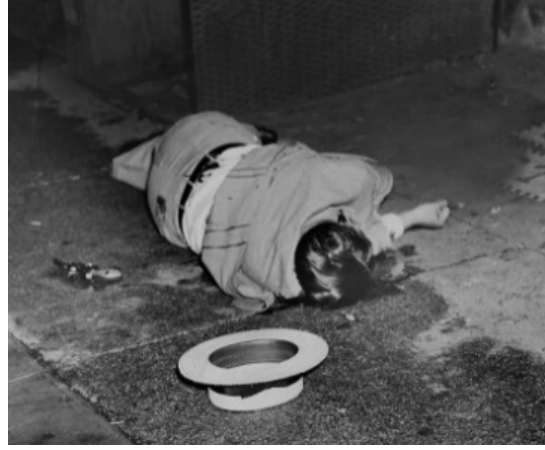

Weegee photograph of murder victim Dominick Didato (1936).

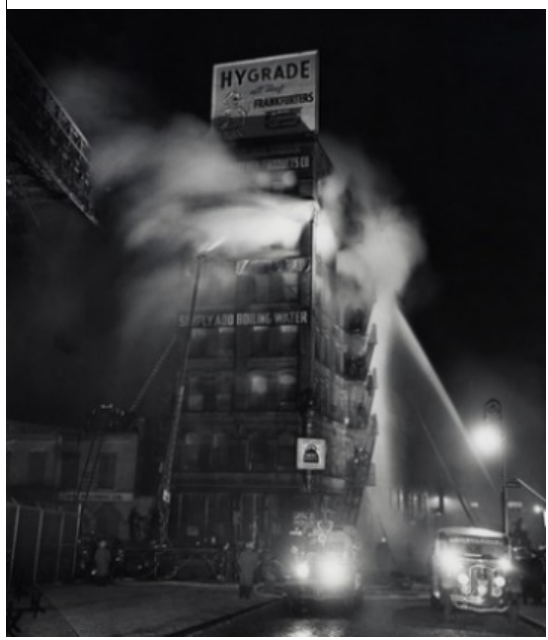

Weegee photograph of Hygrade Frankfurters building on fire with the logo, "Simply add boiling water" (1943).
Hard Lighting - the darling of the film noir genre, ${ }^{145}$ and of crime photographers of the 1930's and 40 's, ${ }^{146}$ most notably Arthur (Usher) Fellig (known as "Weegee"), ${ }^{147}$ hard light features strong and harsh key lighting with weak or nonexistent fill lighting and backlighting, to create dark and vivid shadows in high contrast to the brightly lit dominant subjects. ${ }^{148}$ Hard Lighting creates highly dramatic images, and often suggests a mood of mystery, suspense, and danger. ${ }^{149}$ Flash photographs taken in extremely low ambient light will often display the hard lighting effect. ${ }^{150}$ It is unlikely that an attorney will seek out or create a hard light, film noir-type image, but, as with low key lighted scenes, artifact images from the case record may feature hard lighting.

145. See Patrick Keating, Hollywood Lighting from the Silent Era to Film Noir 244 64 (John Belton ed., 2009) (discussing lighting in the film noir era); Place \& Peterson, supra note 136, at 30-35; ANDREW SPICER, FILM NOIR 4-5 (2002).

146. Jodi Hauptman, FLASH! The Speed Graphic Camera, 11 YALE J. CRITICISM 129, 129-37 (1998); V. Penelope Pelizzon \& Nancy M. West, "Good Stories" from the Mean Streets: Weegee and Hard-Boiled Autobiography, 17 YALE J. CRITICISM 20, 20-50 (2004) (describing Weegee's style as "hard-boiled").

147. See generally Arthur Fellig (“WeEgee”), Weegee By Weegee: An Autobiography (1961); ARTHUR FELLIG ("WeEGEE"), NAKED CITY (1945) (containing over 200 original Weegee photographs); BRIAN WALLIS, WEEGEE: MURDER IS MY BUSINESS (2013) (exploring Weegee's style and career in New York City).

148. On hard lighting generally, see BROWN, supra note 136, at 64-67; KEATING, supra note 145, at 244-64; Place \& Peterson, supra note 136, at 30-35; SPICER, supra note 145, at 4-5.

149. See sources cited supra note 146.

150. See, e.g., Michael Freeman, The Complete Guide to Light \& Lighting In Digital PHOTOGRAPHY 91-95 (2007). 


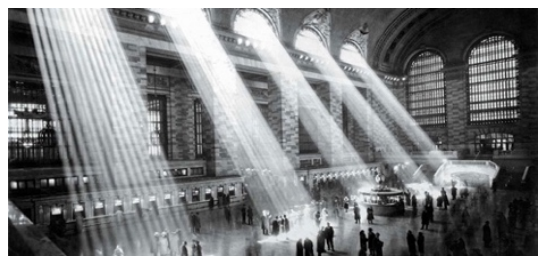

Alfred Stieglitz, Grand Central Terminal (1929).

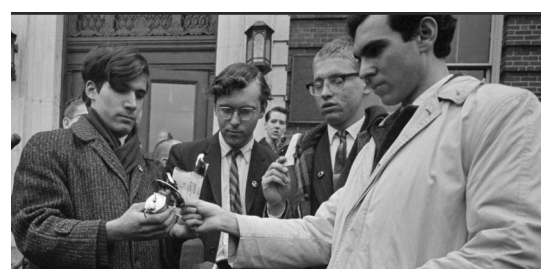

David O'Brien and others burning their draft cards, leading to United States $v$. O'Brien. ${ }^{152}$ The ambient lighting here happens to be High Key.
Motivated Lighting - Light in a scene with a definite revealed source such as a window, a lamp, or a fireplace is referred to as motivated lighting. In mise en scène analysis, motivated lighting is an actual subject of the scene, and it may be the dominant subject if (in film or video) it is moving (e.g., a flashlight or searchlight beam). ${ }^{151}$

Ambient Lighting - The most common lighting expected to be employed or encountered by attorneys in images is ambient lighting, lighting provided by the natural outdoor or indoor lighting at the scene. Ambient lighting varies in intensity depending on the time of day outdoors, or the placement of light sources in the interior space. ${ }^{153}$

As noted above, litigators often inherit artifact photographs from the investigation or discovery of the case, and these can be a mixed bag when it comes to lighting. Ambient lighting is the most common lighting to be used when images simply are recorded, as opposed to created in photographic or motion picture production. But sometimes artifact photographs will have more unusual lighting, and augmentation or highlighting might be employed to properly communicate the subjects and message of the scene. ${ }^{154}$

\section{Color vs. Black and White}

The debate between black and white (grayscale) and color in film and photography is not just an artistic debate, it can have significant effects on

151. On motivated lighting generally, see Brown, supra note 136, at 74-78; JOHN FrEEMAN, LightiNG FOR INTERIORS: PHOTOGRAPHY (2002); KEATING, supra note 146, at 57-71.

152. Bettmann, Pacifists Burning Draft Cards (1966), GETTY IMAGES, https://www.gettyimages.com/d etail/news-photo/reporters-gather-near-cna-pacifists-david-a-reed-of-news-photo/514682300 [https://perma .cc/UWU2-4X8F] (depicting David Reed, David O’Brien, David Benson, and John Phillips burning their draft cards, the subject of United States v. O'Brien, 391 U.S. 367 (1968)).

153. On ambient lighting generally, see BROWN, supra note 136, at 74-80; FREEMAN, supra note 151 , at $23,109-11,149-51$.

154. See sources cited supra note 142 (regarding admissibility of evidence altered to enhance visibility). 
perception and cognition. ${ }^{155}$ The use of color can profoundly change the clarity and impact of the visual and might communicate the message intended by the author much better than in black and white or grayscale. ${ }^{156}$ In legal contexts, the difference might affect the outcome of a case.

"In recent years, as electronic filing and transmission of documents" becomes the norm, "judges and law clerks are as likely to view... pleadings and briefs on a computer or tablet screen as they are to" grab "hold of a paper filing." 157 Attorneys can now use color images and diagrams as often as black and white, and there is a good chance the judge and her law clerks will view them in full color. ${ }^{158}$ Cases that previously suffered from a grayscale and black-and-white only universe, might have different outcomes when finders of fact and adjudicators are able to see the subject matter of disputes in color.

Readers should note that color and black and white speak the narrative of the situation differently. ${ }^{159}$ In a case with particularly gruesome facts, color imagery might be more striking and indelible, but the shock and awe of the scene might detract from the narrative by the vividness of the images. ${ }^{160}$ As a warning to readers, the next several examples explore this concept further.

155. E.g., Kathleen A. Akins, Black and White and Colour, in CONSCIOUSNESS INSIDE AND OUT: Phenomenology, NeuroscienCE, AND THE NATURE OF EXPERIENCE 173-223 (Richard Brown ed., 2013); Mitchell G. Ash, Gestalt Psychology in German Culture, 1890-1967: Holism and THE QUeST FOR OBJeCTIVITY 302-04 (1998); Dahlia W. Zaidel, Brain and Art: Neuro-Clues from Intersection of Disciplines, in NEUROAESTHETICS ch. 8 (Martin Skov \& Oshin Vartanian eds., 2018); Joshua Yumibe, Moving Color: EARly Film, Mass Culture, Modernism 6-11 (2012).

156. See Joseph Dumit, Critically Producing Brain Images of Mind, in CRITICAL NEUROSCIENCE: A Handbook of the Social and Cultural ConteXts of Neuroscience 213 (Suparna Choudhury \& Jan Slaby eds., 2016) (discussing Louis Sokoloff's research which found that the eye cannot see all shades of gray and that the introduction of color can "make subtle distinctions more visible"); YumiBe, supra note 158, at 6-11. See generally Patricia SloAne, The Visual Nature OF COLOR (1989).

157. Murray, Sharpest Tool, supra note 5, at 68; see also R. Lainie Wilson Harris, Ready or Not Here We E-Come: Remaining Persuasive Amidst the Shift Towards Electronic Filing, 12 LEGAL COMM. \& RHETORIC: JALWD 83, 85 (2015); Porter, supra note 9, at 1693.

158. See sources cited supra note 157.

159. See sources cited supra notes 155 and 156.

160. See Dennis J. Devine, Jury Decision Making: The State of the Science 147-49 (2012); KÄREN M. HESS ET AL., CRIMINAL INVESTIGATION 58 (11th ed. 2016) (noting that gruesome color photography can be deemed so inflammatory as to be inadmissible); PAUL LESTER, Photojournalism: An EthicAl ApProach 58-59 (2015); Edward M. Robinson, Crime Scene PHOTOGRAPHY 703-04 (3d ed. 2016). 


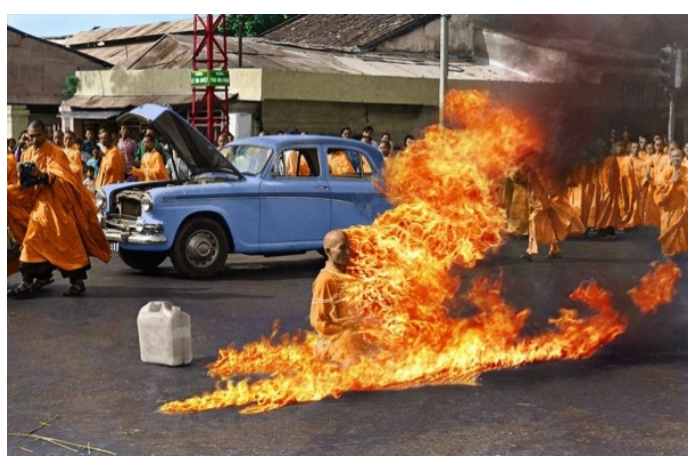

The self-immolation of Buddhist Monk Thích Quang Duc in Saigon, Vietnam on June 11, 1963 was undertaken to protest the South Vietnamese Diem regime's treatment of Buddhist monks. ${ }^{161}$ The colorized image of the suicide, undertaken in a very public place on a main thoroughfare in Saigon, demonstrates the effect of vivid color imagery of a horrifying scene. ${ }^{162}$ The grayscale version of the Pulitzer Prize-winning photograph by Malcolm Browne (Associated Press), reproduced below, was the original image that was circulated worldwide by the Associated Press. ${ }^{163}$

There is no doubt about the fact that both the color and the grayscale photographs are arresting because of the nearly incredible subject matter and the narrative it expresses - the serenity and stillness of the monk as the flames spectacularly lick off his body. The photograph captures the decisive moment of suicide, death, and cremation in one still image. The mise en scène of the color photograph is striking in both the matching color of the flames and the saffron-colored robes of the monks viewing the scene; the complimentary blue color of the automobile in the background against the orange flames is beautiful if excruciating. Perhaps the most remarkable element of the mise en scène is the fact that the monk's body exudes huge violent flames, but the body itself does not appear burnt (yet). This is explained by the fact that it is the fumes of the gasoline that are on fire, and not the body of the monk, but the image does have an otherworldly quality to it. This is made all the more poignant by the fact that the burning man is a religious person.

161. David Halberstam, Diem Asks Peace in Religion Crisis, N.Y. Times, June 12, 1963, at 3; Thich Tam Phuong, The Self-Immolation of a Buddhist Monk, BudDHIST Information, http://www.buddhistinformation.com/self_immolation.htm [https://perma.cc/KUV8-59V6] (last visited Oct. 12, 2019); Josh Sanburn, A Brief History of Self-Immolation, TIME (Jan. 20, 2011), http://content.time.com/time/world/article/0,8599,2043123,00.html [https://perma.cc/J7TU-SKNZ].

162. Malcolm Browne, Self-immolation of Buddhist Monk, Thich Quang Duc, in Saigon, Vietnam, on June 11, 1963 (1963) (AP Photo/Malcolm Browne) (colorized by Reddit user mygrapefruit).

163. Id. (original grayscale image). 
The grayscale version of Malcolm Browne's photograph ${ }^{164}$ is striking, but not quite as violent and arresting as the colorized photograph. Here, it becomes more obvious that the composition of the photograph needed to show the placement of the

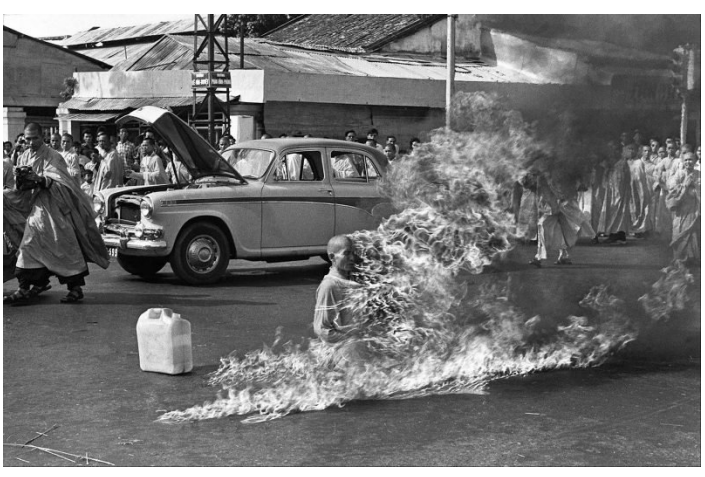
gasoline can and the stopped car with its trunk open to explain that the narrative is about a person who had gasoline poured on them and who then was set on fire, rather than a picture of a fiery car accident victim. The narrative that the monk self-immolated himself is not evident in either photograph and would have to be explained verbally in text accompanying the images.

In comparison, additional photographs taken by Malcolm Browne $^{165}$ several minutes into the immolation suicide communicate a different message. Most of the scene is the same, but the skin of the monk has darkened-it is more obvious that he is burning alive. These photographs depict the same event, and are highly dramatic, but the images are revolting and would most likely repulse the viewer rather than engage them to learn the monk's narrative of protest. ${ }^{166}$

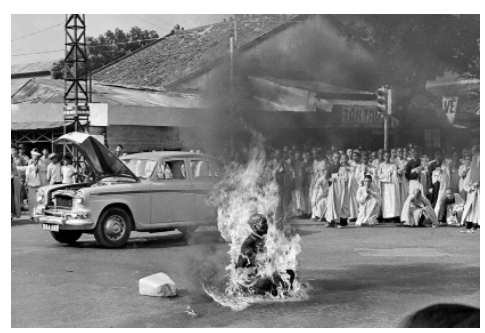

164. Id.

165. Malcolm Browne, Vietnam Monk Protest (1963) (Associated Press) (capturing the selfimmolation, several minutes in, with the gas can tipped over); Malcolm Browne, Vietnam Monk Protest, No. 2 (1963) (depicting a zoomed-in image of Thích Quang Duc's self-immolation several minutes into the incident).

166. Self-immolation itself is a provocative, highly visual act that often motivates others to act. In this century, Tarek el-Tayeb Mohamed Bouazizi, a Tunisian street vendor, set himself on fire on December 17, 2010, and this act became a catalyst for the Tunisian Revolution, and soon thereafter, the wider Arab Spring uprisings. See Lilia Blaise, Self-Immolation, Catalyst of the Arab Spring, Is Now a Grim Trend, N.Y. TIMES (July 9, 2017), https://www.nytimes.com/2017/07/09/world/africa/selfimmolation-catalyst-of-the-arab-spring-is-now-a-grim-trend.html [https://perma.cc/F5G3-2V6X]; Marc Fisher, In Tunisia, Act of One Fruit Vendor Sparks Wave of Revolution Through Arab World, WASH. POST 
The color versus grayscale choice creates a dilemma in a criminal prosecution or personal injury case (or any case with physical injuries to people, especially children and vulnerable adults), when the prosecution or plaintiff is in possession of extremely graphic color images that display in gory detail the full extent of a victim's or plaintiff's injuries. ${ }^{167}$ On the one hand, the gory or prurient display may cause a sympathetic reaction in the viewers that motivates them to award damages in a higher amount or assign blame more readily because the injuries look so painful, bloody, and extensive, and the crime appears to be so terrible. ${ }^{168}$ The color media allows this reaction by vividly depicting the pain and suffering. But on the other hand, gory, bloody, or prurient images may provoke an extremely hostile and negative reaction in viewers, who might lash out not at the injustice of the injuries but at the cruelty of the author, the attorney, who forced the audience to witness these terrible images. ${ }^{169}$

In Section II.E.3 below, I analyze a series of photographs taken during the May 1970 Kent State Vietnam War protest shootings. Ohio National

(Mar. 26, 2011), https://www.washingtonpost.com/world/in-tunisia-act-of-one-fruit-vendor-sparks-waveof-revolution-through-arab-world/2011/03/16/AFjfsueB_story.html?noredirect=on\&utm_term=.399f2bd47 368 [https://perma.cc/6H3S-N4HR].

167. See sources cited supra note 160.

168. See generally David A. Bright \& Jane Goodman-Delahunty, Gruesome Evidence and Emotion: Anger, Blame, and Jury Decision-Making, 30 L. \& HuM. BeHAV. 183, 184-86 (2006) (finding that the conviction rate was significantly higher where photographs were used); Kevin S. Douglas et al., The Impact of Graphic Photographic Evidence on Mock Jurors' Decisions in a Murder Trial: Probative or Prejudicial?, 21 L. \& HUM. BEHAV. 485, 492 (1997) (finding that mock jurors who were shown graphic photographs returned a guilty verdict approximately twice as often as mock jurors who were not shown photographs); Bryan Edelman, The Impact of Graphic Injury Photographs on Liability Verdicts and Non-Economic Damage Awards, JURY EXPERT (Sept. 1, 2009), http://www.thejuryexpert.com/2009/09/the-impact-of-graphic-injury-photographs-on-liability-verdic ts-and-non-economic-damage-awards/ [https://perma.cc/232G-4VYQ](finding that participants who saw injury photographs were significantly more likely to find for the plaintiff). See also sources cited supra note 160.

169. See sources on "priming" cited supra note 128. A similar decision confronts news media as to whether to publish extremely graphic and gory photographs depicting current events. Roger Tooth, Graphic Content: When Photographs of Carnage Are Too Upsetting to Publish, GuARDIAN (July 23, 2014, 1:55 PM), https://www.theguardian.com/world/2014/jul/23/graphic-content-photographs-tooupsetting-to-publish-gaza-mh17-ukraine [https://perma.cc/3F7J-KQEQ]. 


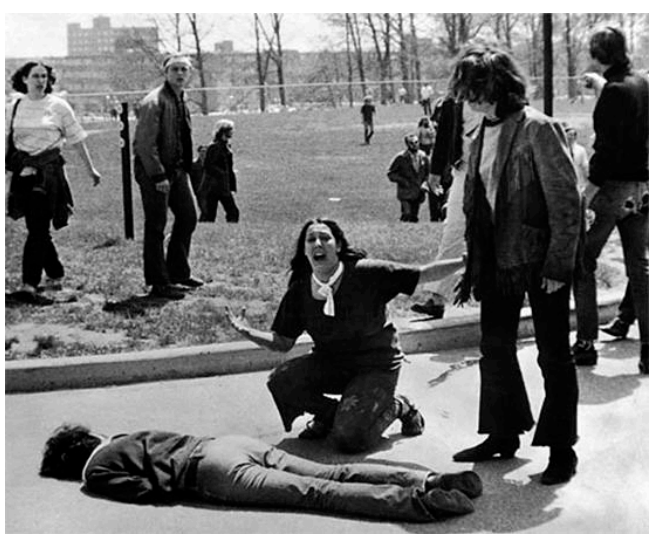

Guard soldiers killed four college students at Kent State University. ${ }^{170}$ The best known photograph of the series is the Pulitzer Prizewinning black and white image of Mary Ann Vecchio, a fourteen-year-old runaway from Miami who joined the protests at Kent State, ${ }^{171}$ and was photographed by student photojournalist John Paul Filo as she was wailing in grief over her slain friend, Jeffrey Miller. ${ }^{172}$

An image not nearly as well-know, but also by John Paul Filo, shows a very different subject matter, namely the striking image of blood pouring from the body of Jeffrey Miller. ${ }^{173}$ The almost bizarre appearance of the blood trail, looking all the more like black paint or highway repair tar, rather than actual blood, is strikingly gruesome, but as an image intended to communicate a narrative of tragedy, it is not effective simply because of the confusing and distracting appearance of the blood. A viewer may well focus on the remarkable rendering of the image, rather than on the loss of Jeffrey Miller's life depicted in the scene. Although a color image most likely would have been less confusing, it would have been incredibly more gruesome, as well as distracting and revolting simply from the subject matter.

The subject matter of the lawsuit or

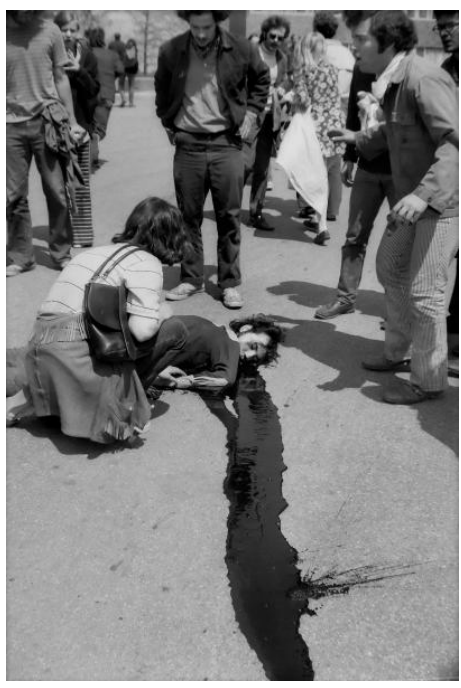
dispute will weigh heavily in the decision to use color or black and white images, or to use images at all. If the subject of the suit is war crimes or

170. Cydney Adams, May 4, 1970: Guardsmen Open Fire on Kent State Protesters, CBS NewS (May 4, 2016, 5:59 AM), https://www.cbsnews.com/news/on-this-day-may-4-1970-guardsmen-openfire-on-kent-state-protesters/ [https://perma.cc/6HDM-NG2P].

171. Mary Ann Vecchio Just Wants to Forget Kent State, Associated Press (May 5, 1990), https://www.apnews.com/5ba6c1b8b4ebcd3de354dea7639c5540 [https://perma.cc/65U4-6H3N]; Associated Press, Kneeling with Death Haunted a Life, N.Y. Times, May 6, 1990, at 32.

172. John Paul Filo, Kent State Shootings (1970).

173. John Paul Filo, Untitled (1970) (capturing a woman kneeling next to slain student Jeffrey Miller with a blood trail clearly visible). 
genocide, the use of extremely arresting images may be considered. It is reported that the use of the film Nazi Concentration Camps at the Nuremburg Trials in 1945 helped to turn the tide of the proceedings against the Nazi war criminal defendants. ${ }^{174}$ The following images relate to genocide, which naturally means the subject matter is drastic and unnerving.

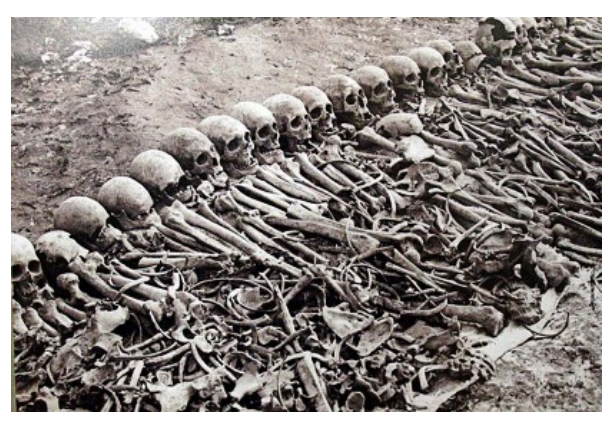

Armenian Genocide, 1915: Skulls and Bones of Victims of the Armenian Genocide (1915). ${ }^{175}$ The image, while arresting in its subject, is oddly distracting in that there is a certain art in the arrangement of the skeletons. The dominant image may not be effective if the intent was to focus on the tragedy of the victims and not the visual arrangement of their remains.

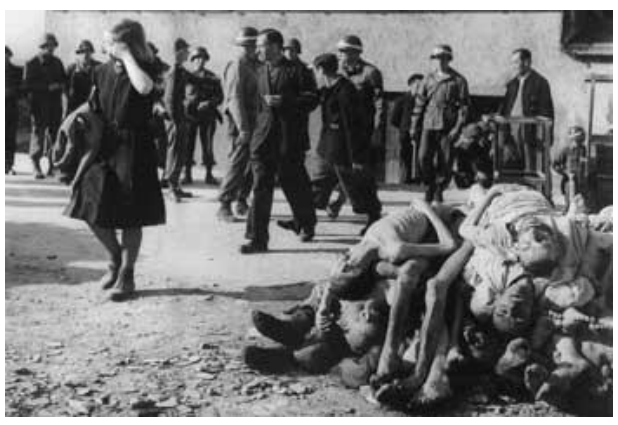

Buchenwald Concentration Camp, 1945: Citizens of Weimar, Germany, Forced to Walk Past Piles of Jewish Concentration Camp Victims at Buchenwald (1945). ${ }^{176}$ This piece by the master photographer Margaret BourkeWhite communicates well the narrative of guilty bystanders forced to look at the evidence of Nazi atrocities. The image is both striking and revolting even in black and white.

174. See Yvonne Kozlovsky-Golan, The Shaping of the Holocaust Visual IMAge By the NUREMBERG TRIALS: THE IMPACT OF THE MOVIE NAZI CONCENTRATION CAMPS 13-15 (2008) (noting that footage taken for the Nuremburg Trials shaped consciousness of the Holocaust); Lawrence Douglas, The Shrunken Head of Buchenwald: Icons of Atrocity at Nuremberg, in VISUAL CULTURE AND THE HOLOCAUST 286 n.42 (Barbie Zelizer ed., 2001).

175. Skulls and Bones of Victims of the Armenian Genocide (c. 1915). See Adrian Gregorich, $A$ Genocide Forgotten, SENTINEL PROJECT (Apr. 24, 2014), https://thesentinelproject.org/2014/04/24/agenocide-forgotten/ [https://perma.cc/8U5M-XYMU].

176. Margaret Bourke-White, Citizens of Weimar, Germany, Forced to Walk Past Piles of Jewish Concentration Camp Victims at Buchenwald (1945) (Margaret Bourke-White/Time \& Life Pictures/Getty Images). 


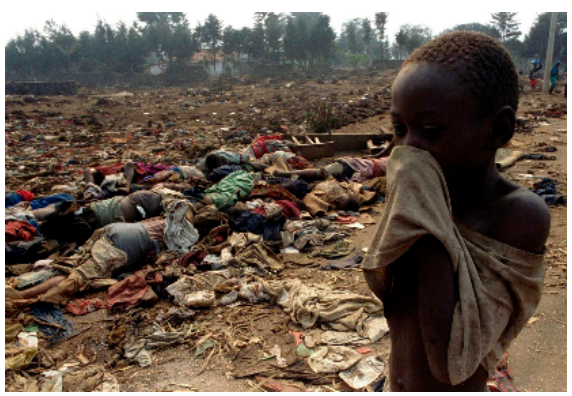

Rwanda, 1994: Genocide Victims in Rwanda (1994). ${ }^{177}$ Although this image of a young witness to genocide is in color, the horror of the scene is mercifully reduced simply by the confusing clutter of the composition. Nevertheless, the image is haunting because of the youthfulness of the witness forced to hold his nose against the stench of the atrocity.

Color images may well demonstrate the extent and severity of the damages and the pain and suffering endured by the victim much more effectively than grayscale versions of the images; but attorneys must judge well their audience and the audience's likely reaction to viciously graphic and gory color images, and whether that reaction may be to turn against the attorney author and her client in reaction to be subjected to the viewing of graphic, gory images. ${ }^{178}$

\section{Point of View and Perspective}

Images have an author, and the author selects the particular perspective and point of view of the image. ${ }^{179}$ The point of view can distort the importance of certain objects and emphasize others. ${ }^{180}$ The perspective gives a single focal point on a scene that necessarily excludes

177. Corinne Dufka, A Rwandan Boy Covers His Face from the Stench of Dead Bodies (1994) (REUTERS/Corinne Dufka).

178. See sources on "priming" cited supra note 128. As noted earlier, this article is not undertaking a discussion of evidence law and the admissibility of gory, gruesome images for proof of facts as evaluated under Federal Rules of Evidence 401 and 403 and similar state evidence rules. For further reading on that topic, see Murray, The Ethics of Visual Legal Rhetoric, supra note 12, at 11322; 22A Charles Wright et Al., Federal Practice and Procedure Evidence $\$ 5215.4$ (2d ed. 2018); 2 Michael H. Graham, HandBook of Federal Evidence $\S 401: 7$ (8th ed. 2018). See also Pike v. State, 809 S.E.2d 756, 761 (Ga. 2018) (finding that autopsy photographs were "not especially gory or gruesome" so as to be prejudicial); Ragland v. Commonwealth, 476 S.W.3d 236, 248 (Ky. 2015) (noting that showing the jury several gory images might increase the prejudicial effect with little probative value, affecting the overall Rule 403 analysis); Key v. State, 616 P.2d 774, 776 (Wyo. 1980) (supporting admission of photograph of stab wound because it showed the location of the injury and was not excessively gruesome).

179. On perspective and point of view, see Steven Aguilera, A New Perspective: PHOTOGRAPHY \& FILMMAKING EDITION 3-7, 81-86 (2008); BARRY ANDERSSON, THE DSLR FILMMAKER's HANDBOOK: REAL-WORLD PRODUCTION TECHNIQUES 114-20 (2d ed. 2015) (discussing the various camera positions to capture different perspectives); ELSPETH KYDD, THE Critical Practice of Film: An Introduction 119-25 (2011). See also sources cited supra notes 5 and 54.

180. Graham Clarke, The Photograph 191 (1997); 2 Robert N. Colwell, Manual of REMOTE SENSING 1266 (Robert N. Colwell et al. eds., 2d ed. 1983); SARAH Hamill, David SMith IN TWO Dimensions: PHOTOGRAPHY AND THE MATTER OF SCULPTURE 75-77 (2015). 
a complete viewing of the scene. ${ }^{181}$ When critiquing the communicative potential of images in making a point or persuading an audience of the rightness of the author's position, an attorney must consider how the point of view and perspective of the attorney's own or an opponent's images may affect the viewer's perception, reception, and cognition of the message, and be ready to act if the perspective or point of view potentially distracts from or distorts the scene, and potentially could lead to deception or obfuscation of the meaning of the scene. ${ }^{182}$

In photography and motion picture production, perspective and point of view are described through various camera angles: eye level shot (captures the torso and head of human subjects), medium shot (captures the entire human form in the shot), long range shot (distorts the size of objects and often the distance between objects or the distance from the viewer), high level (diminishes the size and the metaphorical importance of humans and objects in the scene), birds-eye view (diminishes the size and distorts the appearance of humans and objects in the scene; it often dehumanizes the people in the shot, making them appear like ants), close up shot (shows only the face of human subjects), and extreme close up (often distorts the appearance of objects by zeroing in on a part not normally perceived by viewers). ${ }^{183}$

It is particularly important to consider the point of view and perspective of a static medium, such as photography, because it does not change in the viewing. You have one shot, one view, one angle, reflected in the point of view and perspective chosen by the author. Unlike with motion pictures and video, the photographic camera does not pan back and forth, zoom in on faces, or pull back to reveal a more complete perspective on the scene. ${ }^{184}$

181. See JACQueline T. Fish ET AL., CRIME SCEne InVESTIGATION 63 (3d ed. 2014) (discussing the benefits of multiple cameras shooting in different perspectives and video that takes wide-angle shots followed by zooming in to capture the entire scene and specific details); GERALD MILLERSON \& JiM OWENS, TELEVISION PRODUCTION 149-50, 156-57 (15th ed. 2009) (discussing the benefits of moving the camera, panning, and zooming).

182. See generally AGUILERA, supra note 179, at 3-7; ANDERSSON, supra note 182, at 117; KYDD, supra note 182 , at $123-25$.

183. On shot types and camera angles and their effect on perspective, see AGUILERA, supra note 182, at 4-7; ANDERSSON, supra note 179, at 114-17; KYDD, supra note 179, 119-21; MILLERSON \& OWENS, supra note 181, at 143-48.

184. See sources cited supra note 181. 
To demonstrate this point, consider a famous photograph taken in a medium shot at ground level in Times Square on V-J Day (Victory over Japan Day, August 14, 1945). ${ }^{185}$

Whatever your reaction might be to Alfred Eisenstaedt's photograph of American sailor George Mendonsa kissing dental assistant Greta Zimmer Friedman ${ }^{186}$ - appreciation for joyful celebration of the end of WWII hostilities; nostalgia for the Greatest Generation; admiration of a graceful dip with lip-lock; or revulsion at the unwelcome oral assault of a sailor on an unwitting dental assistant - the narrative of the photograph is necessarily

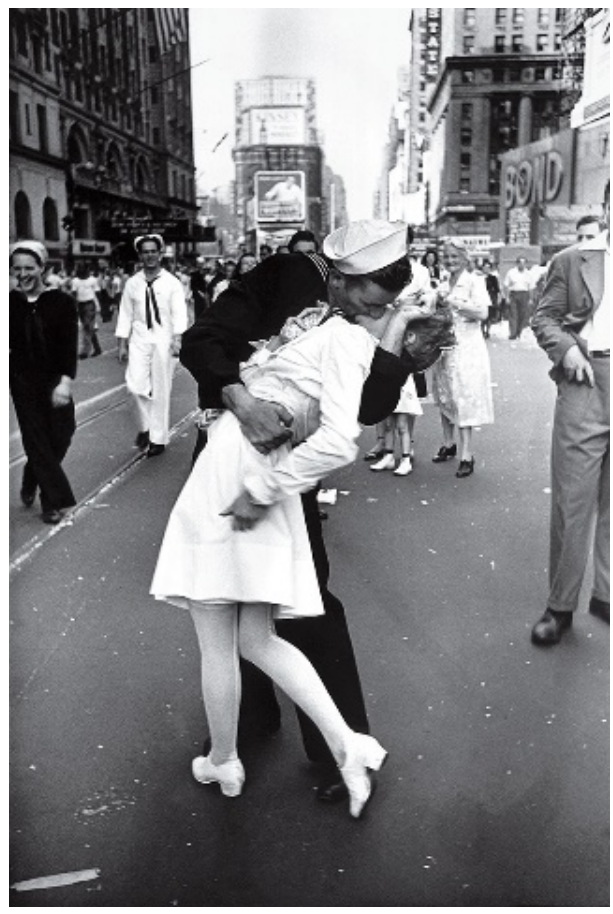
incomplete because it is a single image from a single perspective capturing one split second of an entire event on a given day in Manhattan.

The Alfred Eisenstaedt photograph appearing above is the one that ran in Life magazine in a twelve-page internal section of photographs entitled "Victory Celebrations" in the August 27, 1945, edition of the magazine. ${ }^{187}$

185. Eisenstaedt, Sailor Kissing White-Clad Woman, No. 2, supra note 1.

186. The identities of both subjects have been confirmed to be American sailor George Mendonsa and dental assistant Greta Zimmer Friedman. Elizabeth Chuck \& Erin Calabrese, Greta Zimmer Friedman, 'Nurse' in Iconic WWII Kissing Photo, Dies at 92, NBC News (Sept. 10, 2016, 2:31 PM), https:// www.nbcnews.com/news/us-news/greta-zimmer-friedman-nurse-iconic-wwii-kissing-photo-dies-92-n6461 11 [https://perma.cc/8F55-CBE3]; Mark D. Faram, The Kiss Heard 'Round the World WWII Sailor Gives Lip Service Over Famous Photo, NAvYTIMES (Oct. 24, 2005), https://www.navytimes.com/news/yournavy/2018/03/08/the-kiss-heard-round-the-world-wwii-sailor-gives-lip-service-over-famous-photo/ [https:// perma.cc/7PUW-ZSY7]. A poignant note from the story was that Greta Zimmer Friedman was an Austrianborn Jewish Holocaust/Shoah survivor who had emigrated to the United States in 1939. AP, Jewish Woman in Iconic WWII Times Square Kiss Photo Dies at 92, TIMES ISRAEL (Sept. 11, 2016, 10:13 AM), https://www.timesofisrael.com/jewish-woman-in-iconic-wwii-times-square-kiss-photo-dies-at-92/ [https://p erma.cc/4T9P-K8E6].

187. Victory Celebrations, LifE, Aug. 27, 1945, at 21, 27. 


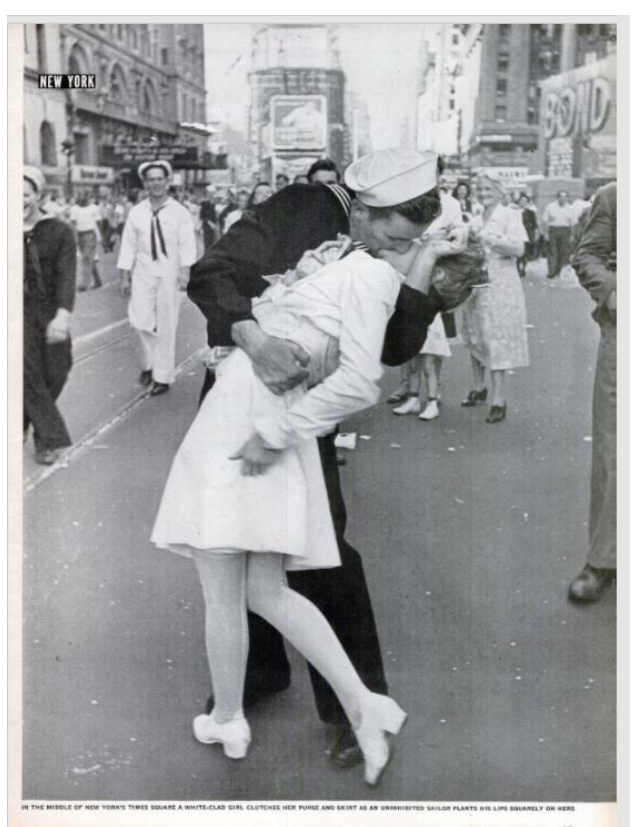

Life magazine appears to have agreed with the "assault" narrative, because it ran a caption for the photograph that read, "In the middle of New York's Times Square a whiteclad girl clutches her purse and skirt as an uninhibited sailor plants his lips squarely on hers." $" 188$

The Life magazine image surely is the most famous photograph of George Mendonsa kissing Greta Zimmer Friedman on V-J Day, but it is by no means the only photograph of the kiss. The photograph stands out because Eisenstaedt framed it so beautifully with the classic architecture of Times Square in the background, the right balance of bystanders cheerfully giving focus to the scene before them, and the striking contrast of the white-clad outfit of the dental assistant against the black Navy uniform of the sailor. Compositionally, although the dominant subjects are featured dead center in the image, the lines in the street, the vectors of the buildings, and the bystanders' focus, all point to the dominant subjects in an eye-pleasing manner.

However, if the Life magazine photograph was a crucial exhibit in litigation - perhaps in the hypothetical sexual assault case of Friedman $v$. Mendonsa - then the narrative of this single snapshot is incomplete. The single Life magazine shot does not indicate the duration of the kiss, which apparently was considerable, because Eisenstaedt was able to take four photographs ${ }^{189}$ of the subjects before Mendonsa quit his "assault."

188. Id.

189. Alfred Eisenstaedt, Contact Sheet Images from Alfred Eisenstaedt's Film, Aug. 14, 1945 (1945) (Time \& Life Pictures/Getty Images). 
Eisenstaedt's Life magazine photograph (Eisenstaedt \#2) (left) ${ }^{190}$ - This was the second of the four photographs taken which Eisenstaedt favored because of its perspective and composition. ${ }^{191}$

Eisenstaedt \#1 (right) ${ }^{192}$ - This photograph was the first taken of the encounter, but it most likely was rejected because the nearest bystander on the left is facing and walking in the opposite direction, drawing focus away from the "kiss" scene.
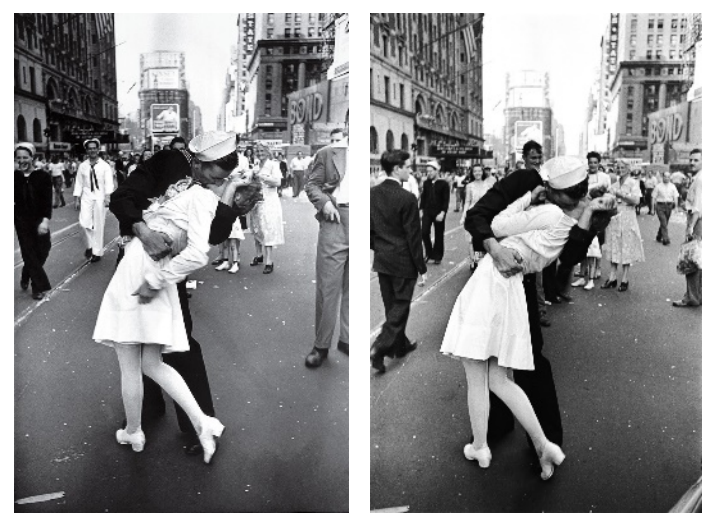

Eisenstaedt \#3 (left) ${ }^{193}$ - The third photograph is off-balance: the sailor on the left is too large, the bystander on the right is cut in half, and the black uniform of the sailor on the left competes with Mendonsa's black uniform.

Eisenstaedt $\# 4^{194}$ (right) - The fourth photograph probably was rejected because the bystanders are not as cheerful and joyful as in the Life magazine shot, and the background appears cluttered in its "figureground" relationship. ${ }^{195}$
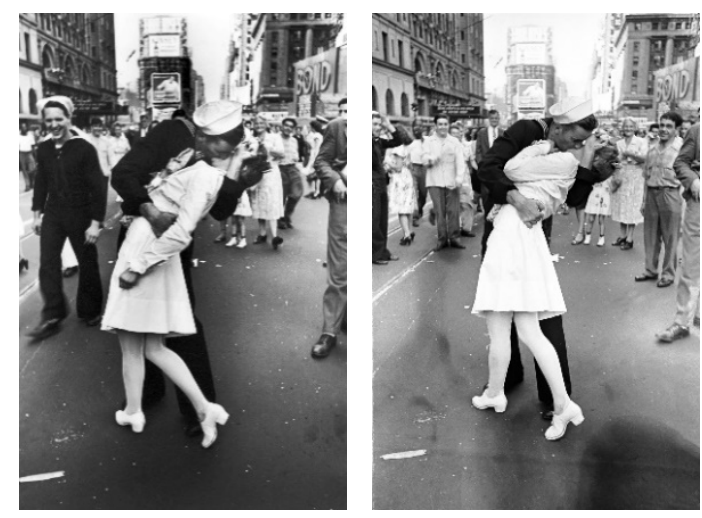

In addition, other bystanders took their own photographs of the "kiss," giving alternative perspectives and points of view on the scene, such as in this less famous but hardly less striking photograph by Navy photographer

190. Eisenstaedt, Sailor Kissing White-Clad Woman, No. 2, supra note 1.

191. Regarding the four photographs of "the kiss" he was able to take, Eisenstaedt favored the perspective and composition of the second, the Life magazine photograph, explaining, "[o]nly one is right, on account of the balance. In the others the emphasis is wrong - the sailor on the left side is either too small or too tall. People tell me that when I am in heaven they will remember this picture." V-J Day kiss in Times Square, 1945, RARe Historical Photos (Oct. 7, 2016), https:// rarehistoricalphotos.com/v-j-day-kiss-times-square-1945/ [https://perma.cc/N3RT-DZG9] (quoting ALFRED EISENSTAEDT, EISENSTAEDT ON EISENSTAEDT (1985)).

192. Alfred Eisenstaedt, Sailor Kissing White-Clad Woman in Times Square, V-J Day, Aug. 14, 1945, No. 1 (1945) (Time \& Life Pictures/Getty Images).

193. Alfred Eisenstaedt, Sailor Kissing White-Clad Woman in Times Square, V-J Day, Aug. 14, 1945, No. 3 (1945) (Time \& Life Pictures/Getty Images).

194. Alfred Eisenstaedt, Sailor Kissing White-Clad Woman in Times Square, V-J Day, Aug. 14, 1945, No. 4 (1945) (Time \& Life Pictures/Getty Images).

195. See discussion on the Figure-Ground relationship infra Section II.E. 
Lt. Cmdr. Victor Jorgensen (below right). ${ }^{196}$

The reaction of the female bystander on the left is eye-catching, but Jorgensen did not frame the picture with the classic Times Square skyline compared to Eisenstaedt, and Jorgensen's composition is a little more cluttered in its "figure-ground" relationship. More importantly to our hypothetical sexual assault case, from the perspective and point of view of Jorgensen's photograph we can observe that Ms. Friedman's body does not appear to be as gracefully

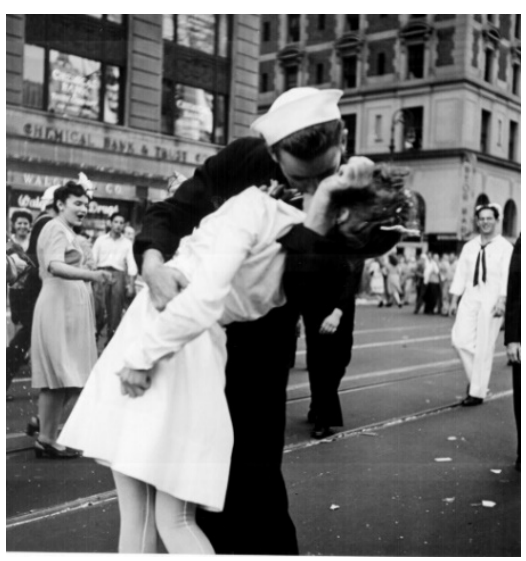
"dipped" as in the Life magazine shot. She appears more to have been grabbed, mashed, and clutched like a rag doll here, rather than embraced and kissed romantically.

Building a narrative from still photographs is tricky, ${ }^{197}$ but even a video account taken from a single perspective has its own narrative limitations. ${ }^{198}$ A modern classic in single point perspective is the patrol officer's dashboard camera or body camera video. ${ }^{199}$ Police departments have increasingly invested in dashboard cameras and body cameras for their patrol officers, ${ }^{200}$ which creates artifact video for use in prosecutions

196. Victor Jorgensen, Kissing the War Goodbye (1945) (Lt. Victor Jorgensen/National Archives).

197. See Handbook of NARRATive InQuiry: Mapping a Methodology 290 (D. Jean CLANDININ ed., 2007) (discussing how persons engaged in visual narrative inquiries typically create hundreds of photographs to build a narrative). See generally MiCHAEL FREEMAN, THE PHOTOGRAPHER'S STORY: THE ART OF VISUAL NARRATIVE 6, 80-82 (2012) (discussing the process of using multiple photographs to compose a story); ALEXANDER PODDIAKOV, Photographs and Counter-Narratives, in 12(1) NARRATIVE INQUIRY 113-14 (2002) (describing use of photographs to build narrative or counter-narrative).

198. See Ken DanCyger, The Technique of Film And Video Editing: History, Theory, AND PRACTICE 161-63 (5th ed. 2011); ROSS HOCKROW, OUT OF ORDER: STORYTELLING TECHNIQUES FOR VIDEO AND CINEMA EDITORS 80-85 (Karyn Johnson et al. eds., 2015).

199. See Adam Benforado, The Hidden Bias of Cameras, Slate (Aug. 12, 2015, 1:43 PM), https://slate.com/news-and-politics/2015/08/police-body-and-dashboard-cameras-how-camera-persp ective-bias-can-limit-the-objectivity-of-jurors.html [https://perma.cc/8JYB-KBWN] (discussing the dashcam footage the court relied on in Scott v. Harris, discussed above). See also ADAM BENFORADO, UNFAIR: THE NEW SCIENCE OF CRIMINAL INJUSTICE 99-104 (2015); Kahan et al., Whose Eyes Are You Going to Believe?, supra note 50, at 843-44, 852-54, 879-80 (showing that people reached different conclusions after viewing the dashcam footage from Scott v. Harris based on their cultural and ideological background).

200. Chauncey L. Alcorn, Police Body Camera Business Is Booming in Wake of Dallas Shootings, FORTUNE (July 9, 2016), http://fortune.com/2016/07/09/police-body-cameras-dallas-shootings/ [https://per ma.cc/C67B-3Z76] (noting the rise in police agencies and departments using dashboard cameras and body 
or litigation. Dashboard camera and body camera videos display one perspective on what occurs in front of a patrol car or patrol officer, but the naïve realism or cognitive illiberalism ${ }^{201}$ of viewers will kick in and convince viewers that they have seen exactly what occurred in the incident that was filmed. ${ }^{202}$ One huge problem with that conclusion of viewers is that dashcam or bodycam videos are extremely one-sided in the sense that the defendant or other witnesses at the scene are not running their own video from their own perspective and point of view (although that sometimes occurs, too). In every instance, the dashcam or bodycam video distorts the scene because the camera is fixed in place and focused to film in one direction - forward - and it rarely moves to capture the sides of the scene and the behavior of witnesses and bystanders. ${ }^{203}$ The camera does not zoom in to capture facial expressions or body-language of the subjects filmed, which, if captured, would be very important to an evaluation of the mood or tension of the scene. ${ }^{204}$ A dashboard camera might be bounced around in a car chase, or a body camera might be blocked or jerked around in a struggle with persons at the scene. Unlike most surveillance cameras that run constantly, patrol officers often are in charge of the decision to turn on and turn off their cameras, so the officers involved will make a definite impact on what or how much of a record is made even from the limited perspective and point of view the cameras. ${ }^{205}$ All of this must be considered when evaluating your own or an opponent's use of artifact video from a static camera, such as a patrol officer's dashboard camera or body camera.

\footnotetext{
cameras); Robinson Meyer, Body Cameras Are Betraying Their Promise, ATLANTIC (Sept. 30, 2016), https://www.theatlantic.com/technology/archive/2016/09/body-cameras-are-just-making-police-departmen ts-more-powerful/502421/ [https://perma.cc/3SEB-7QCG] (same); MichAEL D. WHITE, OFF. JUST. PROGRAMS, DEP'T OF Just., POLICE OfFICER BODY-Worn CAMERAS: ASSESSING THE EVIDENCE 11-13 (2014), https://www.prisonpolicy.org/scans/Police_Officer_Body-Worn_Cameras.pdf [https://perma.cc/B3 TY-CFU4] (same).

201. See sources cited supra notes 49-51.

202. Kahan et al., Whose Eyes Are You Going to Believe?, supra note 50, at 896-97.

203. Id. See sources cited supra notes 51 and 202.

204. See sources cited supra notes 179-81.

205. The August 2014 police shooting of Michael Brown in Ferguson, Missouri, and the July 2014 choking death of Eric Garner incident to his arrest in New York City, focused public attention on police actions that raised questions of police misconduct and excessive use of force. Jay Stanley, Police BodyMounted Cameras: With Right Policies in Place, a Win for All, ACLU (Mar. 2015), https://www.aclu.org /other/police-body-mounted-cameras-right-policies-place-win-all [https://perma.cc/U3S8-X6KM]. Body cameras for officers on foot and dashboard cameras for officers in patrol cars were suggested as a possible means to record and allow a check on police activities. Id. The ACLU, in evaluating this suggestion, emphasized that police officers should not be able to "edit on the fly"-meaning, turn on and turn off their own cameras - and thereby choose which and how much of encounters to record. Id. See also Meyer, supra note 200 .
} 
Consider one example: the United States Supreme Court's decision in Scott v. Harris ${ }^{206}$ provoked an outpouring of discussion on visual rhetoric in general, and the nature of naïve realism in particular. ${ }^{207}$ Scott was an

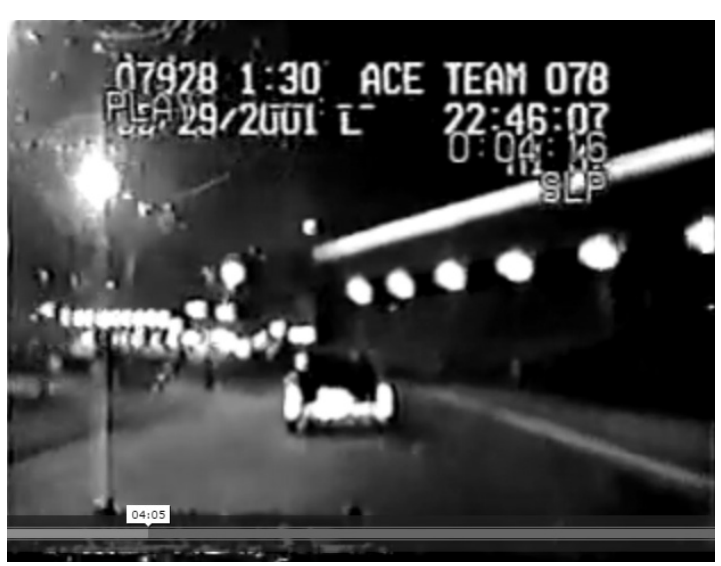

appeal from a personalinjury lawsuit in which the plaintiff was the driver of a car speeding away from patrolmen engaged in the pursuit of the plaintiff. $^{208}$ The patrolmen decided to end the high-speed chase with the plaintiff by bumping the rear of his car in what is described as a "Precision Intervention Technique" (PIT) maneuver. ${ }^{209}$ This caused the plaintiff's car to veer off the road, where it overturned and came to a nasty halt in a ditch. ${ }^{210}$ Plaintiff suffered severe injuries in the crash and sued the highway patrolman who performed the PIT maneuver under a theory that the decision to bump and the execution of the bump itself was made and done recklessly and constituted an excessive use of force. ${ }^{211}$

The grainy, "low key" lit dashboard camera video from the pursuing patrol car $^{212}$ was used substantively in the case to aid the argument that, based on the facts of the case, the officer was not reckless nor unreasonable, but in fact acted in an "objectively reasonable" manner in the circumstances. ${ }^{213}$ One of the main reasons the case gained fame in the legal academy was that Justice Scalia argued that the video "quite clearly" showed all the facts that were needed to make this determination. ${ }^{214}$ In Justice Scalia's view, the video "quite clearly" showed the circumstances

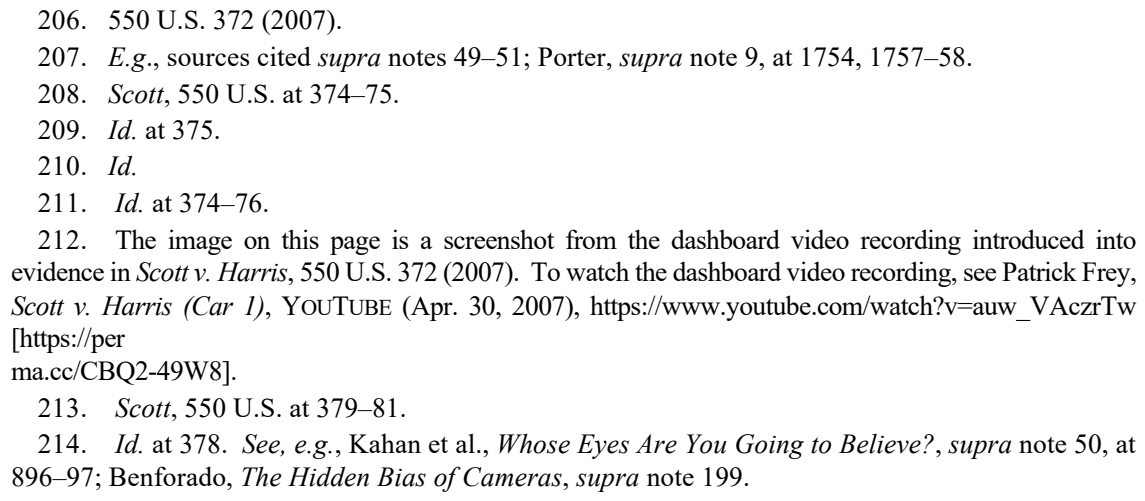

212. The image on this page is a screenshot from the dashboard video recording introduced into evidence in Scott v. Harris, 550 U.S. 372 (2007). To watch the dashboard video recording, see Patrick Frey, Scott v. Harris (Car 1), YouTUBE (Apr. 30, 2007), https://www.youtube.com/watch?v=auw_VAczrTw [https://per ma.cc/CBQ2-49W8].

213. Scott, 550 U.S. at 379-81.

214. Id. at 378. See, e.g., Kahan et al., Whose Eyes Are You Going to Believe?, supra note 50, at 896-97; Benforado, The Hidden Bias of Cameras, supra note 199. 
to a degree of certainty that allowed the finder of fact to find that the officer's conduct in bumping the back of the claimant's car was objectively reasonable. ${ }^{215}$ Other law-trained viewers of the grainy, dark, nighttime footage, taken entirely from the single-camera perspective of the police officer's patrol-car dashboard, argued that the video was not "the truth"; it was simply one recorded perspective on the scene, limited in detail, and limited in what it can tell us about objectively reasonable actions in the circumstances. ${ }^{216}$

I do not question the use of the Scott video in the presentation of the defendants' case as unethical. It is a recorded perspective on the actual incident that led to the lawsuit, and however limited it might be in its grainy, dark, single-point perspective, it does not lie. The fact that the car chase and the "bump" from the police officer is recorded on video is useful in an evidentiary and rhetorical sense to help construct the events of that evening and build knowledge and understanding in the audience. However, it is equally true that seeing the car chase from other perspectives would give a much better and fuller understanding of what transpired on that evening. ${ }^{217}$

The United States Supreme Court ultimately determined that there was no disputed question of material fact concerning the reasonableness and propriety of the officer's actions, based in large part, if not solely, on the basis of the justices' viewing of the video. ${ }^{218}$ The Supreme Court

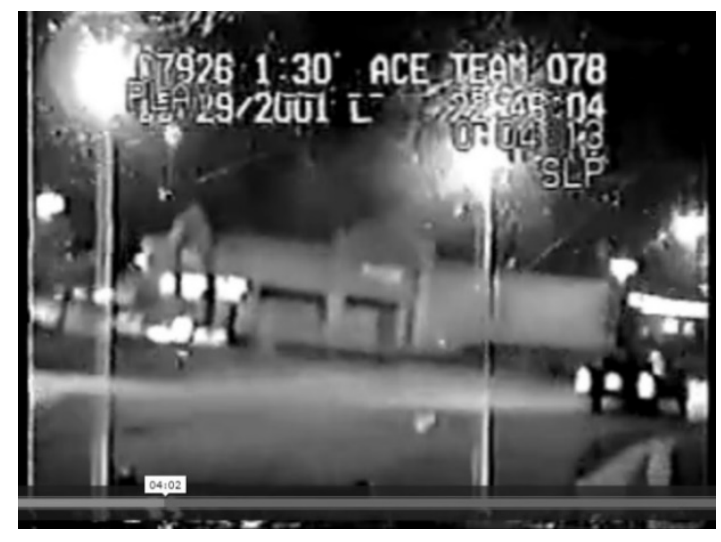
reversed the Court of Appeals' decision denying summary judgment because the videotape of the car chase filmed from the pursuing police car "quite clearly contradict[ed] the version" of the facts put forth by the respondent Harris, and accepted by the Court of Appeals; Justice Scalia, writing for the majority, stated that the Court of Appeals "should have viewed the facts in the light depicted by the videotape." 219

215. Scott, 550 U.S. at $378,383-86$.

216. See sources cited supra notes 50 and 199 .

217. The image on this page is a screenshot from the dashboard video recording introduced into evidence in Scott v. Harris, 550 U.S. 372 (2007). See supra note 212.

218. See Scott, 550 U.S. at $378,386$.

219. Id. at $378,380-81$. 
E. Composition and Framing, Including the Arrangement of Subjects, the Gestalt Theory, and the Figure-Ground Relationship

The topic of composition touches on all aspects of the analysis of the effectiveness of the communication of visual devices. ${ }^{220}$ Composition is the total package that makes up the "decisive moment." 221 It is a combination of attributes of visual works that determines a great visual from a mediocre or poor visual. ${ }^{22}$

The topic of composition takes into account several rules of thumb on the arranging subjects that will be discussed below: (1) the rule of thirds and the Golden Ratios; (2) the rule of odds; (3) the rule that subjects should fill enough of the frame, but not overcrowd the frame; and (4) Gestalt psychology and the figure-ground relationship.

1. The Rule of Thirds and the Golden Ratios

The "rules" of composition are merely guidelines, but even though these "[r]ules are made to be broken," ${ }^{, 23}$ they persist in photographic and film analysis. The most endearing rule, especially to photography, is the "rule of thirds," "224 which itself is a derivation (some would say a simplification) of the Golden Ratios (also known as the "Golden Section," "Golden Spiral," and other "golden" names) ${ }^{225}$ passed down from the Renaissance-era study and propagation of lessons of the principles of composition of classical painting, which itself reflected lessons from the study of ancient art and architecture. ${ }^{226}$

220. See Nancy Allen, Seeing Rhetoric, in Writing the Visual: A Practical Guide fOR TEACHERS OF COMPOSITION AND COMMUNiCATION 32-35 (Carol David \& Anne R. Richards eds., 2008); Marvin J. Rosen \& David L. DeVries, Photography \& Digital IMAging 337-38 (5th ed. 2002); Peter Ward, Studio and Outside Broadcast Camerawork: A Guide to MultiCAMERAWORK PRODUCTION 208-09 (2d ed. 2001).

221. Ellen Anon \& Josh Anon, See It: Photographic Composition Using Visual INTENSITY 177-78 (2013); BRYAN PETERSON, UNDERSTANDING COMPOSITION FIELD GUIDE: HOW TO SEE AND PHOTOGRAPH IMAGES WITH IMPACT 243-45 (2012); DAVID TAYLOR, UNDERSTANDING COMPOSITION: THE EXPANDED GUIDE 90-91 (2014).

222. See sources cited supra notes 220-21.

223. Alan L. Detrick, Macro Photography for Gardeners and Nature Lovers: The EsSENTIAl Guide to Digital TeChNiQues 82-83 (2008); TOM Gallovich, POWER COMPOSITION For Photography: Develop Your ARTistic Eye 5 (2015); Ross HoddinotT \& Ben Hall, The WILDLIFE PHOTOGRAPHY WORKSHOP 56 (Gerrie Purcell et al., eds., 2013).

224. Peterson, supra note 221, at 148-54; David Prakel, Basics Photography 01: COMPOSITION 24-25 (2006); TAYLOR, supra note 221, at 17, 56-57.

225. PETERSON, supra note 221, at 147-53; PRAKEL, supra note 224, at 25; TAYLOR, supra note 221 , at 58.

226. Md. Akhtaruzzaman \& Amir A. Shafie, Geometrical Substantiation of Phi, the Golden Ratio and the Baroque of Nature, Architecture, Design and Engineering, 1(1) INT'L J. ARTS 1, 2 (2011), http://article 
The rule of thirds states that dominant subjects should not be in the center of the image, a horizon line of an image should not evenly divide the image top to bottom, a vertical line should not divide the image evenly right to left, and the dominant subjects should not be placed too close to the edges of the image, top or bottom, right or left. ${ }^{227}$ What is left is described as the rule of thirds, meaning that the dominant subjects should fall at or near the intersections of vertical and horizontal lines dividing the image into thirds.
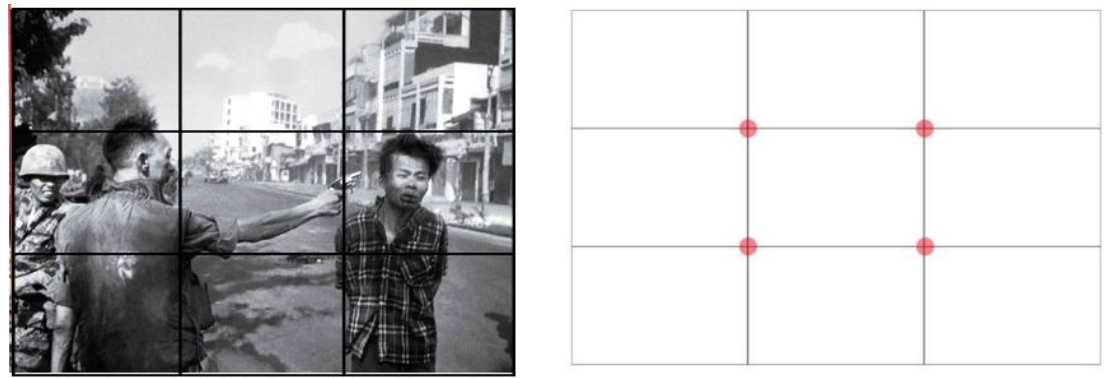

Eddie Adams, Saigon Execution (1968).

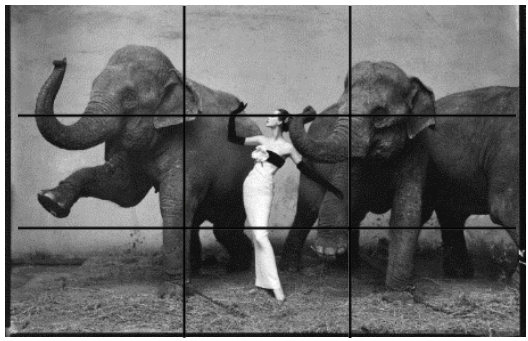

Richard Avedon, Dovima with Elephants, Cirque d'Hiver (1955).

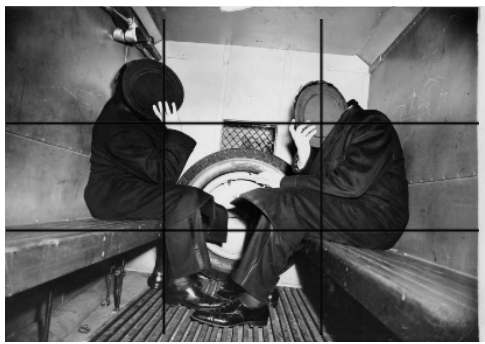

Weegee, Charles Sodokoff and Arthur Webber Use Their Top Hats to Hide Their Faces (1942).

The Golden Ratio is a mathematical formula that in composition translates to a spiral or a series of geometric shapes, which indicate a sweet spot (the center of the spiral) where the most important feature of the composition should lie. ${ }^{228}$ The spiral can be flipped or inverted depending on the orientation of the scene.

.sapub.org/pdf/10.5923.j.arts.20110101.01.pdf [https://perma.cc/8N4P-Y7UH]; PETERSON, supra note 221, at $147-48$.

227. See sources cited supra note 224.

228. See sources cited supra note 225. See generally Akhtaruzzaman \& Shafie, supra note 226, at 2-6 (discussing the mathematical properties of the Golden Ratio). 

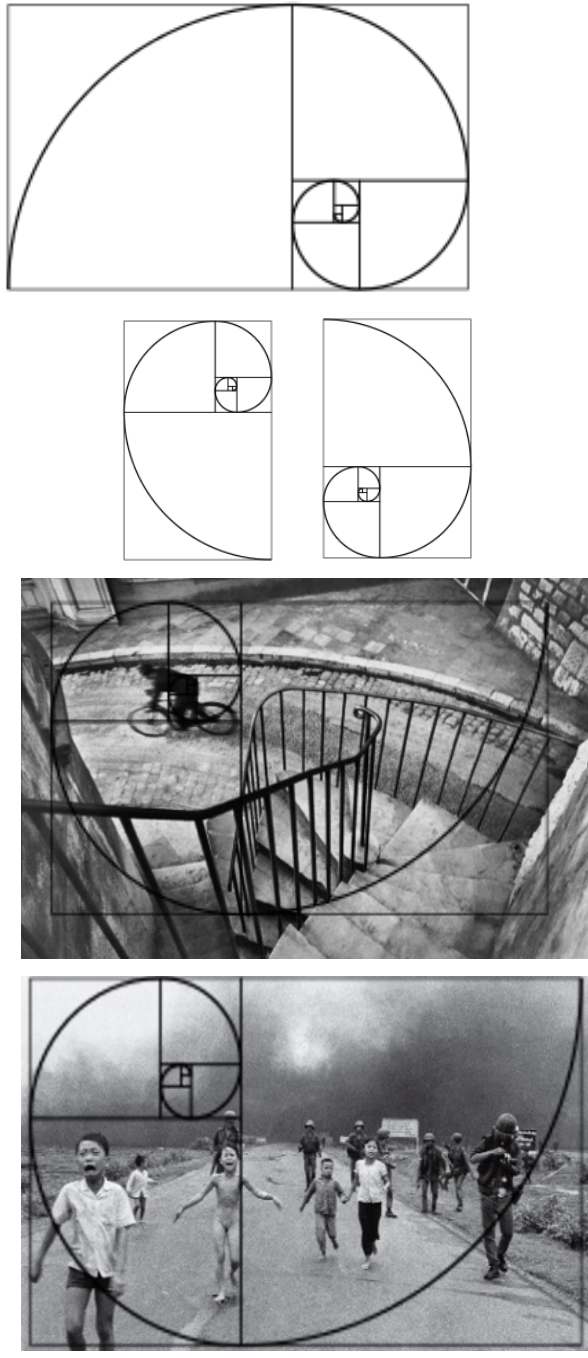
general rule of thumb, not a strict prescription.
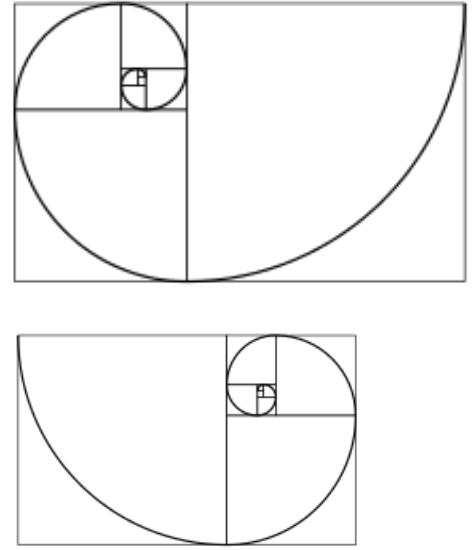

Cartier Bresson, whose art career began as a painter, is understood to have applied the Golden Ratios in his photographs' composition, as in this photograph of a Cyclist in Hyères, France. ${ }^{229}$

News photographs, such as Nick Ut's Pulitzer Prize-winning photograph of children running from a napalm attack, ${ }^{230}$ do not always fit the Golden Ratio exactly, but it is close.

The goal of the application of the rule of thirds or the Golden Ratios is to produce an image that is pleasing to the eye. It is a

229. Henri Cartier-Bresson, Hyères, France (1932) (Henri Cartier-Bresson/Magnum).

230. Nick Ut, The Terror of War (1972) (AP Photo/Nick Ut). 
2. The Rule of Odds

The rule of odds holds that a picture is more interesting if there is an odd number of dominant subjects; three is better than two or four, for example. ${ }^{231}$
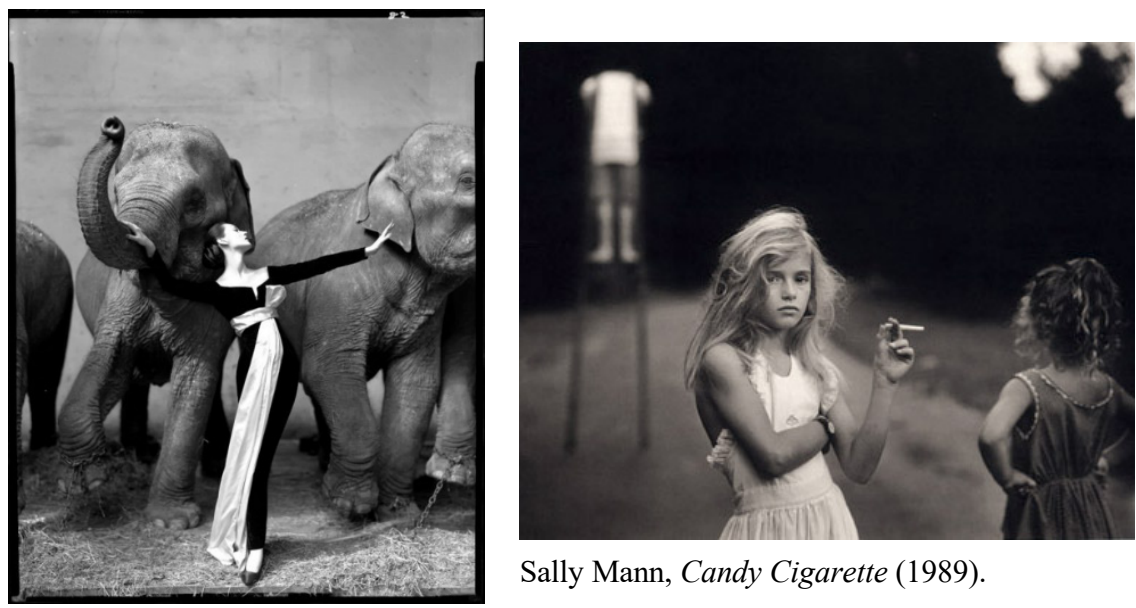

Sally Mann, Candy Cigarette (1989).

Richard Avedon, Dovima with

Elephants, Cirque d'Hiver, No. 2 (1955).

\section{Filling the Frame Without Overcrowding}

A general rule of thumb in photography is to "fill the frame" but not to overcrowd the image. ${ }^{232}$ Images should have a prominent dominant subject, which is not too small. Small, of course, is relative to the message of the image; the message of the image may be to drive home that something is small. But images should not be crowded and subjects should not block or obscure important subjects of the image. ${ }^{233}$

231. Laurie Excell, Composition: From Snapshots to Great Shots 115-16 (2014); TAYLOR, supra note 221, at 60.

232. Saxon Holt, Composition 101: Fill the Frame, РнотоBотANIC (Feb. 16, 2013), https://photobot anic.com/living-book-library/garden-photography-workshop/good-garden-photography/composition-101fill-the-frame/ [https://perma.cc/4S7T-J42F]; PETERSON, supra note 221, at 47-53; TAYLOR, supra note 221, at $81-82$.

233. E.g., BO BERGSTRÖM, ESSENTIALS OF VISUAL COMMUNICATION 140 (2008); AARIS SHERIN, introduction to Graphic Design: A Guide to Thinking, Process \& Style 71-73 (2018) (discussing the importance of white space). 


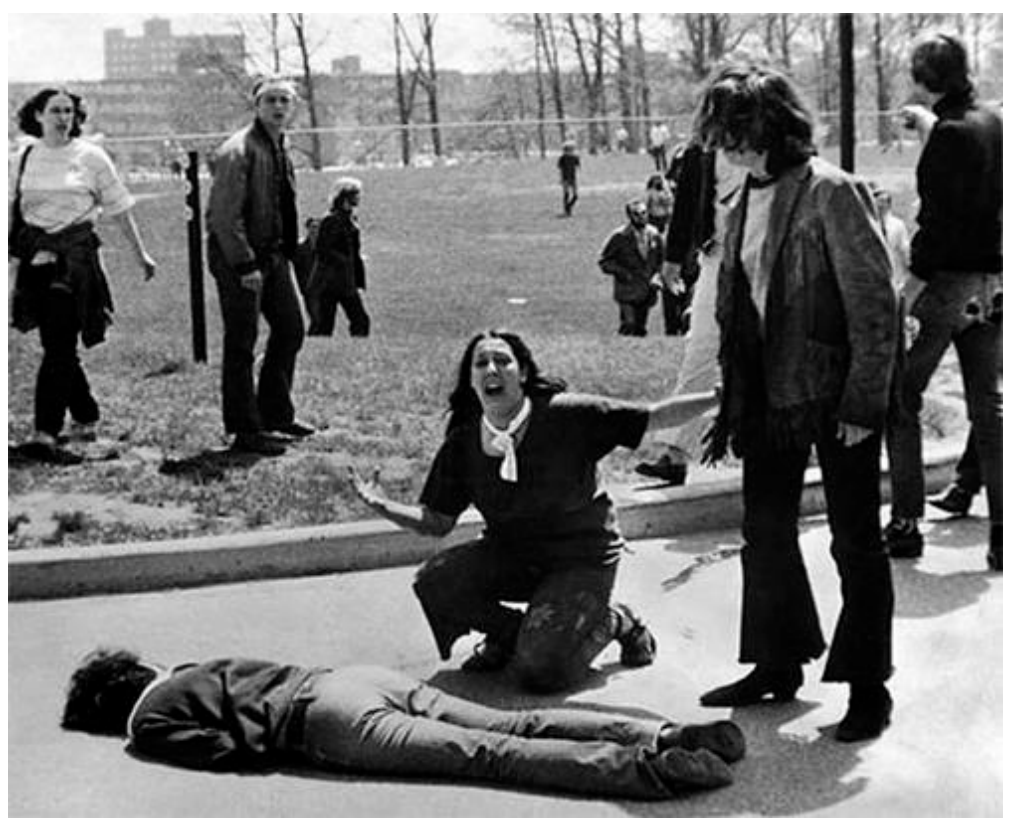

The photographs from the Kent State Vietnam War protests in 1970 illustrate these principles. On May 4, 1970, students at Kent State University in Ohio staged a protest regarding the extension of United States bombing from North Vietnam into Cambodia. ${ }^{234}$ Units of the Ohio National Guard were deployed to contain the demonstrations; at a certain point the National Guardsmen opened fire on the students, killing four of them. ${ }^{235}$ John Paul Filo took a Pulitzer Prize-winning photograph of Mary Ann Vecchio in anguish as she kneels over the body of fallen student, Jeffrey Miller. ${ }^{236}$ The photograph was famously published in major news outlets, including Life and Time magazines. The photograph's Pulitzer Prize credential is attributable in large part to the fact that it tells a story of a terrible and tragic event, and the life-changing nature of the event, all in one moment captured in the photograph of a distraught student kneeling over a deceased student. This photograph is an indelible image for anyone living through or studying this 1970 event of the Vietnam War and protest movement.

234. See generally Kent State Shooting, HISTORY (June 7, 2019), https://www.history.com/topics/ vietnam-war/kent-state-shooting [https://perma.cc/6DDY-RDUG]; Jerry M. Lewis \& Thomas R. Hensley, The May 4 Shootings at Kent State University: The Search for Historical Accuracy, KENT ST. U. (1998), https://www.kent.edu/may-4-historical-accuracy [https://perma.cc/5PJK-WTVR].

235. See sources cited supra note 234.

236. Filo, Kent State Shooting, supra note 172. 


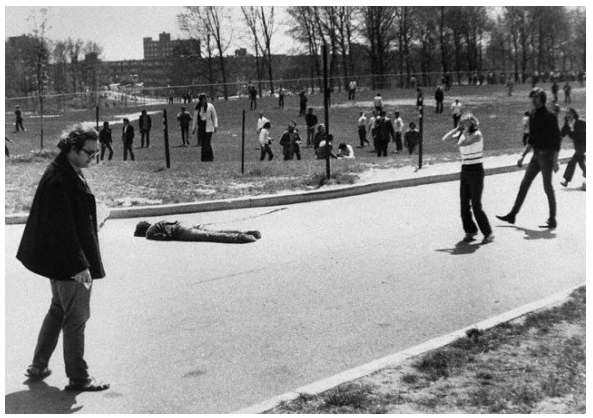

A second John Paul Filo photograph $^{237}$ was taken seconds before Mary Ann Vecchio arrived at the scene-she is pictured at the far right, running toward the fallen student, Jeffrey Miller. The streak of Miller's blood is visible in this photograph, but it was obscured in the Pulitzer Prize photograph because Ms. Vecchio knelt on top of the blood trail. Purely from a rhetorical mise en scène critique, this photograph is not as powerful as the more famous Filo photograph. Although the student at the right has her hands up in a classic pose of shock and distress (as in Edvard Munch, The Scream ${ }^{238}$ ), the composition is cluttered, and some bystanders look disinterested. There are many background images competing for attention in this scene.

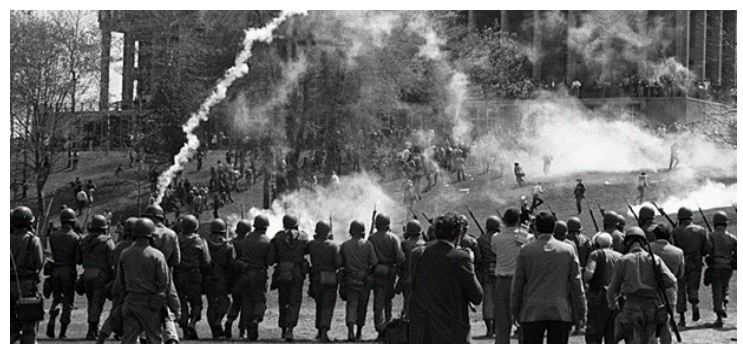

Other images of May 4, 1970, at Kent State are alarming and striking - they depict the chaos of a war zone, far from the typical idyllic tranquility of a college campus. ${ }^{239}$ Any

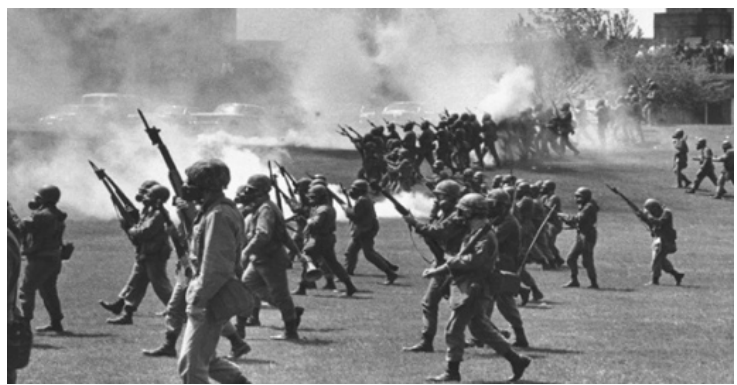
one of these images could have been used to communicate the violence and chaos of that fateful day. The photographs reveal a military invasion force advancing on a college campus.

Nothing about these images communicates a narrative about proper policing, law enforcement, peacekeeping, or security. It communicates insurrection and assault, albeit carried out by Ohio National Guard soldiers.

\footnotetext{
237. John Paul Filo, Slain Student Jeffrey Miller, Kent State, May 4, 1970 (1970).

238. Edvard Munch, The Scream (1893) (Nasional Museet).

239. Ohio National Guard Uses Tear Gas to Disperse Student Protesters at Kent State University on May 4, 1970 (1970) (Kent State University Archives via Reuters); Ohio National Guard Moves in on Rioting Students at Kent State University (1970) (AP File Photo).
} 
As powerful as the Filo photographs of Mary Ann Vecchio were, they did not make the cover of Life magazine in the issue following the Kent State killings. ${ }^{240}$ Instead, this photograph by Howard Ruffner of wounded student John Cleary ${ }^{241}$ was chosen. Perhaps the editors at Life believed it was important to show persons at the scene stepping in to provide aid to the wounded.

The Ruffner photograph of John Cleary $(1970)^{242}$ portrays a good composition capturing the arched back of Cleary as he lies in

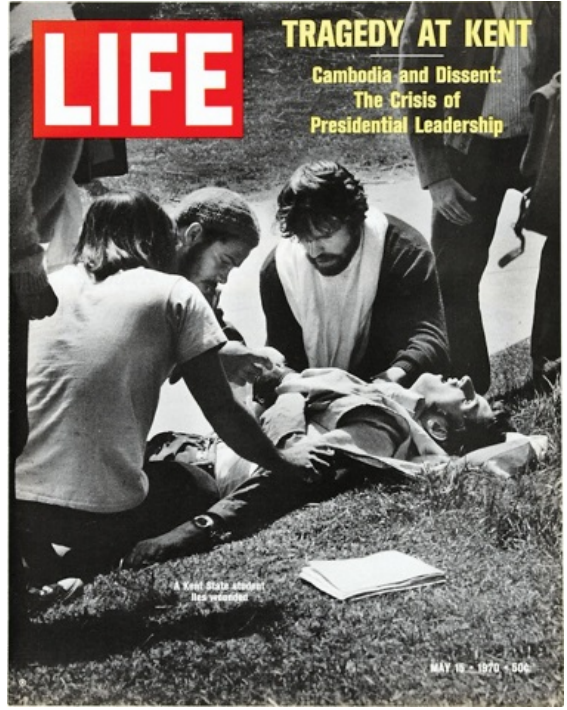
pain. Additionally, the dominant subjects are naturally framed by concerned on-lookers who give focus to the dominant subjects (Life magazine's cropping of the photograph to focus on the central figures also was an excellent editorial decision).

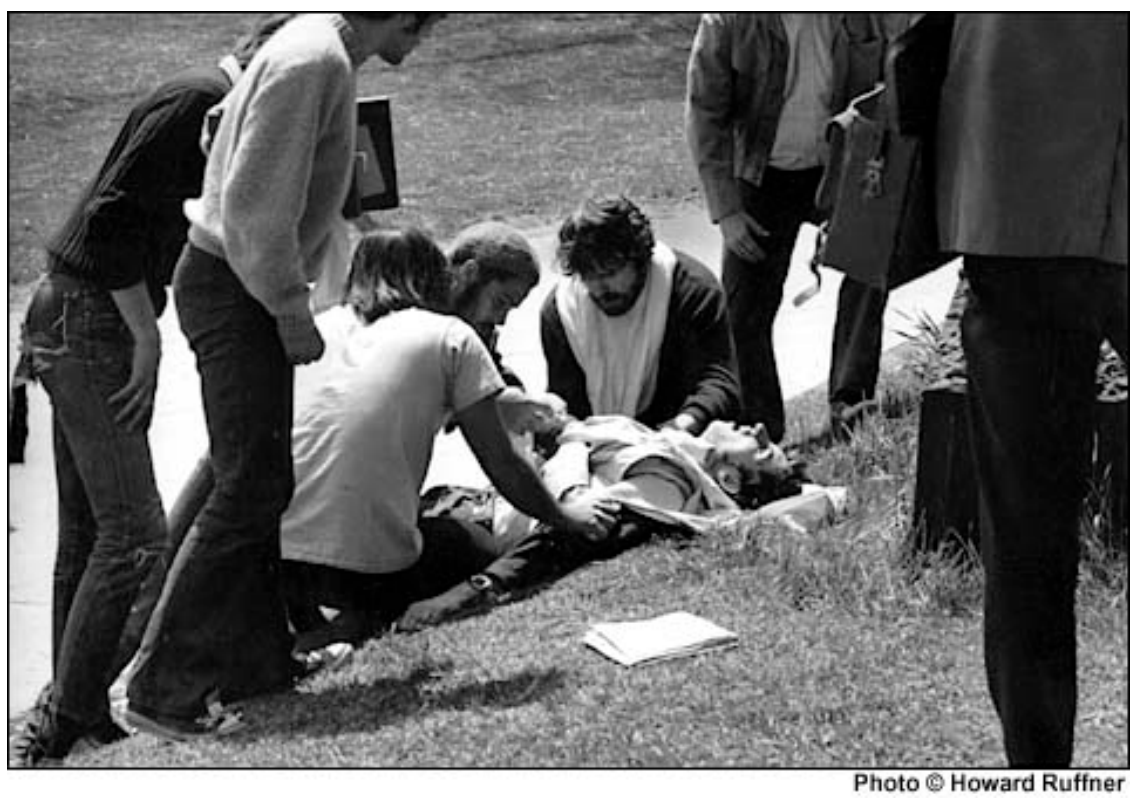

240. Tragedy at Kent, LIFE, May 15, 1970 (cover featuring Howard Ruffner, Wounded Student John Cleary at Kent State (1970) (Howard Ruffner/Getty)).

241. Ruffner, supra note 240.

242. Id 
Ruffner and Life magazine, in focusing on the central figure in the photograph - the bearded student looking over John Cleary with the brightly contrasting light and dark jacket - was perhaps intentionally or unconsciously making an artistic allusion either to an image of Moses (Charlton Heston, in
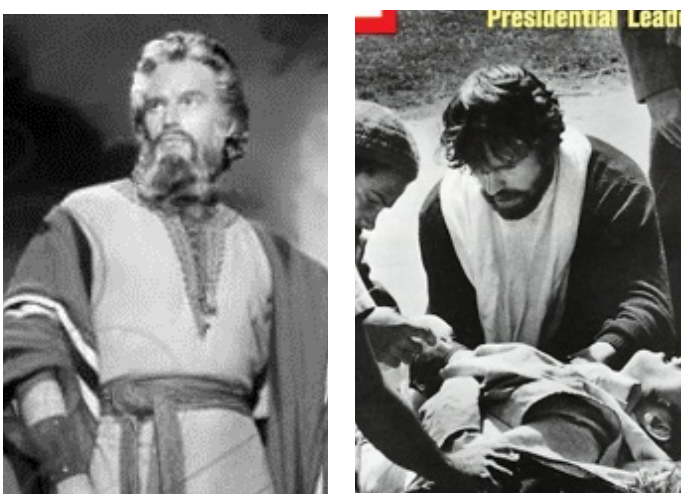
Commandments ${ }^{243}$ ), or to
The Ten "massacre by troops". image by Third of May. ${ }^{244}$

4. Gestalt Theory and the Figure-Ground Relationship

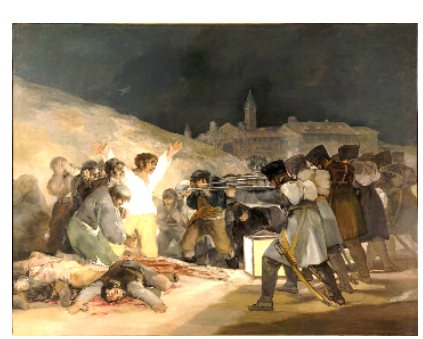

Gestalt psychology has contributed to photographic and film analysis the Gestalt theory ${ }^{245}$ which explains the cognitive function of continuation, closure, and completion with regard to the subjects and actions communicated by visual media. ${ }^{246}$ Continuation, closure, and completion in this context mean that cognition makes up for missing, unknown, unperceived, or non-present parts and draws from life experience to fill in and form a complete whole (a "gestalt"); this process of completion, closure, or continuation of the whole drawing from life experience is

243. Charlton Heston as "Moses," in THE TEn CommandmEnTs (Paramount Pictures 1956).

244. Francisco de Goya, The Third of May 1808 in Madrid (1814) (Museo Nacional Del Prado).

245. The Gestalt theory of cognitive psychology concerns the perception and interpretation of visual input. See Rudolf ARnheim, ART and Visual Perception: A PSYchology of the Creative Eye 4-6 (2004); E. Bruce Goldstein, Cognitive Psychology: Connecting Mind, RESEARCH, AND EVERYDAY EXPERIENCE 74-78 (2005) (discussing the Gestalt laws of perceptual organization); PAUl THAgARD, COHERENCE IN THOUght AND ACTION 58-59 (2000). The Gestalt theory is not connected to Gestalt Psychotherapy, aside from sharing the root word, "gestalt" (German for "shape," "form," or "configuration"). ARNHEIM, supra note 245, at 4. The connotation of "gestalt" as used in cognitive psychology is that the "form" or "shape" referred to as the "Gestalt" is a whole that is constituted by smaller parts, but the whole (or the meaning of the whole) is greater than the sum of the individual parts, and dissembled parts would not convey the meaning that the whole conveys. Bruno Petermann, The Gestalt Theory and the Problem of Configuration 29-39 (Meyer Fortes trans., 1999); Gestalt, MERRIAM-WEBSTER DICTIONARY, https://www.merriam-webster.com/d ictionary/gestalt [https://perma.cc/6R3N-77AF].

246. See ARNHEIM, supra note 245, at 4-6; GOLDSTEIN, supra note 245, at 64, 71-72; THAGARD, supra note 245 , at $58-59$. 
referred to as "gestalten." 247 Because of the viewer's experiences, a static visual image may nonetheless be perceived by viewers as a frame in a continuation of real events; a still in a movie reel if you will. ${ }^{248}$ With visual narrativity and storytelling, the average viewer is both adept at and comfortable with filling in the missing narrative that precedes the scene, and completing the actions depicted, bringing closure to the scene in the viewer's mind. ${ }^{249}$ A skillful user of images will make use of this skill in the viewer's mind to suggest or argue that events are "depicted" in a scene even if the events suggested are of a sequence and longer duration than the single split-second of action displayed in the image. ${ }^{250}$

A separate part of Gestalt psychology and perception is the analysis of the figure-ground relationship of the subjects to the "grounds" (background, middle ground, foreground) of the image. ${ }^{251}$ An image should not be cluttered in the foreground, middle ground, or background so that it is difficult to pick out the dominant images, or to clearly discern the dominant images against the background or middle ground. ${ }^{252}$ Occasionally, the point of the photograph is to show clutter, chaos, and confusion, ${ }^{253}$ but in most instances a distinct dominant is preferred over one that confusingly blends in with the "grounds" of the image.

247. See Lisa Graham, Gestalt Theory in Interactive Media Design, 2 J. Human. \& Soc. Scr. 1, 1-2, 7 (2008); see also ARNHEIM, supra note 245, at 4-6; GOLDSTEIN, supra note 245, at 64, 74-78; THAGARD, supra note 245 , at $58-59$.

248. 1 E. BRUCE GOLDSTEIn, ENCYClOPEDIA OF PERCEPTION 458-59 (2010); Graham, supra note 247, at 1; Kurt KoffKa, Principles of Gestalt Psychology 147-53, 167-71 (1999); SCOTT MCClOUd, UNDERSTANDING COMICS: THE INVISIBLE ART 62-69 (1994) (discussing closure in the sequential storytelling device of comics); TERENCE WRIGHT, THE PHOTOGRAPHY HANDBOOK 75-77 (2d ed. 2004).

249. See generally EdWARD BRANIGAN, NARRATIVE COMPREHENSION AND FILM 34-47 (1992) (describing how visual narrative viewers can close the narrative despite missing certain context); Michalis Kokonis, The Spectator's Reality: A Revision of Screen Space Aesthetics Through Cognitive Film Semiotics, in InTERnATIONAL HaNdBook OF SEMiotics 1121-23 (Peter Pericles Trifonas ed., 2015); Rod A. Martin, The Psychology of Humor: AN InTEgrative ApProACH 81-82 (2007); see also 6 Principles of Gestalt Psychology That Can Improve Your Photography, 42 WEST (May 21, 2012), https://www.adorama.com/alc/0013706/article/6-Principles-of-Gestalt-Psychology-That-CanImprove-Your-Photography [https://perma.cc/6KZD-RQ4S].

250. See generally sources cited supra notes 247-49.

251. See ARNHEIM, supra note 245, at 227-34; Graham, supra note 247, at 3-4; 7 KOFFKA, supra note 248, at 177; The OXford Handbook of Perceptual Organization 259-61 (Johan Wagemans ed., 2015).

252. See, e.g., Meredith Davis \& Jamer Hunt, Visual Communication Design: AN INTROduction to DESIGN CONCEPTS IN EVERYDAY EXPERIENCE 36-37 (2017); ALEX W. White, The Elements of Graphic Design: Space, Unity, Page Architecture, AND Type 19-25 (2011).

253. See supra notes 101-02 and accompanying text discussing Stieglitz's Steerage photograph; see also supra notes 108-09 and accompanying text discussing the photographs used by Justice Kennedy in Brown v. Plata, 563 U.S. 493 (2011). 


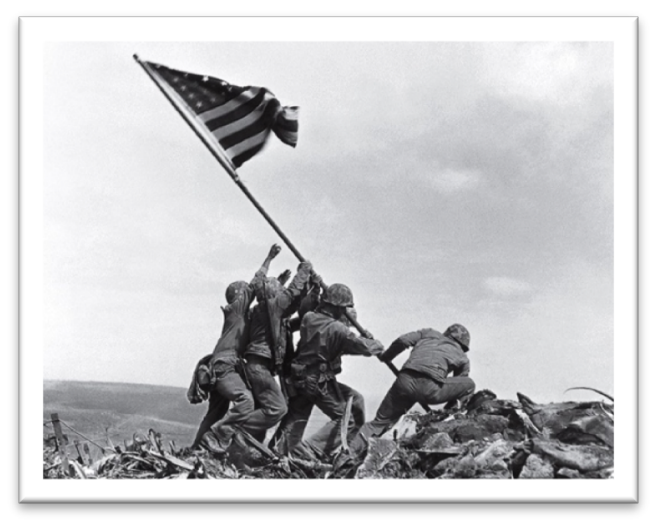

To illustrate this phenomenon concerning completion of narrative development from still images and the figureground relationship, consider the Pulitzer Prize-winning work of Joseph Rosenthal who captured the image Raising the Flag on Iwo Jima $^{254}$ for the Associated Press on February 23, 1945.

As with other images in this article, the Pulitzer Prize-winning image was not the only image taken by Rosenthal and other photographers on Mt. Suribachi that day during the United States Marines' assault on this Japanese island stronghold. ${ }^{255}$ Yet, the image is the most compelling and visually interesting image. Aside from the distinct dominant images separated from the background - the engaging diagonal of the flag staff, the pyramid shape of the four Marines and one Navy corpsman raising the flag, and the flag itself against the sky — and the fact that the image follows the Rule of Odds (seven subjects: five humans, a flag pole, and the flapping flag itself), the Raising the Flag on Iwo Jima photograph communicates a narrative of teamwork, struggle, American pride, and accomplishment of an important war objective. How does it accomplish all of this? By the effect of Gestalt psychology, and the ability and willingness of viewers to construct an entire narrative around a single still image. ${ }^{256}$

No one views the Raising the Flag on Iwo Jima photograph as an image of an admirable, but ultimately unsuccessful, attempt to raise the flag. Quite the contrary, every viewer can be comfortable with the perception that the flag was raised and secured upright as would be the natural completion of the split second of the scene depicted. The planting and raising of the flag looks difficult - the body language of the two lead men on the right looks strained and laboring - and in addition, it shows that five men were needed to raise the flag, making the scene a fitting communicator of the struggle of the Marines' assault on the island itself. It also tells a tale of teamwork; viewers can imagine the group ascending

254. Joseph Rosenthal, Raising the Flag on Iwo Jima (1945) (Associated Press).

255. Thom Patterson, The Inside Story of the Famous Iwo Jima Photo, CNN (Feb. 23, 2016, $12: 14$ PM), https://www.cnn.com/2015/02/22/world/cnnphotos-iwo-jima/index.html [https://perma.cc/4EV S-P2RW].

256. See sources cited supra note 249. 
the mountain, struggling with the flagpole, working together, and feeling a rush of patriotism and pride when Old Glory was finally flapping over the mountain on Iwo Jima. It is also meaningful that none of the faces of the Marines and the Navy corpsman are visible, which allows the image to stand metaphorically for collective bravery, teamwork, and comradery—no heroes, just group effort. It features five combatants, who stood together to make a statement about America and its willingness to fight a war and get the job done, even on a mountain on a tiny island in the South Pacific. All of this is possible because of the viewer's ability and willingness to construct a complete narrative around the split-second image depicted. ${ }^{257}$

The flag raising photograph can be compared to others taken on the summit that same day by Rosenthal, Marine Sgt. Louis Lowery-a photographer for Leatherneck magazine (a Marine Corps publication) and by Marine PFC Bob Campbell. ${ }^{258}$ Lowery trekked up the mountain earlier in the morning, and snapped several photographs of the first flag raised, a smaller flag. ${ }^{259}$ The Marines' celebration over the smaller flag raising prompted a fire fight with the Japanese near the summit of the mountain (at all times in the flag raising and photographing of the same, Mt. Suribachi was an active combat zone), and in diving for cover, Lowery smashed his camera. ${ }^{260}$ Rosenthal ran into Lowery as the latter was moving back down the mountain to retrieve another camera and more film, and Rosenthal was told that he missed it, the flag was up, and the pictures were taken. ${ }^{261}$ But Rosenthal decided to finish the climb, and when he arrived, he found another group of Marines who had a larger flag borrowed from one of the Navy ships supporting the Marines' assault on Iwo Jima, and Rosenthal thought he would be able to get pictures of the larger flag's raising, which he did. ${ }^{262}$

Sgt. Louis Lowery's photographs are more Marine-centric, and focus more on the people, and less on the flag.

257. Id.

258. Patterson, supra note 255 .

259. Id.

260. Id.

261. Id.

262. Id.; LST-779, 1944-1946, NAVAL HIST. \& HERITAGE COMMAND, https://www.history.navy.mil /research/histories/ship-histories/danfs///lst-779.html [https://perma.cc/ZXT9-CRU8] (last visited Oct. 14, 2019). 

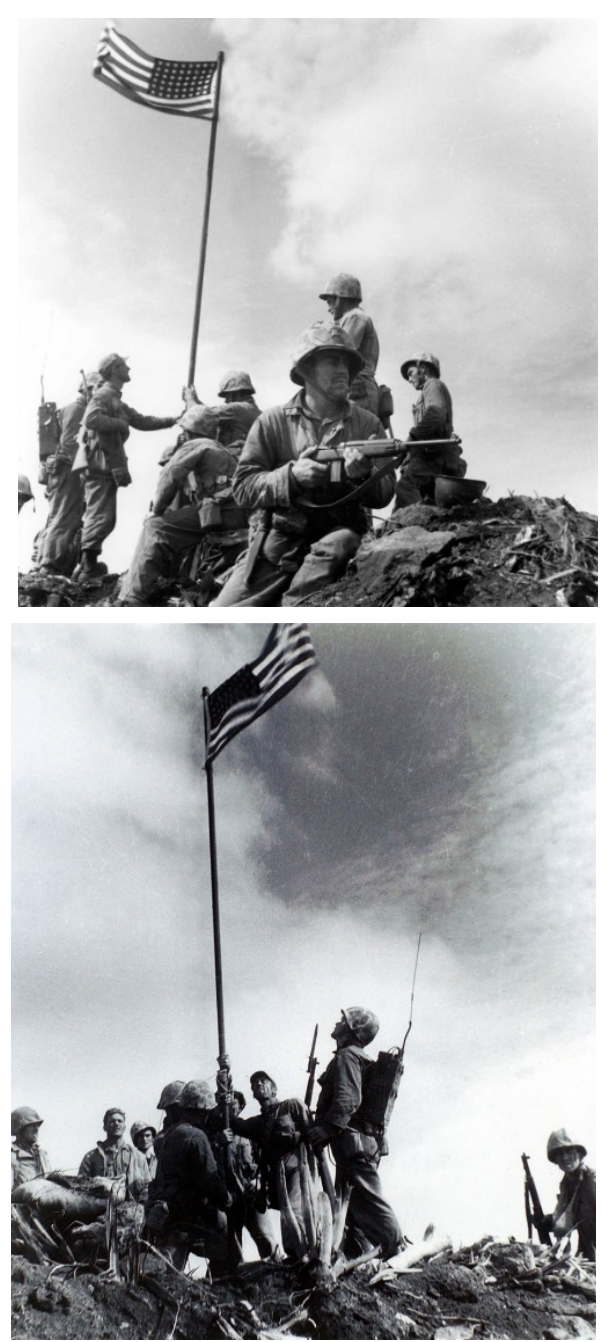

fourth wall and staring straight out at Lowery's camera. of left to right.

Sgt. Lowery's primary flag photograph $^{263}$ shows a Marine front and center, the dominant image in the scene. It casts this Marine as a symbol for the Corps and its struggles on Iwo Jima. Unfortunately, the composition is not as compelling as Rosenthal's; the figure-ground relationship between the dominant subject and the Marines in the background is not as distinct as desired, and the flag is flying right to left, instead

Lowery's second photograph $^{264}$ is taken from an angle where the flagpole is too long, and the flag is too far distanced from the Marines below. Nevertheless, the scene has a good narrative, because most of the Marines are staring upward in a kind of reverence for the flag and what it symbolizes to them on that day, in a combat zone in which many of their comrades had died to allow them to get to this point in the island's conquest. It is unfortunate that one Marine on the far right is breaking the

263. Louis Lowery, Marines and Flag on Iwo Jima, No. 1 (1945) (Leatherneck Magazine). 264. Louis Lowery, Marines and Flag on Iwo Jima, No. 2 (1945) (Leatherneck Magazine). 
Marine Private First Class Bob Campbell had a camera on the summit of Mt. Suribachi that morning too, and captured both flags flying in the breeze: the smaller one being taken down and the larger one already having been raised. ${ }^{265}$ It is a curiosity to have captured the moment of the two flags flapping at the same time, but it otherwise does not tell a compelling narrative of the scene.
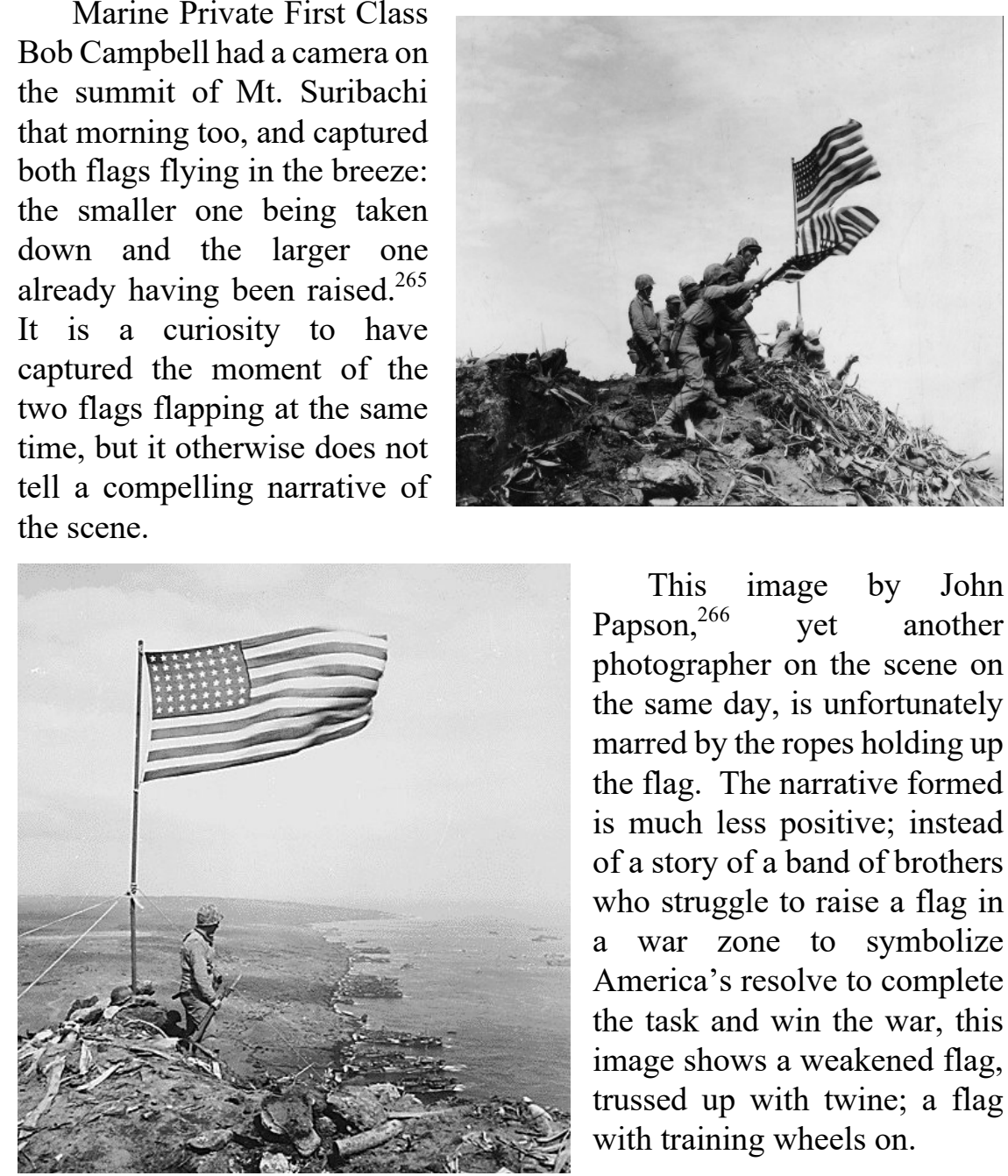

$\begin{array}{cr}\text { This image by John } \\ \text { Papson, }{ }^{266} & \text { yet }\end{array}$ photographer on the scene on the same day, is unfortunately marred by the ropes holding up the flag. The narrative formed is much less positive; instead of a story of a band of brothers who struggle to raise a flag in a war zone to symbolize America's resolve to complete the task and win the war, this image shows a weakened flag, trussed up with twine; a flag with training wheels on.

265. Robert Campbell, Two Flags Over Iwo Jima (1945); Paul Farhi, The Iwo Jima Photo and the Man Who Helped Save It, WASH. POST (Feb. 21, 2013), https://www.washingtonpost.com/lifestyle/style/iwojima-photo-and-the-man-who-saw-it-shot/2013/02/21/ee11ab6c-77af-11e2-aa12-e6cfld31106b_story.html ?noredirect=on [https://perma.cc/5WBW-9JEV].

266. John Papson, Flag Flying Over Iwo Jima (1945) (U.S. National Archives). 
An iconic photograph of the Great Depression and the Dust Bowl era of migrant workers moving west was taken by photographer Dorothea Lange in 1936 in Nipomo, California. ${ }^{267}$ Lange's subject was Florence Owens Thompson and her children in a dismal shelter in a migrant camp. $^{268}$ The image sums up the grim experience of a migrant mother, dusty, downtrodden, and displaced with her children in this time of hardship.

The picture ${ }^{269}$ is remarkable for the way that the mother, the central figure, is shown with wrinkles in all of her "worry spots," prematurely aged by her experiences, giving a 1,000-mile stare into an unknown future. She is surrounded not by happy cherubs but by grimy children with homemade chopped haircuts, who cannot bear the outside attention, and bury their faces from the camera's viewing. A third child is barely visible on the mother's lap,

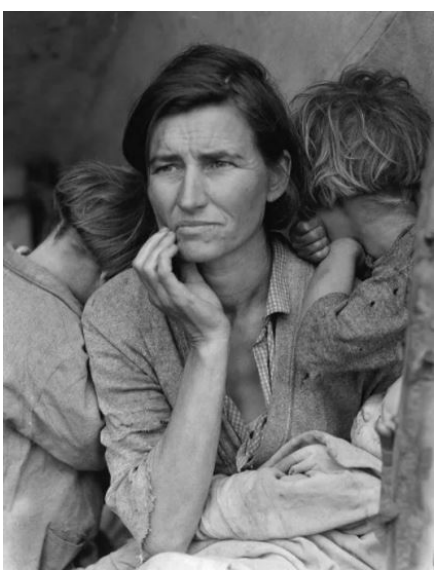
indicating that the mother's circumstances are so grave that she cannot focus even on a tiny child's needs in this situation. Using Gestalt principles of continuation and closure, the photograph tells the story of a woman in terrible circumstances that cause despair, and who is facing an uncertain future. ${ }^{270}$

As with other examples here, the famous Migrant Mother photograph was not the only picture taken by Dorothea Lange on that visit to a dismal migrant shelter. ${ }^{271}$

267. American Women - Exploring Contexts: Migrant Mother, LIBRARY CONG., https://memory.loc.go v/ammem/awhhtml/awpnp6/migrant_mother.html [https://perma.cc/RD7G-9N4S] (last visited Oct. 14, 2019); Molly Gottschalk, The Fateful Roadside Stop That Led to Dorothea Lange's "Migrant Mother," ARTSY (Jan. 12, 2018, 4:45 PM), https://www.artsy.net/article/artsy-editorial-fateful-roadside-led-dorothealanges-migrant-mother [https://perma.cc/K8EB-DUMC].

268. Gottschalk, supra note 267.

269. Dorothea Lange, Migrant Mother (1936) (Library of Congress).

270. Some observers have commented that Lange's framing of this work alluded to a "Madonna and Child surrounded by two cherubs" scene. See, e.g., Master of the Saint Ursula Legend, The Virgin and Child with Two Angels (c. 1480) (Thyssen-Bornemisza Museo Nacional). James C. Curtis, Dorothea Lange, Migrant Mother, and the Culture of the Great Depression, 21 WINTERTHUR PORTFOLIO 1, 9-10 (1986) (noting that the Migrant Mother is often called the "Migrant Madonna"). This comparison perhaps triggers additional feelings of sympathy for the mother and her circumstances. ROBERT HARIMAN \& JOHN LOUIS LUCAITES, NO CAPTION NEEDED: ICONIC Photographs, Public Culture, AND Liberal Democracy 54-59 (2007) (discussing the parallels between Migrant Mother and the Madonna and Child and the emotions both images evoke); Gottschalk, supra note 267.

271. The Migrant Mother photograph is "one of a series of photographs that Dorothea Lange made 


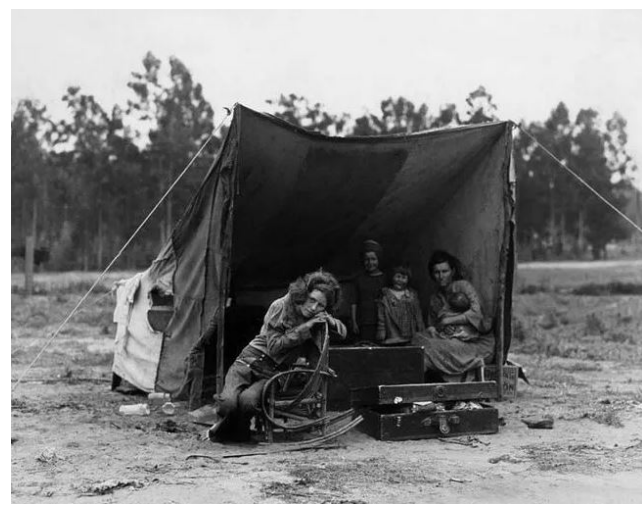

This image shows the whole family. Although this photograph shows the complete picture of the living conditions of this migrant family, the image is not as compelling as the betterknown Migrant Mother image shown above. Only the figure of the daughter at front left is distinct and properly lighted in the ambient light of the scene. The mother and children in the lean-to are obscured by shadows.

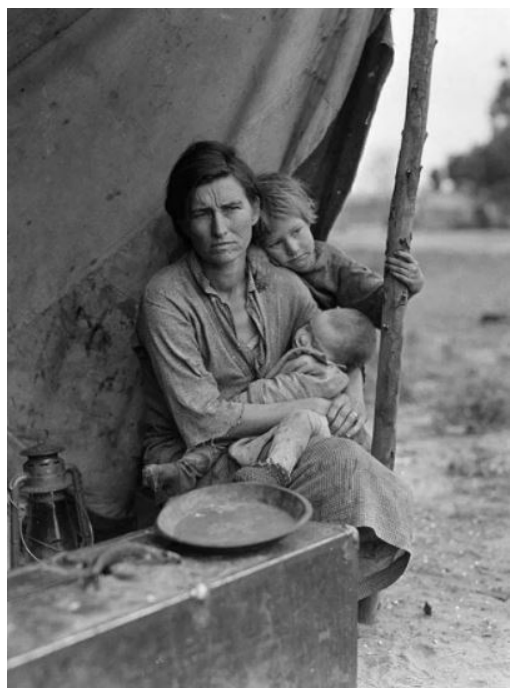

This photograph is not as effective at conveying the tragic circumstances of the scene simply because the mother is unsympathetic. She appears cross and defensive, rather than weary, heavy laden, and vulnerable as compared to the more famous work by Lange. Although the child at her side appears properly chagrined by her or his circumstances, the child still looks cute, which undercuts the narrative being formed by the Gestalt of the scene. The empty plate so prominent in the foreground seems a bit forced"Oh, and they have no food, either."

of Florence Owens Thompson and her children in March of 1936 in Nipomo, California." Dorothea Lange's "Migrant Mother" Photographs in the Farm Security Administration Collection, LIBRARY CONG., https://guides.loc.gov/migrant-mother (last visited Oct. 24, 2019). The images in the Migrant Mother series shown below are in the U.S. Farm Security Administration-Office of War Information Collection, and are housed in the Library of Congress Prints and Photographs Division. See Migrant Mother Series of Images, LIBRARY CONG., https://guides.loc.gov/migrant-mother/images (last visited Oct. 24, 2019). 


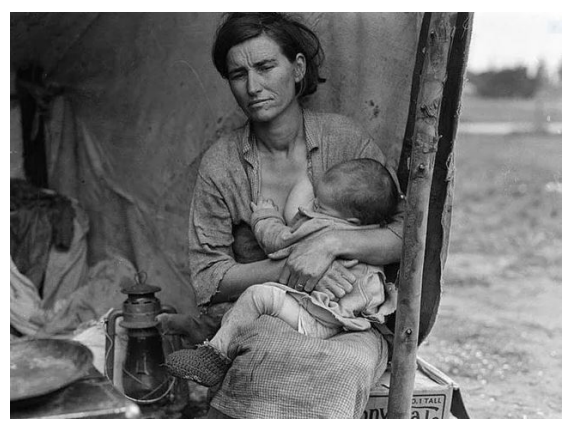

This photograph of the migrant mother breast-feeding is attentionworthy simply because it depicts breast-feeding in a 1936 photograph. In the context of the times, this image might have communicated a powerful narrative of someone so destitute, so down and out, that they have no ability to maintain any semblance of personal dignity. However, I believe this photograph did not achieve the fame of the Migrant Mother image because in this photograph the mother looks indifferent, almost casual, about her circumstances, rather than covered in dirt-caked wrinkles and worry-lines, staring off into an uncertain future.

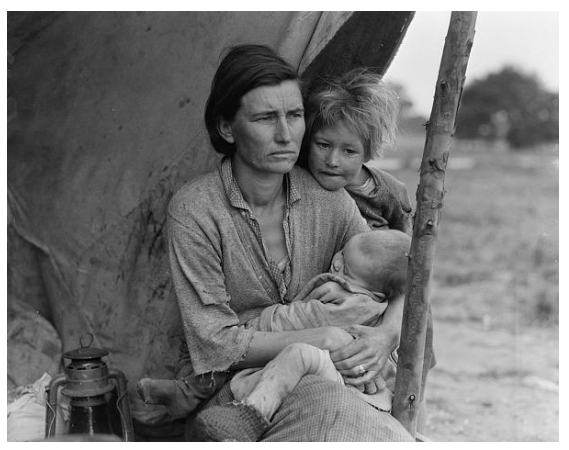

above.

Gestalt principles aid the user of visual rhetoric. Images convey narrative because it is possible for viewers to see a still image, one second captured in time, and read into it an entire chronicle of a person or an event, complete with logos and pathos. ${ }^{272}$ Part of this is attributable to the aforementioned heuristic of naïve realism that causes viewers of highly representational media, such as photographs and video, to believe they are seeing the facts; they believe that they have a window into reality, and that they see the real scene as it occurred on that day and at that time, without authorship and without mediation. ${ }^{273}$ Gestalt principles of continuation and closure will fill in the details of the story behind the scene, so that the scene makes sense in the viewer's construction of meaning and understanding of the scene. ${ }^{274}$

The effects of naïve realism and Gestalt continuation and closure do

272. See generally sources cited supra notes 247-49.

273. See generally sources cited supra notes 49-51, 54, 57.

274. See generally sources cited supra notes 247-49. 
have limits. The realization of authorship and mediation of the image will enter into the calculus if the scene seems staged, as discussed in the section below.

\section{F. Staged vs. Unstaged Photographs and Video}
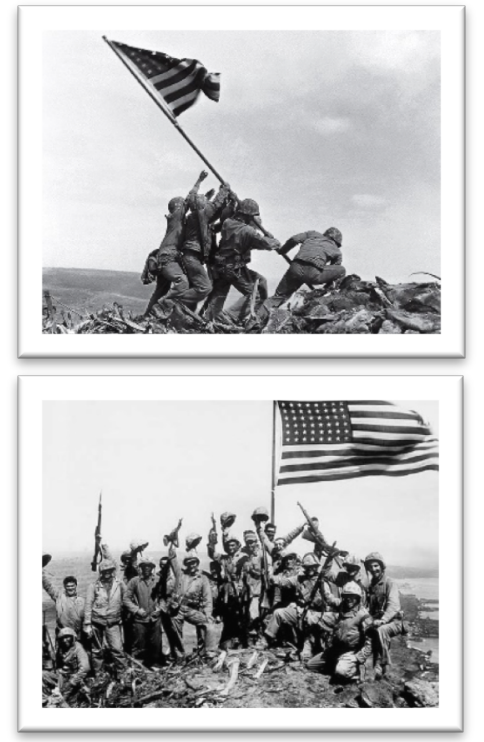

As discussed above, Joe Rosenthal's February 23, 1945, image, Raising the Flag on Iwo Jima, ${ }^{275}$ became an indelible image of the war effort, encouraging all who viewed it that the war was being won, and America would be victorious.

Later the same morning, Rosenthal took yet another photograph of Marines and the flag - this one was called the Gung Ho photograph ${ }^{276}$ by Rosenthal.

To no one's amazement, the Gung Ho photograph was staged. But a short time after the flag event, after Louis Lowery had learned that Rosenthal had "scooped" the small flag-raising scene previously captured by Lowery, someone approached Rosenthal and asked him "if he posed his picture." Rosenthal, believing the question was referring to the Gung Ho photograph, replied, "[Y]es."278 A short time later-the same dayRosenthal realized the question had pertained to the Raising the Flag on Iwo Jima photograph, and Rosenthal hastened to correct himself. ${ }^{279}$ But by then the word was out, the rumor had started, and the damage was done. One of Rosenthal's colleagues, Louis Burmeister, who was present when the photograph was taken, went on the record in a 1993 interview stating, "The picture was not posed." 280 Nevertheless, some persons discounted the power of the flag-raising image, however slightly, because they believed it was staged. Although Rosenthal won the Pulitzer Prize and received international acclaim for the photograph, Rosenthal railed against

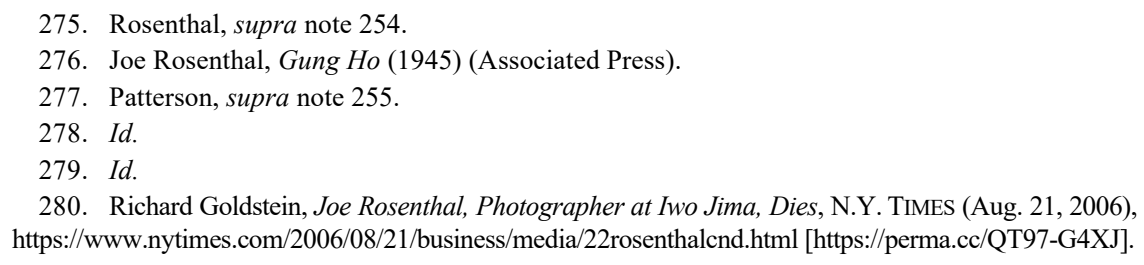


the slight and the inability to correct the misinformation for over sixty years. $^{281}$

Staged photographs and videos lack the verisimilitude and rhetorical power of captured photographs. ${ }^{282}$ The heuristic of naïve realism and cognitive illiberalism is a potent driver to accept the truth of representational visual media, ${ }^{283}$ but when images invite a peek behind the wizard's curtain, ${ }^{284}$ the power of the narrative and message of the image or video is diminished.

Alfred Eisenstaedt provides another example for discussion of the effect of staging. He traveled to Japan in the aftermath of the Hiroshima bombing in 1945, and took a bleak photograph of a mother and child sitting in front of an absolutely devastated landscape. ${ }^{285}$ But I have placed the image side-by-side with a photograph of an atomic bomb victim taken in a hospital. ${ }^{286}$

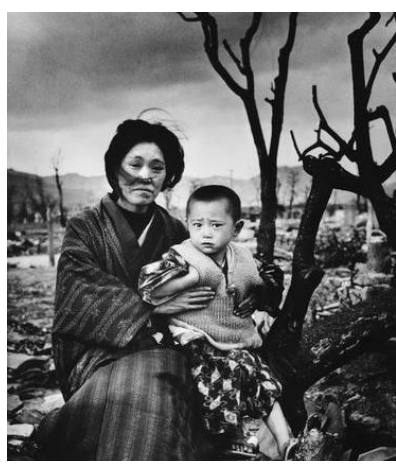

Eisenstaedt's Photograph

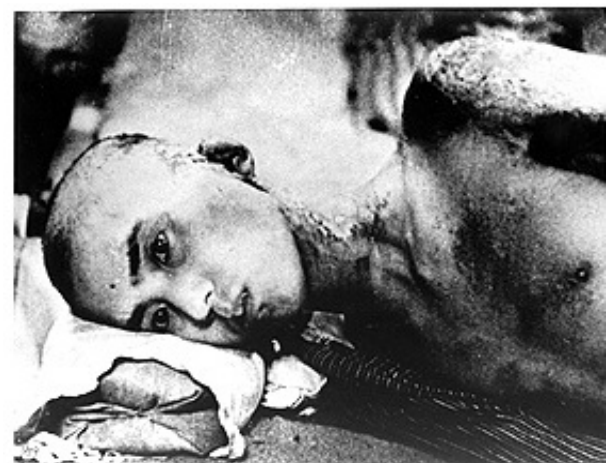

Hiroshima Bomb Survivor

281. Hal Buell, a former executive news photo editor at the Associated Press, recounted that "before Rosenthal died in 2006 at age 94, he told Buell he never got over the controversy." Id. "It always annoyed him - 'the same charges and allegations over and over,' Buell said." Patterson, supra note 255 .

282. See James Lastra, From the Captured Moment to the Cinematic Image: A Transformation in Pictorial Order, in The Image in Dispute: ArT And Cinema In THE Age OF Photography 267-70 (Dudley Andrew ed., 1997); John RoBerts, Photography AND ITs Violations 3-4, 50-51, 53, 127-32 (2014) (explaining that, while staged photographs have their effective uses, they still maintain a "putative aesthetic status").

283. See generally sources cited supra notes 49-51, 54, 57.

284. See THE WIZARD OF Oz (Metro-Goldwyn-Mayer Studios 1939) (interpreting L. FranK BAUM, THE WONDERFUL WIZARD OF OZ (1900)).

285. Ben Cosgrove, Figures in a Wasteland: Mother and Child, Hiroshima, 1945, TiME (Oct. 5, 2014), https://time.com/3881060/wasteland-mother-and-child-hiroshima-1945/ [https://perma.cc/U2W2-TJBM].

286. This photograph is believed to be of a "Hibakusha-Victim" of the atomic bombing of Hiroshima, taken as a screen capture at minute marker 2:10 from a video purporting to depict this and other images of victims. See Stephanie Muson, Atomic Bombs in Hiroshima Health Effects, YOUTUBE (Apr. 3, 2016), https://www.youtube.com/watch?v=d_1GhZZtFoc. "Hibakusha" is a term used in Japan to refer to surviving victims of Hiroshima and Nagasaki atomic bombings. Hibakusha - Atomic Bomb Survivors, UN OFF. DISARMAMENT AFF., https:/www.un.org/disarmament/education/slideshow/hibakusha/ [https://perma.cc/MXY7-G8ZF] (last visited Oct. 19, 2019). 
Eisenstaedt's photograph is striking because the background is completely blasted and burned. It has an unworldly quality that speaks to the narrative of complete destruction and annihilation represented by the atomic bomb. The woman and the child look concerned, but the incongruous aspect of the scene is that they both look heathy and relatively unharmed, and they are comfortably attired in substantial and attractive clothing. Were it not for the expressions on their faces and the blasted and burnt background, the two might have been posing for a normal portrait. The photograph appears to be staged, and so lacks an important element of verisimilitude. Contrast this with the utterly bleak appearance and blank stare of the atomic bomb burn victim in the photograph at right. There is nothing here but a scene of pain and injury. The completely unposed and unstaged nature of the image gives great verisimilitude to the image.

Judge Posner, who in the last decade of his judicial career became well-known for inserting photographs into his judicial opinions, ${ }^{287}$ crossed a line in the assessment of some critics when he staged a photograph involving the subject matter of the appeal pending before him: ${ }^{288}$

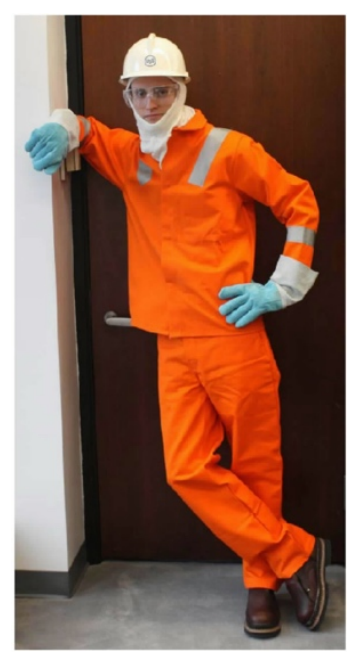

$$
\begin{gathered}
\text { SANDIFER V. US. STEEL CORP. } \\
\text { Cite as } 678 \text { F F } 3 \text { S } 590(7 \text { (7th Cir. 2012) }
\end{gathered}
$$

The case, Sandifer v. United States Steel Corporation, ${ }^{289}$ involved a question of whether certain items worn by U.S. Steel workers were "clothing" or "safety equipment," which was central to the question of

287. Porter, supra note 9 , at 1715.

288. Sandifer v. U.S. Steel Corp., 678 F.3d 590, 592 (7th Cir. 2012). The black and white image shows the photograph as printed in the Federal Reporter, which can be accessed through Westlaw.

289. Id. at 591-92. 
whether the employees would be paid for the time it took them to don and remove the clothing in their work day. Judge Posner had one of his law clerks $^{290}$ dress up in the items, thought the items looked like clothing, and inserted a photograph of the dress-up session into his opinion. ${ }^{291}$ Critics focused on the extra-judicial, extra-evidentiary nature of this dress-up show; the parties were not present, had no knowledge, and had no input into how the items were used in the staged wearing. ${ }^{292}$ Judge Posner concluded that the items should be considered clothing and not safety equipment. ${ }^{293}$ It seems evident from the opinion that Judge Posner was impressed in part by the fact that the items could be donned so easily and casually by a law clerk who, one might presume, had no experience or affinity to a steel mill. ${ }^{294}$ Judge Posner's use of the photograph influenced at least one United States Supreme Court justice - in the oral argument of the case, Justice Ginsburg referenced the photograph of the clothing used in the Seventh Circuit opinion, and stated, "[F]rom the picture, that looks like clothes to me." 295

This point concerning the verisimilitude of staged vs. unstaged photographs may be further illustrated by videos of Ahed Tamimi, a Palestinian teenager, now age eighteen, ${ }^{296}$ who willfully provoked Israeli soldiers stationed in the Israeli-occupied West Bank town where Tamimi lives. On December 15, 2017, Ahed Tamimi, sixteen-years-old at the time, and her cousin, twenty-year-old Nur Tamimi, were filmed on cellphone videos confronting armed Israeli soldiers who were standing in front of Ahed's house. ${ }^{297}$ Ahed is shown pushing, swatting, kicking, and striking the face of an Israeli soldier who was responding to violent protests in Tamimi's neighborhood. ${ }^{298}$

290. See Richard A. Posner, REFlections on Judging 146 (2013) (confirming model was Judge Posner's law clerk).

291. Sandifer, 678 F.3d at 593-94. There is no suggestion in the case or commentary surrounding the case that Judge Posner intentionally told his law clerk to assume a jaunty pose while wearing the items.

292. See Porter, supra note 9, at 1779-80.

293. Sandifer, 678 F.3d at 593-94.

294. See id. (referencing the "de minimis" time it takes to put on and wear the items, which Judge Posner repeatedly refers to as "clothing" in the opinion).

295. Transcript of Oral Argument at 5, Sandifer v. U.S. Steel Corp. (Sandifer II), 134 S. Ct. 870 (No. 12-417). See Porter, supra note 9, at 1690.

296. See, e.g., Yasmeen Serhan, A Symbol of the Palestinian Resistance for the Internet Age, ATLANTIC (Jan. 5, 2018), https://www.theatlantic.com/international/archive/2018/01/internet-famous-in-the-westbank/549557/ [https://perma.cc/5LM5-QNV8]; Alexia Underwood, How Ahed Tamimi, a 17-year-old Palestinian Activist, Became an International Icon, Vox (Aug. 3, 2018, 2:43 PM), https://www.vox.com /2018/8/3/17639254/ahed-tamimi-palestinian-activist-israel [https://perma.cc/DKQ5-5QSU].

297. See sources cited supra note 296.

298. Serhan, supra note 296 (including a video of the interaction). 


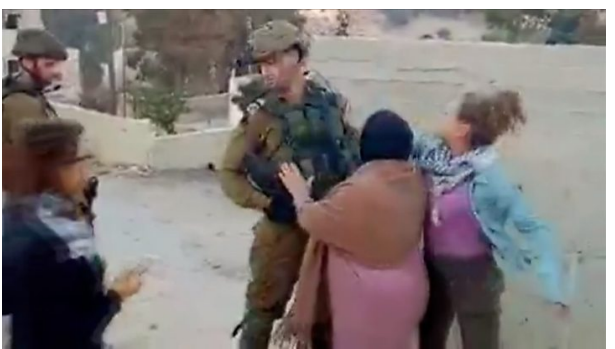

The soldier who was struck in the face appears to have been in a courtyard or car park in front of the Tamimi residence, ${ }^{299}$ and Ahed confronted him with verbal threats and orders to "Get out!," followed by kicks, swats, and a slap to the face to drive the soldier and his partner out of the courtyard or car park. ${ }^{300}$ At least four smartphone videos exist, each showing different activities. In one, Tamimi reaches out and strikes the face of the soldier; ${ }^{301}$ in two other videos, she kicks the boots of the soldier and swats at his arm; ${ }^{302}$ in the fourth, the most complete of the four videos, ${ }^{303}$ she pushes and pursues the soldier with a sequence of shoves, swats, kicks, and one slap to the face to drive the soldier and his partner from inside the courtyard/car park though the entrance to the sidewalk and street beyond. After the video "went viral," the Israeli military arrested and jailed Tamimi without bail and prosecuted her for various offenses relating to her conduct against the soldiers. ${ }^{304}$ She later accepted a plea bargain with credit for time served and was released. ${ }^{305}$

The videos and the prosecution provoked reactions from viewers ranging from criticism of the Israeli military for prosecuting a girl who

299. This image is a screen capture of a frame of the video of Ahed Tamimi slapping the face of an Israeli soldier. For the video, see Palestinian Girl Charged After Slapping Soldier on Video, BBC (Jan. 1, 2018), https://www.bbc.com/news/world-middle-east-42535685 [https://perma.cc/X9MLQ55S] [hereinafter Palestinian Girl Charged].

300. Id.

301. Julia Robinson, Palestinian Girl, 17, is Arrested After she was Filmed Slapping Israeli Soldiers in the West Bank in an attempt to provoke them,' DAILY MAIL (Dec. 19, 2017), http://www.dailymail.co.uk/video/news/video-1593944/Palestinian-girl-slaps-Israeli-soldier-face-

West-Bank.html [https://perma.cc/3HYL-XTTK] (including video footage of Tamimi slapping the soldiers).

302. Palestinian Girl Charged, supra note 299 (minute marker 00:01-00:16 shows Tamimi swatting the soldiers' arms and minute marker 00:28-00:31 shows Tamimi kicking the solder's feet).

303. Mark Weiss, Trial of Palestinian Girl who Slapped Israeli Soldiers Begins, IRISH TIMES (Feb. 13, 2018, 3:36 PM), https://www.irishtimes.com/news/world/middle-east/trial-of-palestinian-girlwho-slapped-israeli-soldiers-begins-1.3390823 [https://perma.cc/9JF9-HG73] (including video footage).

304. See Chris Baynes, Teenage Palestinian Girl who Slapped Israeli Soldiers is Denied Bail Ahead of Military Trial, INDEPENDENT (Jan. 17, 2018, 6:37 PM), http://www.independent.co.uk/news/world/middleeast/palestinian-girl-israel-soldiers-slap-bail-denied-military-trial-idf-ahed-tamimi-palestine-a8164331.html [https://perma.cc/CGQ2-EHQA]; Jacob Magid, Soldier-Slapping Palestinian Girl Remand Extended for Another 5 Days, TIMES ISR. (Dec. 28, 2017, 8:47 PM), https://www.timesofisrael.com/soldier-slappingpalestinian-girl-remand-extended-for-another-5-days/ [https://perma.cc/4LQR-BSXR].

305. Isabel Kershner, Ahed Tamimi, Palestinian Teenager who Slapped Israeli Soldier, is Released from Jail, N.Y. TIMES (July 29, 2018), https://www.nytimes.com/2018/07/29/world/middleeast/ahedtamimi-israel-west-bank.html [https://perma.cc/77AL-8TRH]. 
was protecting her home and bravely standing up to force, to criticism of Tamimi for slapping and provoking a soldier who was doing his job trying to keep her neighborhood safe. ${ }^{306}$ Tamimi's family has said that she struck the two soldiers outside her West Bank home in frustration, believing that one of the soldiers she prodded and slapped had shot her fifteen-year-old cousin, Mohammad Tamimi, in the head with a rubber bullet during nearby stone-throwing clashes with soldiers. ${ }^{307}$

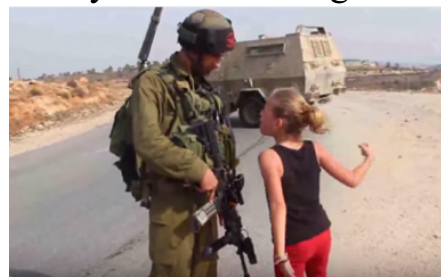

The story is not complete without noting that Ahed Tamimi previously made news by shaking a fist at an Israeli soldier in the West Bank on November 2, 2012, when she was eleven years old. ${ }^{308}$ She made the gesture more than once: ${ }^{309}$
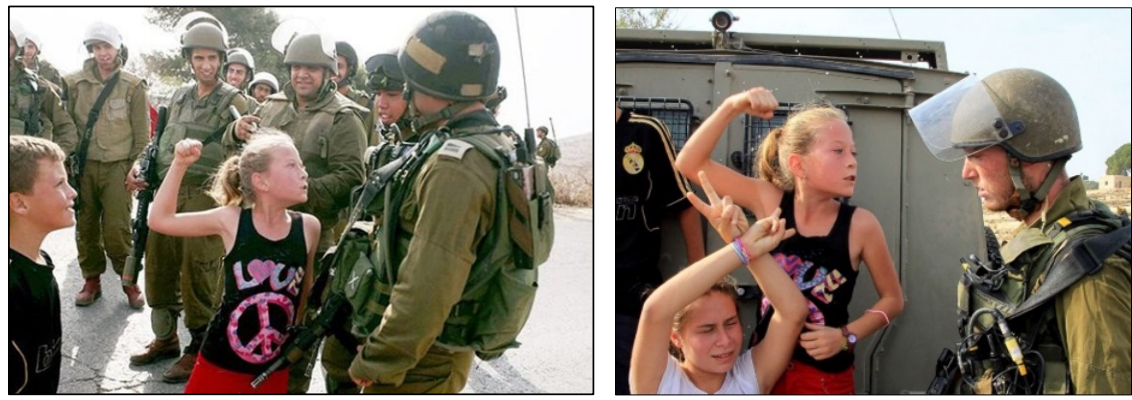

A video of the encounter reveals that Ahed's actions appear to be "staged"- meaning that Ahed stopped, looked at the camera, checked her position, and timed her threatening raised fist to make sure others could catch the encounter on film. ${ }^{310}$

On August 28, 2015, Ahed was photographed ${ }^{311}$ and filmed biting the

306. Palestinian Girl Lauded, Arrested for Confronting Israeli Troops, CBS NEws (Dec. 21, 2017, 9:12 AM), https://www.cbsnews.com/news/palestinian-teen-ahed-tamimi-prosecuted-israel-attack-so ldiers-nebi-saleh/ [https://perma.cc/AR7K-8UF9] (reported by the Associated Press); see also sources cited supra note 304 (highlighting the difference in opinion between Tamimi's supporters and critics).

307. See sources cited supra note 304.

308. Magid, supra note 304. This image is a screen capture of a frame from a video of Ahed Tamimi prodding and raising her fist at Israeli soldiers. For the full video, see Nokta Grup, Brave Palestinian Girl Ahed Tamimi vs Soldier: Where is My Brother ??????, YouTuBE (Dec. 24, 2012), https://youtu.be/E4FM9WGRWdQ [https://perma.cc/8D94-F36D].

309. Ahed Tamimi Raising Fist to Israeli Soldiers (2012) (image on the left); Ahed Tamimi Challenges Israeli Soldiers During a Protest in the West Bank in 2012 (2012) (Qais/Abusamra /Anadolu Agency/Getty Images) (image on the right).

310. See Grup, supra note 308 (showing Tamimi looking at the camera in the first seconds of the video and at other times throughout the video, each time looking at the camera before confronting the soldiers).

311. Abbas Momani, Ahed Tamimi Bites a Soldier's Hand (2015) (Abbas Momani/AFP/Getty Images). 
hand of an Israeli soldier who was trying to arrest Ahed's younger brother for stone-throwing, and again, she stops, turns, checks for the camera, and makes sure someone is filming her actions. ${ }^{312}$

The fact that there are multiple videos of these confrontations allows the viewer a better chance to gather what went on in the scene. But perhaps more importantly, and the reason the videos are discussed in this section of the

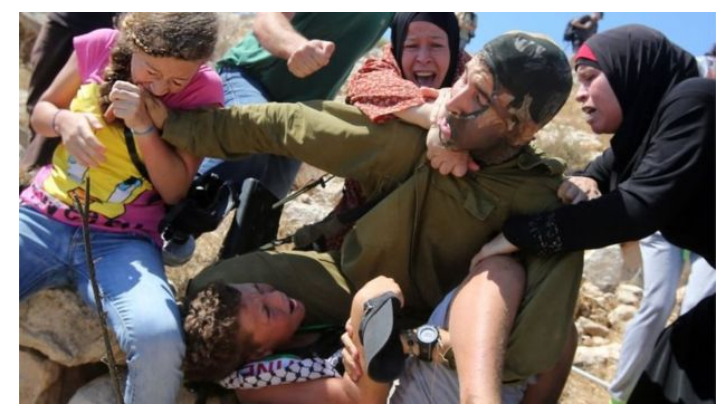
article, is that Ahed Tamimi appears to be staging encounters with soldiers particularly and intentionally to create videos of the encounters she provokes and perpetrates. In each video, Ahed purposefully and repeatedly turns away from the action to make sure the camera is capturing what she is doing. Some of Ahed's swatting and kicking appears pro forma and without much effort, although the bite on the hand in 2015, and the slap on the face in 2017, look completely genuine.

The narrative and rhetorical power of the videos is lessoned because the videos appear to be staged. The staging undercuts the ethos of the narrative because Tamini appears only to be going through the motions of a confrontation, making pro forma swats, and constantly turning to make sure camera-wielding friends and family members caught her last move. It is true, at a basic level, that even half-heartedly swatting at and kicking the boots of a uniformed, helmeted, body-armor-clad soldier who is carrying a large assault rifle and several other weapons is incredibly brave (and incredibly dangerous). Yet, strictly speaking, the apparently staged nature of her actions is less effective a work of rhetoric than this photograph of a single individual standing up to power on June 5, 1989, in Tiananmen Square, Beijing, China: ${ }^{313}$

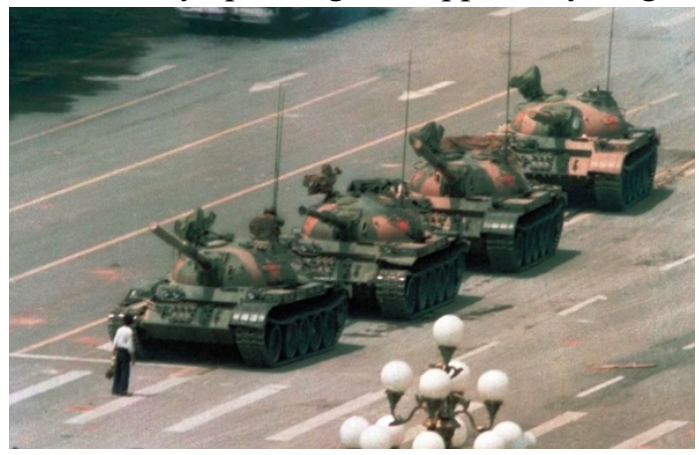

312. See Palestinian Girl Arrested After 'Slap' Video, BBC (Dec. 19, 2017), http://www.bbc.com /news/av/world-middle-east-42417938/palestinian-girl-arrested-after-slap-video [https://perma.cc/N5 9C-K8YQ].

313. Jeff Widener, Tank Man (1989) (Associated Press). 
Or this photograph of Ieshia Evans standing calmly in the face of riot police at the Black Lives Matter Protest in Baton Rouge, Louisiana: ${ }^{314}$

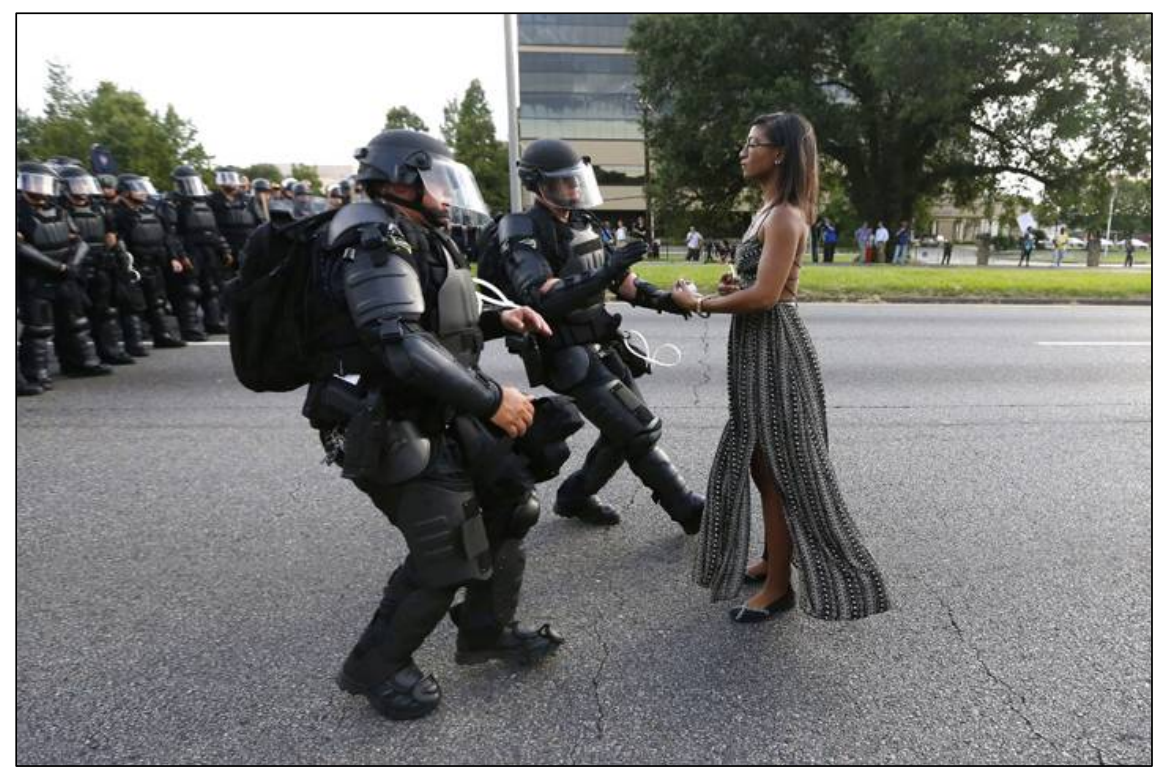

For lawyers contemplating a reenactment of an event for filming, think twice about it. Staging lacks verisimilitude and defeats the advantage of naïve realism and cognitive illiberalism, and it may damage the Gestalt effects of continuation and closure. In other words, the unconscious acceptance that what we see in representational visual media is the truth can be suspended when our conscious mind learns that someone put on a show and actively staged the scene.

\section{CONCLUSION}

Rhetoric is the study of the best available means to communicate in a rhetorical situation, a situation where the speaker can make a difference with her communication, and especially where the matter of the discussion is contested or contestable. The recognition that visual rhetoric is rapid, efficient, constructive, and persuasive reveals the potential of visual rhetorical devices to serve as topics and tropes in legal discourse to construct meaning and to inform and persuade legal audiences. The visual rhetorical topics and tropes inspire inventive thinking about the law that constructs meaning for the author and the audience.

314. Jonathan Bachman, Ieshia Evans Standing Before Riot Police (2016) (Jonathan Bachman/Reuters). 
My conclusions are that visual rhetorical devices can be an impressive and effective form of legal rhetoric if they are used to construct knowledge and understanding of the meaning and message of the communication and do not mislead or prejudice the audience's reception or understanding of the communication.

All images are not created equal, and the point of this article is to begin the process of informing attorneys about the different aspects that make some images clearer and stronger in communicating the narrative of a client's case or situation, or advancing a legal argument using visual rhetorical devices. It also seeks to alert advocates as to possible improprieties that might be perpetrated intentionally or inadvertently by their opponents.

As discussed above, for many members of the legal writing discourse community-judges, practitioners, government agencies, and academics - the modes of persuasion of visual rhetoric can construct meaning and improve the persuasiveness of legal discourse generally in content, arrangement, and style. However, the cautions I have given as to the dangerous power of visuals to deceive or to overpower more deliberative forms of rational thought and analysis are not lightly to be dismissed. The speed and power of visuals is seductive. Visual topics and tropes are subject to abuse and must be examined carefully with regard to their propriety as a tool to create meaning and inspire imagination and not as a tool of deception or obfuscation within the rhetorical situation at hand. This, of course, is a lesson for all rhetoricians of legal discourse, whether employing strictly verbal tools of communication and persuasion, or a mixture of verbal and visual tools. 